Rhode Island College

Digital Commons @ RIC

\title{
Engaging Students in Authentic Discussion in the Secondary English Classroom
}

Lisa Ann Carpenter

Rhode Island College

Follow this and additional works at: https://digitalcommons.ric.edu/etd

Part of the Educational Methods Commons

\section{Recommended Citation}

Carpenter, Lisa Ann, "Engaging Students in Authentic Discussion in the Secondary English Classroom" (2014). Master's Theses, Dissertations, Graduate Research and Major Papers Overview. 105.

https://digitalcommons.ric.edu/etd/105

This Dissertation is brought to you for free and open access by the Master's Theses, Dissertations, Graduate Research and Major Papers at Digital Commons @ RIC. It has been accepted for inclusion in Master's Theses, Dissertations, Graduate Research and Major Papers Overview by an authorized administrator of Digital Commons @ RIC. For more information, please contact digitalcommons@ric.edu. 


\section{DOCTOR OF PHILOSOPHY DISSERTATION}

OF

LISA ANN CARPENTER

\section{APPROVED:}

Dissertation Committee:

Major Professor
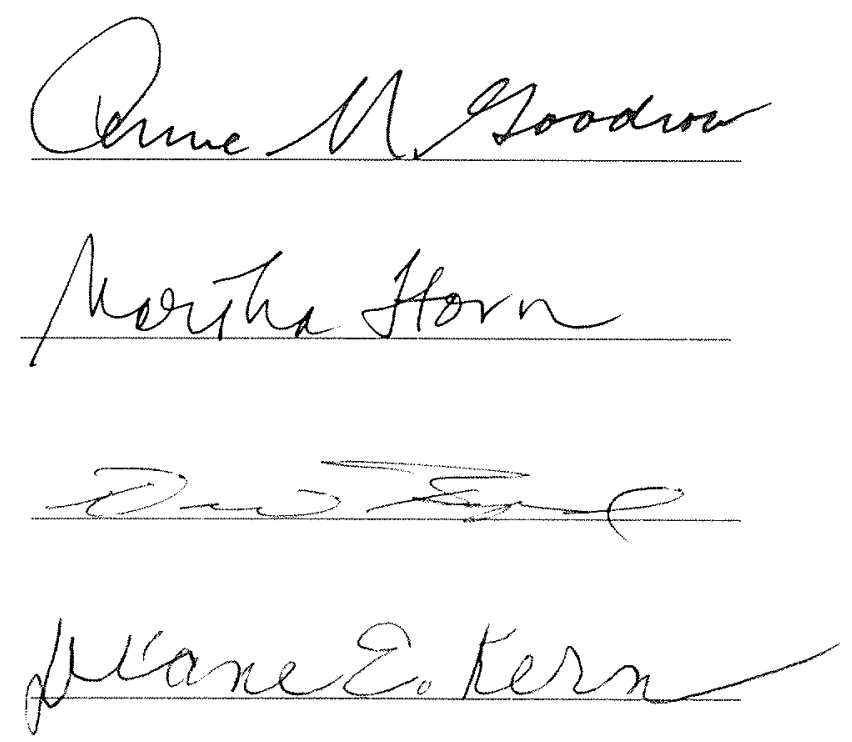

RIC:

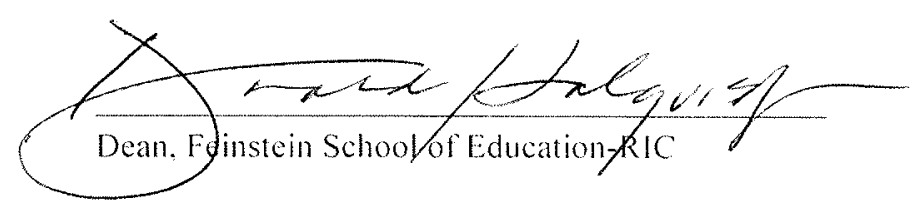

URI:

Dean, The Graduate School-URI

UNIVERSITY OF RHODE ISLAND

AND

RHODE ISL AND COLLEGE 


\section{ENGAGING STUDENTS IN AUTHENTIC DISCUSSION \\ IN THE SECONDARY ENGLISH CLASSROOM}

BY

LISA ANN CARPENTER

A DISSERTATION SUBMITTED IN PARTIAL FULFILLMENT OF THE REQUIREMENTS FOR THE DEGREE OF DOCTOR OF PHILOSOPHY

IN

EDUCATION

UNIVERSITY OF RHODE ISLAND

AND

RHODE ISLAND COLLEGE

2014 


\begin{abstract}
Using the social constructivist lens, I frame a call for action that advocates for the use of critical literacy and a protocol for discussion in the English language arts classroom. Salon authentic discussion will present teachers with a powerful new pedagogy for critical literacy instruction in the secondary ELA classroom especially in this critical time when standards and accountability for both students and teachers is being redefined.
\end{abstract}

As a teacher-researcher, I am in the best position to investigate how students can become equipped to meet proficiency in speaking and listening a standardsbased era. Using grounded theory methodology, I examine authentic discussion that has the power to stir controversy, recognize the claims of others, and continually engage participants in the search for identity and meaning (Ayers, 2004).

An investigation into the literature reveals the difficulties associated with conducting authentic discussion as well as the gap in the literature that provides educators with the necessary ingredients for its success. Grounded theory emerges in an argument advocating the use of a combination of literary theory, social motivation, Accountable Talk, and critical literacy that can be used to best prepare senior high school students for authentic literary discussion. Most importantly, the study's findings point to the need to make students comfortable in the classroom, finding ways to allay their fears of embarrassment, and ensuring that social justice and tolerance is integral part of the classroom community. 


\section{ACKNOWLEDGEMENTS}

The $\mathrm{PhD}$ joint program in education at RIC and URI transformed my thinking as a student and an educator, and surprisingly as a woman in general. The time since 2009 has been filled with change and growth. I like to think that I now am more apt to approach tough issues from a strategic, analytic, perspective versus an emotional, reactive perspective. Incredible professors such as Dr. Elridge and Dr. Sidorkin nurtured this way of thinking and I am indebted to them.

I want to thank my committee members for their extraordinary professionalism and encouragement: Dr. Horn for her gentle prodding to adopt a growth mindset when examining data (and smiling when I began to get it); Dr. Goodrow for taking on a doctoral student midstream, being persistent in finding all the answers and reading and rereading; Dr. Byrd for his sincerity, encouragement, and knowledge that grounded theory was the way to go; and Dr. Kern for her insistence on perfection, incredible knowledge of the field of teaching English, and advice regarding the difficult process of concluding.

I want to thank each member of the 2009 Cohort - what an amazing group of talented people who like a true team, reached out to any member who started to waver and fall and picked him/her back up again. I am indebted to my students for their candor, willingness to take time to do interviews and surveys, and try any ideas that their English teacher brought to their classroom.

I would like to thank Bronwyn, my daughter, who sat through many doctoral classes and even helped me design the special effects for Power Point presentations at the age of 9! Lastly, I want to thank Larry Nichols, without whom I would not 
have been able to face all the challenges that the last few years have presented. 


\section{Table of Contents}

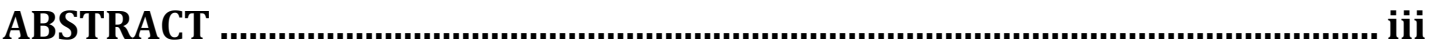

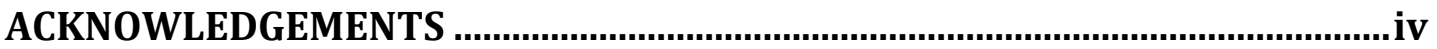

LIST OF TABLES .................................................................................................... viii

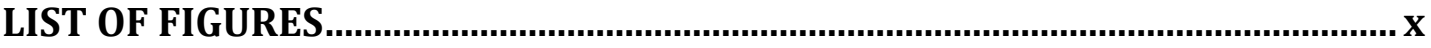

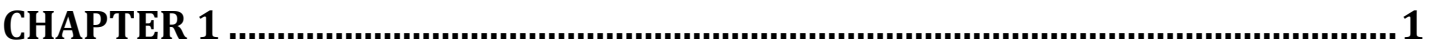

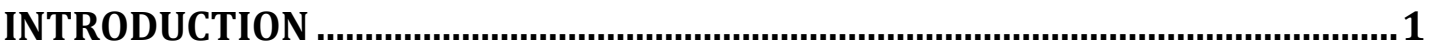

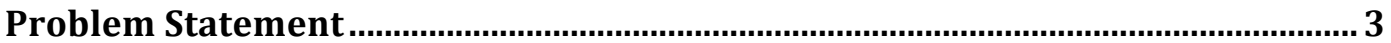

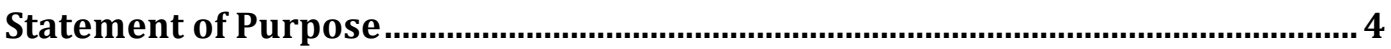

Research Questions ................................................................................................... 6

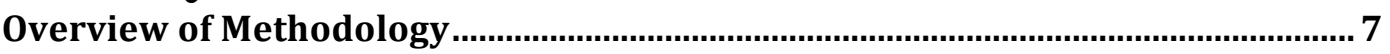

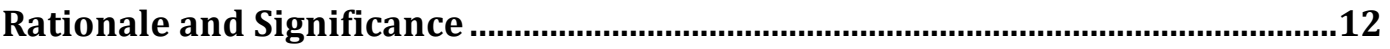

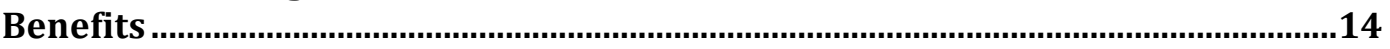

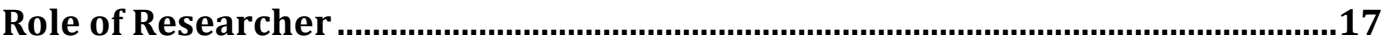

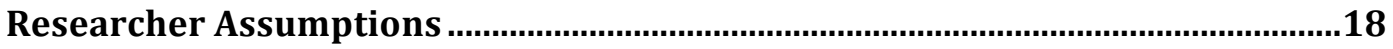

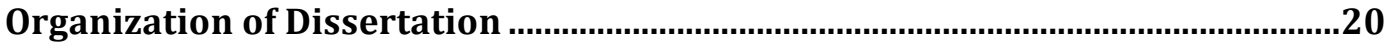

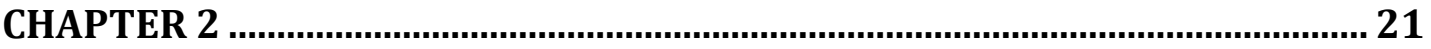

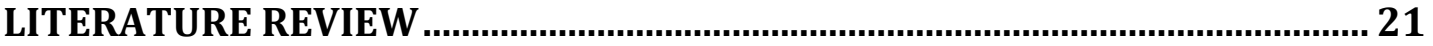

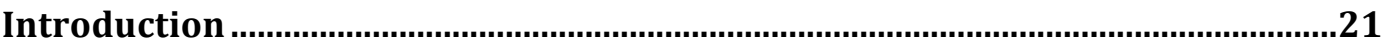

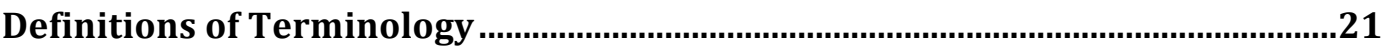

Authentic Discussion and Initiation/Response/Evaluation ......................................... 24

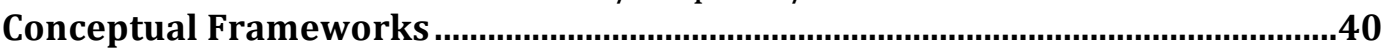

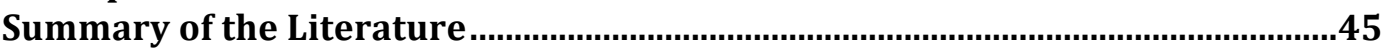

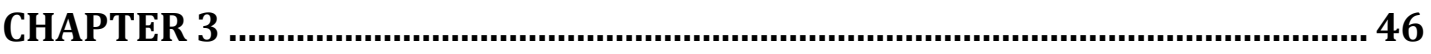

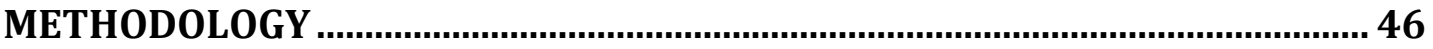

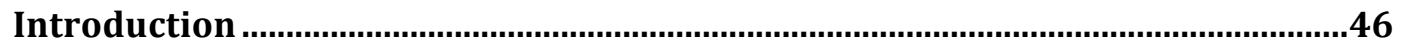

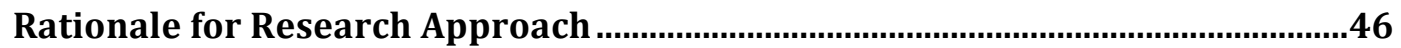

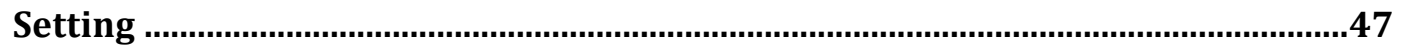

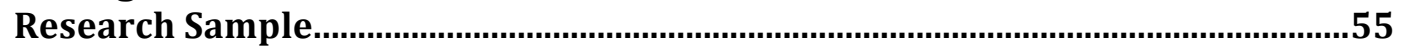

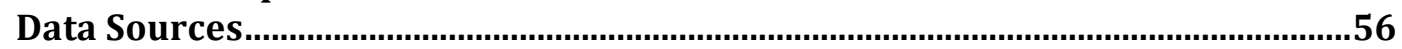

Data Collection Methods ..........................................................................................59

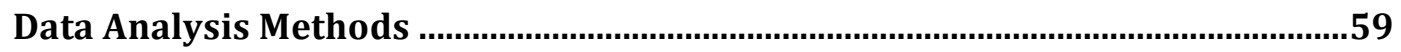

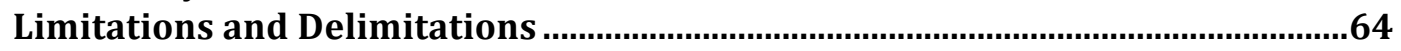

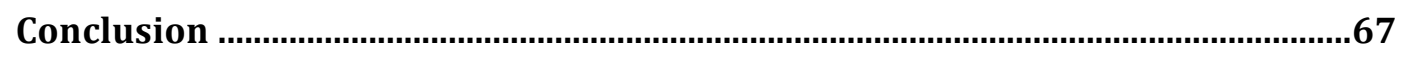

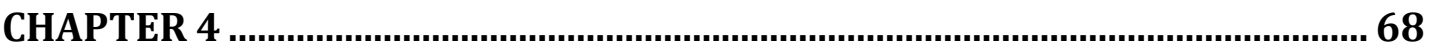

ANALYSIS OF DATA

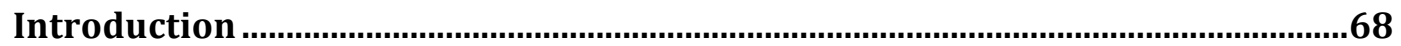

Conceptual Category 1: The Individual...................................................................... 73

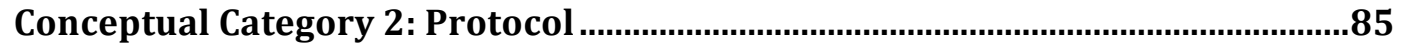

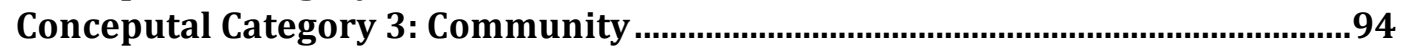

Summary of selective/focused coding in Conceptual Category $3: \ldots . . . \ldots \ldots . . . . . . . . . .103$

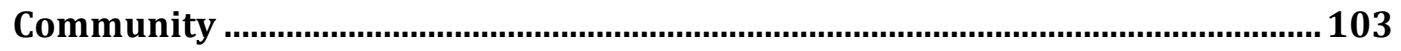


Conceptual Category 4: Knowledge.

Summary of selective/focused coding in Conceptual Category 4: Knowledge117

Conclusion

Emergent Grounded Theory as a Result of Constant Comparative Analysis... 122

\section{THE THEORY, ITS IMPLICATIONS, AND SUGGESTIONS FOR FURTHER}

STUDY

The Wider Purpose of Grounded Theory …......................................................... 123

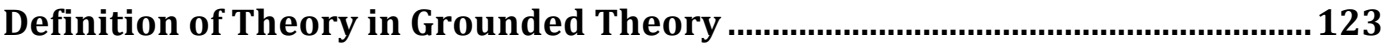

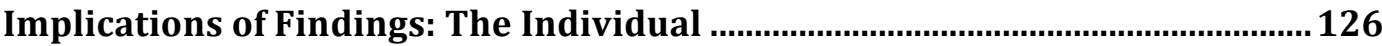

Implications of Findings: Protocol and Community ……..................................... 130

Implications of Findings: Knowledge ............................................................. 131

Using a Wider Lens: Policy Makers and Educational Researchers ..................... 134

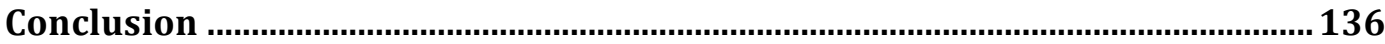

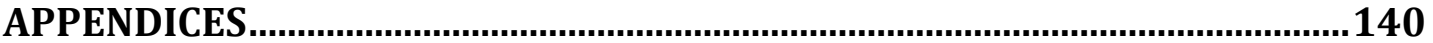

Appendix A: Student Chart of Literary Critical Theories ...................................140

Appendix B: Using Critical Theory in "Oedipus Rex" ........................................... 141

Appendix C: English 100 Syllabus / Studies in Literature ....................................143

Appendix D: English 113 Syllabus/ Approaches To Drama ……...........................145

Appendix E: Literary Criticism In-Class Activity ...............................................147

Appendix F: Everyman Take-Home Writing Prompts ...................................... 149

REFERENCES ..........................................................................................................150 


\section{LIST OF TABLES}

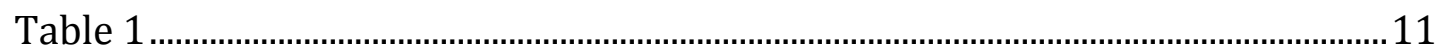

Research Questions, Data Sources, and Triangulation Methods ..................................11

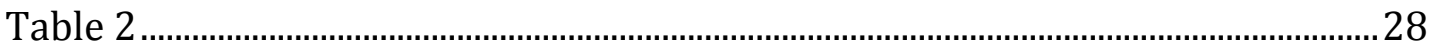

Accountable Talk Stems ………………………………………………………………. 28

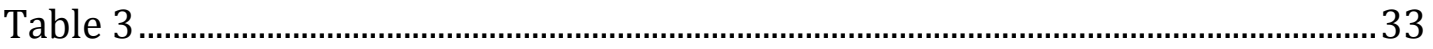

Literary Theory Lenses and Their Assumptions ……………………………………... 33

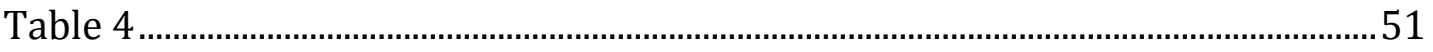

East High School's Student Behavior Compared to Other Schools in the State

(Rhode Island Department of Education, 2013)..................................................51

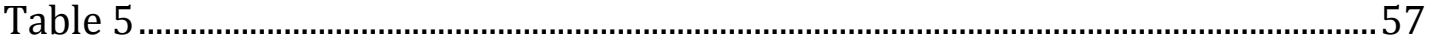

Pre- and Post-Questionnaire ………………………………………………………....57

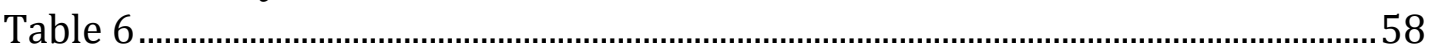

Open-ended questions for the pre- and post-interviews ..............................................58

Table 7 .........................................................................................................................61

Initial Coding of a Student Journal Entry ………………………………………....61

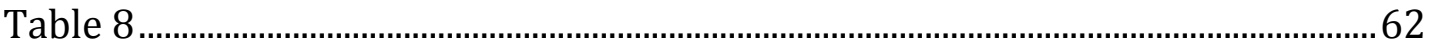

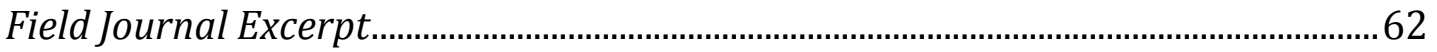

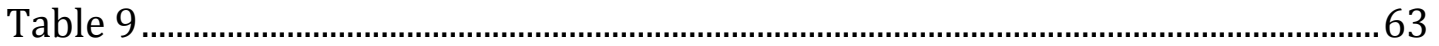

An Example of Focused Coding.....................................................................................6

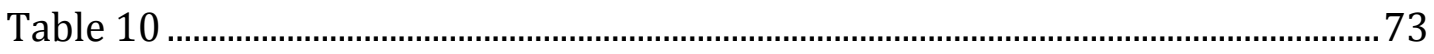

Core Categories that Interact in Authentic Discussion ................................................73

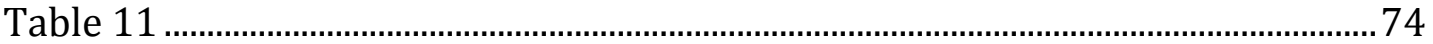

Pre-Questionnaire Responses.....................................................................................

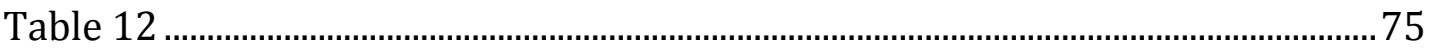

Coding Procedure Leading to First Core Category: The Individual.............................75

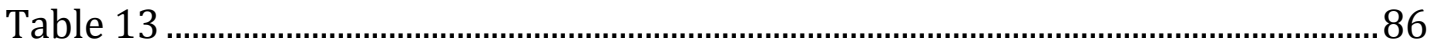

Coding and Memo Writing: Protocol Concerning Attentive Listening .......................86

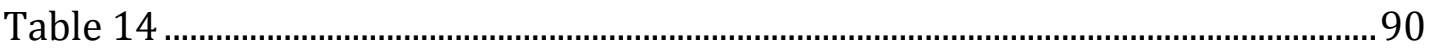

Student Generated Protocol List for Discussion............................................................99

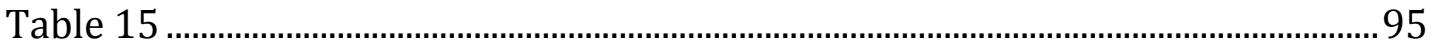

Coded Student Responses: Community ............................................................................95

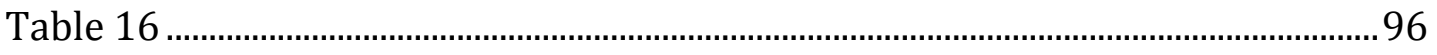

Sample Privilege Walk Questions (adapted from 1994, National Curriculum \&

Training Institute, Inc.) ............................................................................................96

Table 17 ................................................................................................................ 106

Coded excepts of Students Reflecting on Literary Theories/Literary Criticism

Theory Practice Assignments ...............................................................................106

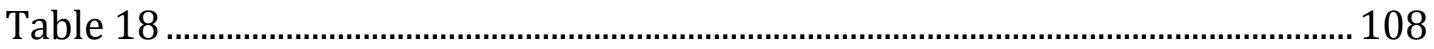

Sample questions from Literary Criticism Group Worksheet.................................... 108

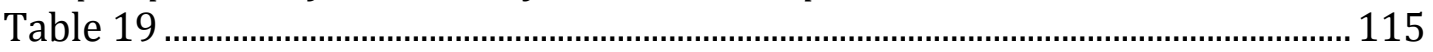

Student Journal Entries Reacting to the Fish Bowl Lesson....................................... 115 


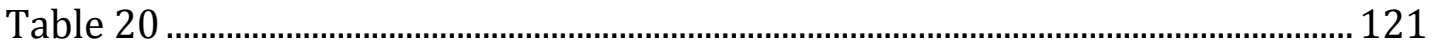

Demonstration of Growth in Average Participants...................................................... 121

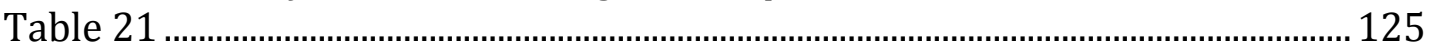

Implications and Suggestions for Further Study as listed within Core Category

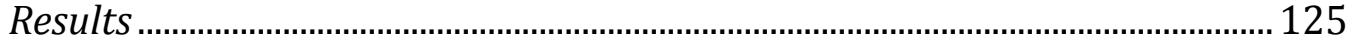

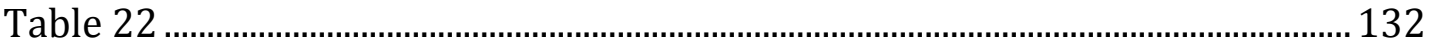

Students Use of Literary Theory the Year After High School Graduation................ 132 


\section{LIST OF FIGURES}

Figure 1. Negotiating the disputed territory between policy makers and academic researchers. Adapted from Wells, G. (1999). Dialogic inquiry: Towards a Sociocultural Practice and Theory of Education" by G. Wells, 1999.

Figure 2. 1910 Class trip to Washington, D.C. (as cited in Mehrtens, 1996) .........49

Figure 3. Rain inside the traditional classroom space Spring 2013 .......................50

Figure 4. One area in the salon classroom ...............................................................5

Figure 5. Graphic Representation of Grounded Theory Process (adapted from

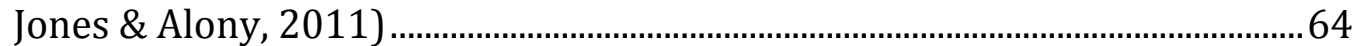

Figure 6. The Relationships between Conceptual Categories ..................................... 71 


\section{CHAPTER 1}

\section{INTRODUCTION}

Secondary English teachers report there is nothing more discouraging than asking an exciting, thought-provoking question regarding an assigned reading only to have that question meet with silence and blank stares (Sappington, Kinsey, \& Munsayac, 2002). The probability exists that some students do not read the assignments or may not have an interest in the text, but another possibility is that secondary students lack the initiative and teacher support to engage in authentic class discussion about literary texts. In this study, I investigate the use of authentic discussion in a high school English class to mitigate this problem. I examine the cognitive and verbal behaviors of student/participants as they engage in authentic discussion as well as the factors that prohibit them from doing so.

Authentic discussion, sometimes termed dialogic discussion (Billings \& Fitzgerald, 2002), embodies three essential characteristics: group members decide what topics are important; understanding is arrived at by the group, not given to the group by the teacher; and the teacher gives up some or all of her control over the content and form of the discussion (Nystrand, 1997; Wells, 1999, 2001). Wells defines classrooms that use authentic discussion as communities of inquiry. Inquiry is about wondering and asking questions, testing conjectures, and mastering information. In the constructivist perspective, students engage in this learning together. While the teacher may release control over the form and content of the 
authentic discussions, she maintains responsibility for engaging students in the topic at hand so that the discussion is productive $(1999,2001)$.

Given that students are in control of authentic discussion and make decisions about important literary themes and elements to discuss, it follows that critical literacy, higher-order thinking skills, and Accountable Talk are needed for students to engage in dialogic or authentic discussion.

Traditional and modern reasons explain why authentic classroom discussion is absent from secondary English classes. Traditionally, a reliance on Initiation/Response/Evaluation (IRE) has defined discussion for many practitioners (Cazden, 2001). In IRE, the teacher initiates a question (with a pre-determined answer), a student raises a hand to respond with what he or she believes is the correct answer or says, "I don't know", and the teacher evaluates the student's response. Then the teacher asks another question and the process begins again. Billings and Fitzgerald (2002) found in their research that most classroom talk followed the format of the teacher functioning as the expert and students as the passive observers in what these researchers labeled as "teacher-fronted" discussions (p. 911). This definition of discussion allows many students to blend seamlessly into the background while a few extraverted students dominate the responding.

The fact that students tend to avoid discussion is exacerbated in the modern classroom in which high-stakes testing has reduced teacher autonomy and creativity. After studying classroom discussion, Costigan and Dickson (2011) observe, "In the past 10 years, ... schools have seen changes in the autonomy teachers are given to develop stimulating curricula...accountability in the form of high-stakes testing and 
more standardized and homogenized methods of teaching has limited students' authentic engagement with literature in favor of utilitarian goals" (p. 148).

Another modern reason for the lack of classroom discussion is society's overreliance on the small sound bites and multi-tasking that characterize social media. Elinor Ochs (as cited in Wallis, 2006, p. 2), anthropologist and director of the UCLA Center on Everyday Lives of Families, found that the impact of technological advances in the last fifteen years has substantially increased the presence of both multi-tasking behavior and decreased interpersonal communication within the modern family. The substantial decrease in students' tendencies to relate to one another interpersonally has direct implications for oral language during classroom discussions. If students are not engaged in meaningful dialogue within the family setting, then it follows that they may be less likely to engage in authentic discussion in the classroom.

\section{Problem Statement}

Researchers claim that students who routinely engage in authentic class discussion demonstrate cognitive growth (Applebee, Langer, Nystrand, \& Gamoran, 2003; Nystrand, 2006; Hadjioannou, 2007). What researchers actually find, however, is that authentic class discussions do not commonly occur in secondary classrooms. In a study of fifty-eight ninth grade English classrooms, Nystrand and Gamoran (1991) found open-ended whole class discussion averaged fifteen seconds a day. What constituted discussion was characterized by teacher-directed questions that required specific answers and lacked "substantive engagement" among the participants (p. 277). This type of instruction does not lead to authentic class 
discussion. Consequently the teacher-directed questions fail to adequately stimulate students' cognitive growth.

Although I find fault with the current emphasis on high stakes testing, teacher evaluations and student success in public school depends on the need for students to achieve high scores on standardized tests. This may be another reason why teachers avoid authentic discussions in favor of lower level question/response formats that merely require students to offer the short text-based answers characteristic of many standardized tests (Costigan \& Dickson, 2011).

\section{Statement of Purpose}

Cognitive scientists (Geersten, 2003; Bissell \& Lemons, 2006) and educators (Nystrand \& Gamoran, 1991; Appleman, 2009; Christensen, 2009) claim that authentic class discussion enables students' cognitive growth. Hadjioannou (2007) defines authentic discussion as a speech genre, with no pre-specified conclusion in which participants explore ideas and experiences in order, "to reach new and more sophisticated understandings" (p. 371). However, there is a dearth of research that explores exactly how authentic discussion can be achieved in the secondary English classroom (Applebee, 1996; Billings and Fitzgerald, 2002; Brookfield \& Preskill, 2005).

The purpose of the study is to help negotiate the "disputed territory" (Wells, 2001) between what the policy makers and educational planners have established as educational goals and what the academic researchers deem important. More specifically, the purpose of the study is to investigate the use and impact of authentic discussion in the English classroom. I hope to contribute to the dialogue among 
educators who utilize this type of discussion in the classroom and open up an exchange between those who set educational policy and those who enact it regarding reasons for and effective uses of authentic discussion in the secondary English classroom.

Figure 1, based on the findings of Wells (1999), illustrates the disputed territory of teacher practice that lies between the national outcomes and assessments created by policy makers and the idea of inquiry-based, constructed knowledge advocated by the academic researchers.

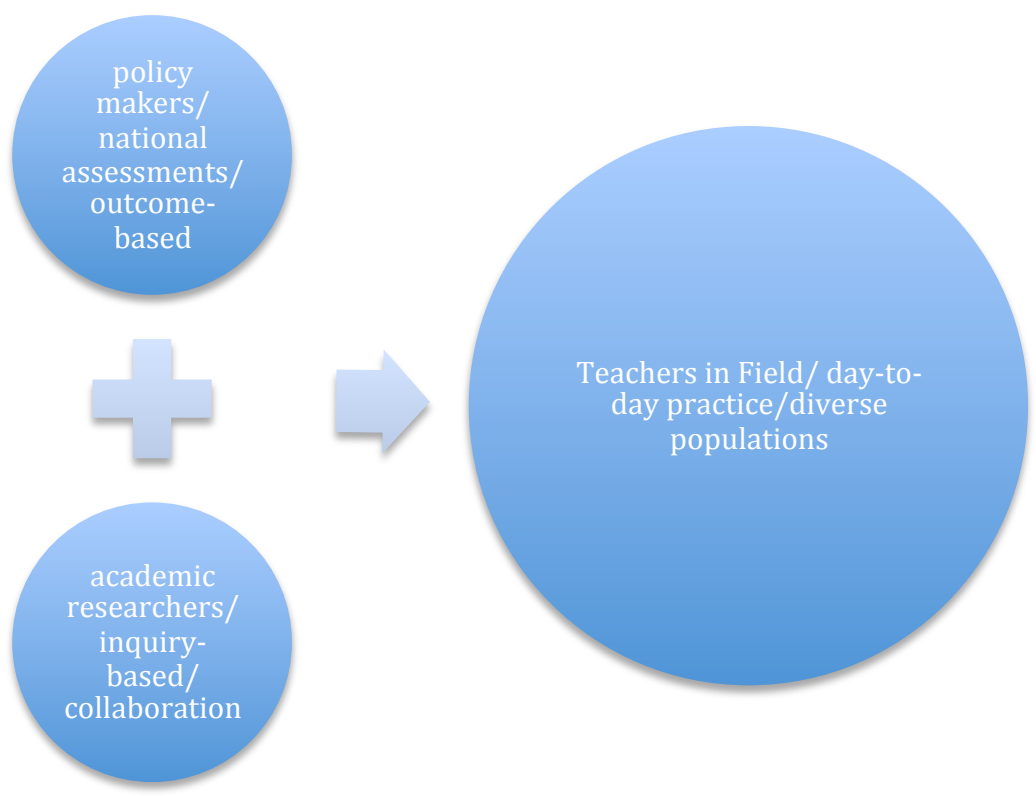

Figure 1. Negotiating the disputed territory between policy makers and academic researchers. Adapted from Wells, G. (1999). Dialogic inquiry: Towards a Sociocultural Practice and Theory of Education" by G. Wells, 1999 
In Accountable Talk students are expected to utilize phrases such as those that link or follow up on the comments of others, elaborate on what others have said, and those that refer to specific pages in text. Students are expected to demonstrate critical literacy by selecting appropriate theories to apply to literature and by articulating why the theories are good choices. In terms of higher order thinking skills, students are expected to demonstrate behaviors within the three higher levels of Bloom's taxonomy such as differentiating, hypothesizing, and creating (Bloom, 1956). In this study, I examined data to discover how these elements contribute to authentic discussion. How do students demonstrate their understanding of critical literacy? That is, what do students say and do when they employ higher order thinking skills? What does Accountable Talk sound like in the classroom setting?

\section{Research Questions}

Given the purpose of discovering the behaviors and language constructions students use while engaging in authentic discussion, the following questions guide the data collection for this study:

1. What language processes do students demonstrate as they participate in authentic discussion, including the language processes involved with critical literacy, higher order thinking skills, and Accountable Talk?

2. How does authentic discussion affect student agency or student responsibility and ownership of the lesson? What do students take away as learners from the experience of participating in authentic discussion? 
3. How do students perceive authentic discussion? Why are some students more inclined than others to participate in authentic discussion in an informal classroom environment?

\section{Overview of Methodology}

Systematic comparative analysis grounded in fieldwork is used in this study to explain what is occurring in the field and to develop a theory that has emerged from observation (Patton, 2002). Constructivist grounded theory presupposes that neither data nor theories are discovered, but are constructed by the researcher as a result of his or her interactions with the field and its participants. Constructivist theory strives to determine why certain behavior and language constructions occur within a unique context (Patton, 2002). Kathy Charmaz (2006), a student of Glaser and Strauss, pioneers of grounded theory, was the first researcher to claim her work was exclusively rooted in constructivist grounded theory. This theory applies the basic strategies of grounded theory within a constructivist paradigm. Charmaz claims, "the grounded theorist's analysis tells a story about people, social processes, and situation. The researcher composes the story; it does not simply unfold" (2000, p. 522). Constructivist grounded theory is an emergent design in which the researcher's choices emerge as the study progresses. The researcher treats the research process itself as social construction (Charmaz, 2008). Both the researcher's prior experiences and the social and cultural context in which the study takes place are an integral part of the methodology.

Participants. Participants from "East High School" include students in two sections of grade twelve, honors-level Early Enrollment Program (EEP) English 
classes (a total of thirty-nine students). The course taught in the fall semester is English 100 Studies in Literature; and the course taught in the spring semester is English 113 Approaches to Drama. Honors level is described in the East High School handbook as a level reserved for those students who excel at reading and writing. When the students were juniors, during the preceding spring semester, the teacher provided an overview of course expectations before students elected to register for the two courses. Together these two courses, English 100 and English 113, comprise the required high school credit for the senior year. The syllabi for these courses are located in Appendix C and D. Students are required to take English all year, for all four years of high school.

Most of the English 100 and English 113 students continue their education at either two or four-year colleges, many at the in-state higher education institutions. Approximately twenty-five percent of the students receive free or reduced lunch. Gender is fairly equally divided and the primarily white students come from middle, lower middle class, or poor socioeconomic backgrounds. East High is located in a New England town, a former mill town that produced blankets and other textiles during the time of the Industrial Revolution through World War II. Many families are descendants of French-Canadian immigrants who came to New England to work in the mills toward the end of the nineteenth century.

Although East High has a school improvement team, parent involvement in the school is uncommon and on average, only ten percent of the parents attend open houses and conference nights. A common complaint among the students is that there is "nothing to do" in the town. 
Setting. The research took place in two adjacent classrooms in which I taught: one was an informal space, and the other was a traditional high school classroom. The informal classroom space was comprised of couches and chairs that could be arranged and rearranged according to need. The room provided enough seating for twenty-seven students. It was decorated with artwork and student work and it included two computer stations. I used the term "literary salon" with the students when referring to this informal space after researching eighteenth century French literary salons that were established to promote lively discussions about reading (Clergue, 1907). A salon setting is a different area in the classroom or the school where students gather for the purpose of engaging in talk about newly acquired information. It can be any area without standard desks that physically and psychologically facilitates talk.

The adjoining, more traditional, classroom consisted of desks in rows. The traditional space contained only a teacher desk, twenty-seven student desks, a white board, and two bulletin boards that displayed student work as well as announcements and schedules.

Data Collection Tools. Interviews, student journals, and observations recorded in the researcher's field journal constitute the data collected for a period of eight weeks. It is important to note that all material I came in contact with while employing grounded theory was potentially fodder used to help generate theory. However, the following three sources, interviews, student journals, and the researcher's field notes, were chiefly used to answer research questions and are included in the matrix that follows (see Table 1). 
Interviews. I employed a research assistant because the Internal Review Board that approved my study did not think it appropriate that the teacher/ researcher assigning student grades should be the one to ask candid questions regarding students' past and present experiences with authentic discussion. The research assistant used a general interview guide to ask open-ended questions designed to elicit information about the participants' perceptions of authentic discussion. Recorded interviews were conducted face-to-face at a time mutually agreed upon between the participant and the research assistant. The assistant transcribed the interviews for the researcher to code.

Student Journals. Students maintained reflection journals that included entries about topics surrounding their perceptions of and participation in authentic discussion. These notebooks were kept in a locked cabinet in the classroom. I read entries and reflected on them continuously for emergent themes and coded in the margins and on a spreadsheet.

Field journal observations. As a teacher-researcher, I wrote in a field journal and recorded impressions, ideas, questions, and reflections during or immediately following each salon discussion. Coding was done in the margin of the field notes and in a spreadsheet.

Data Analysis Process. In Constructivist grounded theory, studied experience is, "embedded in larger and often hidden positions, networks, situations, and relationships" (Charmaz, 2006, p. 13) and is situated in the context and culture in which the study takes place. Charmaz, the originator of Constructed Grounded theory, advocates for an emergent design (the constructive paradigm), and utilizes 
coding strategies established by original grounded theory. Triangulation in this study involves comparing multiple data sources (journals, field notes, interviews) as well as "cutting across inquiry approaches" (Patton, 2002, p. 249) or the use of quantitative data (the questionnaires) along with the other qualitative data sources.

Table 1

Research Questions, Data Sources, and Triangulation Methods

\begin{tabular}{|c|c|c|}
\hline Research Question & Data Source & Method of Triangulation \\
\hline $\begin{array}{l}\text { What language processes } \\
\text { do students demonstrate } \\
\text { as they participate in } \\
\text { Authentic Discussion, } \\
\text { including the language } \\
\text { processes involved with } \\
\text { Critical Literacy, higher } \\
\text { order thinking skills, and } \\
\text { Accountable Talk? }\end{array}$ & $\begin{array}{l}\text { Field notes of Class } \\
\text { Authentic Discussions } \\
\text { Student Journals }\end{array}$ & $\begin{array}{l}\text { Researcher established a } \\
\text { coding system and } \\
\text { selectively coded a } \\
\text { sample of field notes. The } \\
\text { researcher then asked a } \\
\text { colleague who also taught } \\
\text { senior English to code the } \\
\text { same sample and } \\
\text { determine if there was } \\
\text { agreement between } \\
\text { coders. }\end{array}$ \\
\hline $\begin{array}{l}\text { How does } \\
\text { Authentic } \\
\text { Discussion affect } \\
\text { student agency or } \\
\text { student } \\
\text { responsibility and } \\
\text { ownership of the } \\
\text { lesson? What do } \\
\text { students take away } \\
\text { as learners from } \\
\text { the experience of } \\
\text { participating in } \\
\text { Authentic } \\
\text { Discussion? }\end{array}$ & $\begin{array}{l}\text { Interviews } \\
\text { Student Journals } \\
\text { Field Notes }\end{array}$ & $\begin{array}{l}\text { Researcher established a } \\
\text { coding system and } \\
\text { selectively coded a } \\
\text { sample of field notes. The } \\
\text { researcher then asked a } \\
\text { colleague who also taught } \\
\text { senior English to code the } \\
\text { same sample and } \\
\text { determine if there was } \\
\text { agreement between } \\
\text { coders. }\end{array}$ \\
\hline $\begin{array}{l}\text { How and why do } \\
\text { students perceive } \\
\text { Authentic } \\
\text { Discussion? Are } \\
\text { students more }\end{array}$ & $\begin{array}{l}\text { Interviews } \\
\text { Student Journals } \\
\text { Field Notes }\end{array}$ & $\begin{array}{l}\text { Researcher established a } \\
\text { coding system and } \\
\text { selectively coded a } \\
\text { sample of field notes. The } \\
\text { researcher then asked a }\end{array}$ \\
\hline
\end{tabular}




\begin{tabular}{|l|l|}
\hline $\begin{array}{l}\text { inclined to } \\
\text { participate in }\end{array}$ & $\begin{array}{l}\text { colleague who also taught } \\
\text { senior English to code the } \\
\text { Authentic } \\
\text { Discussion in an } \\
\text { informal classroom } \\
\text { environment? }\end{array}$ \\
& $\begin{array}{l}\text { same sample and } \\
\text { determine if there was } \\
\text { agreement between } \\
\text { coders. }\end{array}$ \\
\hline
\end{tabular}

The first stage of grounded theory involves open coding and occurs when the researcher goes back and forth among data sources to code in the margins and comparatively analyze the data in order to begin to see emergent themes. The second stage is defined as selective coding in which core variables are identified in order to guide the coding. Selective coding enables the researcher to filter the open coding and determine which concepts are emerging as most relevant and in so doing, the researcher begins to establish a theory. This process is known as theoretical sampling which results in the researcher's focus and ability to move the study forward at a faster pace. Subsequently, theoretical codes examine relationships among data and allow the researcher to make connections needed to present the study as a unified story with causes and results (Glaser, 1992). The researcher also makes use of memo-writing that will be discussed in more detail in the methodology chapter of the study.

Rationale and Significance

Teachers want to, "understand what motivates [students] and makes them tick, what engages them and interests them" (Ayers, 1993, p. 33). This task is forever ongoing. Teachers are in a unique position to exercise their voices and experience in order to empower students in the democratic classroom (Eisner, 1998; Ayers, 1993; Christensen, 2009). The alternative is to submit passively and silently to the fact that 
teachers have limited control over student activities and assessments, "we [educators] know that the harsh reality in many schools is a structure that disempowers and deskills, a system that prespecifies each teacher's thoughts and oversees and constrains our activities" (Ayers, 1993, p. 18 \& 19). Educationally, pedagogically, and from a human concern perspective, the alternative is not acceptable. What is desirable then, is the act of participating to be "fully present" (Ayers, 1993; Greene, 1973) and to research the daily dilemmas that face teachers and to devise authentic assessments that, unlike standardized testing, involve text-toworld and text-to-self connections (Carbonaro \& Gamoran, 2002; Raudenbush, 2008) as these connections are characteristics of critical literacy.

Pedagogical change that impacts student learning and teaching occurs when teachers in the field take action to solve their own dilemmas, and in the social constructivist tradition, write and talk about the dilemmas with others. ElbazLuwisch (2005) maintains, "viable school change can come about only through a dialectic process in which teachers participate fully" (p. xi). Authentic discussion is part of school change; it is an essential, and often overlooked, component of the learning process. Toby Fulwiler, University of Vermont professor emeritus, has written extensively about the teaching of writing and has concluded that students benefit by talking in small and large groups about newly acquired information before being asked to analyze or write about that information (2007). This component of school change is a stressed skill included at each grade level in the Common Core State Standards (http://www.corestandards.org/the-standards), recently adopted by almost all of the states in this country. Although I am not a proponent of the 
Common Core State Standards and the assessments that accompany them, their widely adopted status suggests a need for teacher/researcher studies that examine how students engage in authentic discussion, for although it remains an identified standard of student learning, there exists a dearth of professional materials created by and for educators.

This study examines student talk and fills a gap in the available literature on authentic discussion in the secondary English classroom. Although studies exist that explain the importance of classroom talk, there are no existing studies that document how speaking and listening might be accomplished based upon the use of critical literacy, higher order thinking skills, and Accountable Talk in a salon setting. Fulwiler observed, "discussions about [the subject] are most productive when students, even in the intermediate grades, leave their desks and sit together in an area designated for class discussions" (2007, p. 17). For this reason, the informal classroom used in the study was designed as a salon setting with authentic discussion in mind.

\section{Benefits}

Students benefit cognitively, emotionally, and socially from a study that requires them to utilize authentic discussion in the classroom. As they engage in authentic discussion, they learn to exercise their voices and share their own ideas. They learn how to employ multiple perspectives to the same text. And they learn the role that social justice plays in both the literature studied and the classroom environment. 
Participants Exercise Voice and Agency. Authentic discussion requires that students develop agency and voice when they share ideas during discussion. Voice is defined as a, "language performance_-always social, mediated by experience and culturally embedded" (Sperling, Appleman, Gilyard, \& Freedman, 2011, p. 71). According to this socially constructed definition of voice, it is the teacher's responsibility to, "Foster students' recognition of when and why they use the discourses that they do" (Sperling et al., p. 81). Agency is defined as the knowledge that one has the potential to disturb the status quo and enact change (Beach, Campano, Edmiston, \& Borgmann, 2010, p. 52). During the pilot study, I conducted the year before with different students in the same course, many students reported that multiple interpretations of text had not been condoned in previous English class discussions. They were expected to answer questions where expectations primarily involved Initiation/Response/Evaluation (IRE) and multiple interpretations of text were not encouraged. As such, exercising voice and agency may not be familiar or comfortable for many of the students who have grown up in an era of IRE teaching and standardized tests (Rex and Schiller, 2009). However, during the pilot study, guided by a social constructivist frame, students became more comfortable exercising voice and agency through continued emphasis that teaching and learning during Authentic Discussion is not the passing on of knowledge, "that the teacher knows and the students lack," but rather, "the practice of developing knowledge through social interaction" (Ayers \& Ayers, 2011, p. 107).

\section{Participants Employ Multiple Perspectives to Analyze Text. Appleman} (2009), a teacher/researcher, identifies eleven different critical theories that can be 
used to foster authentic discussion. These theories, which include Marxist, gender, historical, and biographical theory, have the potential to play a central role in classroom discussion because they allow students to unpack systems of meaning from various perspectives (Beach et al., 2010). Students define and practice applying the different theories to text before they utilize them during authentic discussions.

Participants Interact with Narratives that Promote Social Justice. In addition to the multiple lenses offered by critical theories, authentic discussion benefits students as they develop awareness of the stories and writings of diverse or marginalized populations. In language arts classrooms where social justice education is stressed, students read to cultivate an understanding of what it means to be a member of marginalized groups and in so doing, text is placed within social, cultural, and historical contexts. Students are presented with opportunities, "to understand a wider human experience" and to learn about, "people who disrupt the script society has set for them" (Christensen, 2009, p. 5 \& 6). When students are emotionally moved by the literary content or able to empathize with the protagonists, the teacher increases the possibility of engaging students in authentic discussion (Ansbach, 2012; Bracher, 2009; Glascow, 2001).

Participants Use Protocol Based on Accountable Talk. Lastly, Accountable Talk is a critical component of authentic discussion. Resnik states that Accountable Talk requires three key components: 1) talk must be accountable to knowledge in that students provide evidence for assertions; 2) talk must be accountable to standards of reasoning in that students present rational arguments before making conclusions; 3) talk must be accountable to the learning community itself in that 
students respect the established ground rules and norms of conversation (as cited in Cazden, 2001, p.170). These ground rules include many different norms such as respecting a speaker by not interrupting him or her, using logical connections between expressed ideas and backing up ideas with textual evidence (Michaels, O'Connor, \& Resnik, 2008). It is incumbent upon the teacher/researcher to establish these norms.

Role of Researcher

Qualitative inquiry in education is about, "trying to understand what teachers and children do in the settings in which they work" (Eisner, p. 11). The opportunity to function as both teacher and researcher at the same time is both challenging and rewarding in its dual responsibilities and chance to contribute to existing knowledge in the field.

Elliot Eisner (1998), professor emeritus of art and education at Stanford University School of Education and former president of American Educational Research Association (1992-1993), identifies five characteristics of qualitative inquiry that guides the role of the researcher in this study. First, the research is field focused and occurs in the setting in which the teacher/researcher and students work and learn. The physical setting, the salon classroom in this study, was deliberate and meant to contribute to "how people are supposed to behave and what they are supposed to learn" (Eisner, p. 33).

Second, qualitative inquiry makes use of the self as instrument. I interpreted and analyzed the data collected in the study and as such, my subjectivity and experience or my unique "signature" (Eisner, p. 34) is present within the chapters. This 
subjective experience included the fact that in addition to a pedagogical preference for authentic discussion, over the past decade I had personally witnessed a disturbing decline of authentic discussion in the secondary English classroom.

Third, qualitative inquiry involves my assumptions or conceptual frameworks that inform my interpretation of classroom events. Interpretation has two meanings in regard to qualitative study. It is both, "the ability to explain why something is taking place" and "what experience holds for those in the situation studied" (Eisner, p. 35). Conceptual frameworks influence both definitions of interpretation.

Fourth, qualitative studies involve the researcher's use of expressive language and voice in the text (Eisner, 1998). In this study, I captured not only my own voice as an experienced educator, but also the voices and the experiences of the students as they negotiated authentic discussion. In qualitative inquiry, this is accomplished through "rich description", a term coined by Clifford Geertz (19262006), renowned cultural anthropologist. In ethnography, this type of description is also referred to as thick description of human behavior or one that explains not just the behavior itself, but the context as well (Gertz, 1973).

Fifth, attention to particulars (Eisner, 1998) is a characteristic of qualitative inquiry. Attention to particulars is defined as the ability to capture the unique characteristics of the situation being studied by attention to detail and then the ability to perceive themes within the details (Eisner, 1998). I elaborated on the relationships and themes that emerged from attention to particulars.

\section{Researcher Assumptions}


The research questions identified earlier are addressed from the perspective of social constructivist theory. Social constructivist theory maintains that an individual's cognitive development is the result of social interaction, where language lies at the core between adults and children, and children and their peers (Vygotsky, 1978; Bruner \& Harste, 1987; Halliday, 1993). An essential tenet of constructivism claims that what students come to understand is directly connected to the context in which their learning takes place, their activities in the classroom, and their goals. Prior experience and the nature of the social environment are key components involved in determining what a learner comes to understand (von Glaserfeld, 1989; Rorty, 1991).

Social constructivists view the classroom as a community of learners in which the teacher functions as a facilitator who guides students to make meaning from texts, experiences, and interactions (Duffy, Lowyck, Jonassen, \& Welsh, 2012; Cresswell, 2009; Lebow, 1993). The teacher has the responsibility to provide multiple perspectives, real life contextual scenarios, and meaningful social interactions that support learning and encourage individual student voices and agency. In a constructivist learning environment students take responsibility and ownership in the learning process and they are expected to explain how and why their thinking develops. Knuth and Cunningham have labeled this cognitive process "reflexivity" or an extension of the higher order metacognitive and reflective thinking skills (1993). Reflexivity refers to understanding the thought process of the moment while at the same time engaging in the experience of the moment. For example, a reflexive educator, like a grounded theory researcher, evaluates the lesson 
being taught (or the data collected) at the same time that the lesson (or the research) is occurring.

In order for a teacher to act as a facilitator in a social constructivist mindset and environment, the teacher must have a grasp on the students' background and a solid idea of what the students know and how they are expected to function cognitively when they leave high school behind for college (Sizer, 2002). This idea is the basis for the justification and significance of the study.

\section{Organization of Dissertation}

I have used a five-chapter format to present the dissertation (Bloomberg \& Volpe, 2012). Chapter Two defines terminology used in the study and expands the literature review concerning authentic discussion, critical literacy and higher order thinking skills. Other ideas including aesthetics, social justice, qualitative teacher research, and discourse analysis are addressed in significant detail. Chapter Three examines the methodology used to complete this study, constructivist grounded theory, pioneered by Strauss and Corbin $(1994,1998)$ and Charmaz $(2006,2008)$; Chapter Four presents the findings of the study; and Chapter Five analyzes and synthesizes the study's findings, draws conclusions, and suggests recommendations for further study. 


\section{CHAPTER 2 \\ LITERATURE REVIEW}

\section{Introduction}

This chapter defines the terminology used in the study and reviews the research regarding Authentic Discussion (AD) in the classroom and the philosophical assumptions that support its use as a tool to achieve enhanced student learning and educational improvement.

\section{Definitions of Terminology}

The focus of this study is on authentic classroom discussion where participants are instructed in and taught to employ critical literacy, develop higher level thinking skills, and engage in Accountable Talk. The terms critical literacy, higher level thinking skills, and Accountable Talk may be interpreted in a variety of ways. The following elaborate on the terminologies that are used in this study.

Critical Literacy. Critical literacy is a pedagogy that a teacher employs to encourage students to adopt "critical" perspectives or to use different lenses to analyze text (Appleman, 2009). Beach et al. (2010) explain that critical literacy involves the "unpacking of systems of meaning" (p. ix) for the purpose of "disrupting the commonplace, interrogating multiple perspectives, focusing on the sociopolitical, and taking social action" (p. ix). Critical literacy plays a central role in classroom discussion because such discussions encourage students to read and write about literature from different theoretical perspectives. One way to foster students' use of critical 
literacy is to instruct them in theories or alternative lenses such as Marxism and gender theory, as well as historical, biographical and other lenses through which students may examine works of literature when reader response is no longer sufficient or desired to generate conversation.

Some researchers claim that authentic discussion and critical literacy support one another's development (Applebee, 1996; Applebee et al., 2003; Appleman, 2009; Beach et al., 2010). Nevertheless, few studies exist to demonstrate this relationship. Applebee, who has conducted seminal studies about the discussion of literature, writes about a disturbing, "continuous emphasis on learning about, rather than participating in, traditions of literature and criticism" (1996, p. 28 \& 29). He elaborates, indicating that, "most students [in the study] were expected to figure out the answers the teacher was looking for...Opportunities to discuss alternative interpretations or students' own responses were relatively few" (Applebee, 1996, p. 29).

Applebee, Langer, Nystrand, and Gamoran (2003) conducted a similar large scale, quantitative study designed to determine the common features in classrooms that emphasized discussion approaches to determine if these classrooms were more successful at improving students' critical literacy practices. They found, "high academic demands and discussion based approaches were significantly related to spring performance [end-of-theyear assessment], with controls for initial literacy levels, gender, socioeconomic status, and race/ethnicity" (2003, p. 719). Interestingly, the 
effects were significant across grade levels (seven to twelve) and tracks (ability levels).

Higher Level Thinking Skills. Higher level thinking skills are cognitive skills that rely on multiple processing abilities such as synthesizing, analyzing, inferring, appreciating, and evaluating. These skills are activated when teachers make use of a responsive teaching model that avoids mere recitation and promotes authentic discussion and, "comes closer to the type of language used most effectively for learning in virtually all life contexts other than in schools" (Eisner, 1998, p.136).

Cognitive scientists describe thinking as a, "mental process in which something is turned over in the mind in order to make sense out of experience" (Geertsen, 2003, p.1). What distinguishes higher-level thinking from lower-level thinking is the amount of control exercised by the thinker while processing information (Geertsen, 2003). Bloom (1956) identified a linear continuum or taxonomy of higher-level thinking that includes: memorization, comprehension, application, analysis, synthesis, and evaluation. In this study, three types of thinking at the upper end of the continuum, analysis, synthesis, and evaluation, are identified as higher order skills and are characterized by critical thought or thought that involves making judgments (Geertsen, 2003; Bissell \& Lemons, 2006).

Accountable Talk. Accountable Talk is the name given by Lauren Resnik and her colleagues at the University of Pittsburgh to the kinds of talk needed in a democratic community of learners (Cazden, 2001, p. 170). 
Accountable Talk has three major components: accountability to the learning community, defined as students' ability to link their ideas to those of other students (otherwise known as uptake); accountability to accurate knowledge, defined as students' abilities to support their ideas with evidence from text; and, accountability to rigorous thinking or reasoning, defined as students' abilities to explain their thinking (Cazden, 2001; Billings \& Fitzgerald, 2002; Wolf, Crosson, \& Resnik, 2006).

Accountable Talk, "sharpens students' thinking by reinforcing their ability to use and create knowledge" (Michaels, O'Connor, Hall, \& Resnik, 2008, p. 1). In one study, Nystrand (1997) surveyed over one hundred eighth and ninth grade classrooms and found that uptake, a characteristic of accountability to the learning community, was one of the three features associated with larger literacy improvements over the course of a school year.

Accountable Talk requires teachers to have clear conceptions of academic goals and requires teachers to establish predictable routines and reinforce norms and protocols for talk (Michaels, O'Connor, Hall, \& Resnik, 2008). These goals, routines, and norms must be established before students can show cognitive growth in the three areas of Accountable Talk.

\section{Authentic Discussion and Initiation/Response/Evaluation}

Studies reveal that there are two types of discussion: Question and Answer (Q \& A) also known as Initiation/Response/Evaluation (IRE), and authentic discussion (AD) or dialogic discourse (Cazden, 2001; Wells, 
1999, 2001; Billings \& Fitzgerald, 2002; Hadjioannu, 2007). In IRE, "students recall what has already been encountered" while in authentic discussion, "talk moves from exchange of words to development of ideas, from social interaction to shared social meaning and from knowing to understanding" (Harrison, 2005, p. 69).

Initiation/Response/Evaluation has dominated and continues to dominate discourse in English classrooms (Applebee, 1996; Applebee, Langer, Nystrand, and Gamoran, 2003; Billings \& Fitzgerald, 2002; Hadjioannou, 2007). Billings and Fitzgerald (2002) found that most classroom talk followed this "teacher-fronted" discussion format where the teacher functions as the expert and students as the passive recipients (p. 911). Thus, some students blend seamlessly into the background while a few extraverted students dominate the responding. Researchers have found that teachers rely on IRE because it facilitates classroom management, decreases the need for wait time, and makes use of readily available teacher manuals that contain lower-level questions concerning plot and setting that are typical of IRE (Alvermann \& Hayes, 1989). IRE questions typically involve lower-level questions because they can be answered quickly and the response deemed correct or incorrect.

In contrast to constructivist teaching, IRE is part of the cultural transmission model espoused by traditional education, which has been predominant in the United States since the Industrial Revolution. Therefore, its continued dominance may be explained in part by the fact that this is 
how many teachers were taught when they were in school (Bisin \& Verdier, 2005).

The continued dominance of Initiation/Response/Evaluation can also be explained, in part by high stakes testing. Teacher/researcher Lesley A. Rex discovered that high stakes testing caused her to assist students, "in taking specific procedural, and rubric-driven stances toward what constituted academic performance. Not unexpectedly, student references to how they went about doing their work in and out of school disappeared from the discourse as did their personal texts" (Rex \& Schiller, 2009, p. 124). Rex discovered that when classroom time and stress was placed on high stakes testing, higher order thinking and reflection were replaced by procedural skills.

Higher-order thinking skills are defined as complex, cognitive processing abilities such as synthesizing, analyzing, inferring, appreciating and evaluating (Bloom, 1956). Teacher reliance solely on IRE is ineffective in developing these higher-order thinking skills students need to independently perform critical literacy tasks (Mehan, 1979; Cazden, 1995; Applebee, Nystrand, Langer, \& Gamoran, 2003).

Authentic Discussion and the Supporting Literature. In contrast to IRE, authentic discussion calls for multiple perspectives with no one right answer (Cazden, 2001, p. 30; Wells, 2001). Authentic discussion involves open-ended inquiry in which participants explore ideas and opinions wherein the objective is "to reach new and more sophisticated 
understandings" (Hadjioannou, 2007, p. 371). As productive and preferable as this may sound, authentic discussion is not prevalent in the secondary English Classroom. In a study of 58 ninth grade classrooms, Nystrand and Gamoran (1991) found open-ended whole class discussion averaged a mere fifteen seconds a day (p. 277).

More than ten years after the Nystrand and Gamoran study (1991), Applebee, Langer, Nystrand, \& Gamoran, conducted a mixed methods study involving twenty schools (Applebee, Langer, Nystrand, \& Gamoran, 2003, p. 697). These researchers observed and audio taped classes during authentic discussion in English classrooms. Each class was observed four times. Data included student and teacher questionnaires and recordings of class discussions that were analyzed to identify and measures of student literacy performance (p. 698). Researchers coded for evidence of students' inclinations and abilities to challenge and analyze text during class discussion.

Results of this study revealed that students who participated in scripted question-and-answer lessons in which the teacher asked questions about plot and setting that required right or wrong answers, did not exhibit or develop the skills and knowledge of students in classes where a teacher, "pushed [them] to articulate and expand on their initial reactions" (Applebee et al., 2003, pp. 710 \& 711). Although authentic discussion was new to all the students in the study, those taught by the teacher/researchers 
who embraced its use were able to challenge their own thinking and articulate and expand their ideas.

The teachers who pushed students to articulate made use of "uptake", an element of Accountable Talk, in which students make follow-up comments that call for further elaboration. Stems, or opening phrases of Accountable Talk, are shown in Table 2, originally identified in a power point created by the Malden Public Schools (http//:mpsela6thgrade.wikispaces.com/file/view/Accountable+Talk.ppt). In their study, Applebee et al. used stems similar to those shown in Table 2.

Table 2

\section{Accountable Talk Stems}

I agree with you.

Where do you see that?

How does that connect?

I have a different opinion.

I also noticed...

Is there another way to solve this?

Did everyone hear that?

I have something to add...

What did you mean when you said...?

Say more about what you mean.

What is your evidence?

Who can add to what was said?

Can you repeat what___said?

I would like to add to that.

Additionally, this seminal study specified elements of classroom community deemed necessary for authentic discussion to occur. These elements included the need for teachers to, "treat all students as having important contributions and understandings," and "treat instructional activities as a time to develop understandings rather than to test what 
students already knew" (p. 701). Applebee et al. discovered that students were more likely to display evidence of higher order thinking when, "encouraged verbally or through modeling to take a position, express opinions, or explore personal reactions" (p. 701). Fourteen years earlier Alvermann and Hayes (1989) reached similar conclusions as Applebee et al. (2003) regarding the reasons why teachers are hesitant to utilize authentic discussion.

Alvermann and Hayes (1989), like Applebee et al. (2003) found that although teachers report that they value discussion, teachers possess varied definitions of discussion (p. 306). The researchers conducted a mixed methods study with five high school English teachers and a diverse student sample. This mixed method study included a teacher/researcher intervention designed to increase students' use of higher order thinking and critical reading during class discussion. The five teachers in the study possessed between two and fourteen years of classroom experience. Alvermann and Hayes (1989) found that a reliance on IRE was the result of, "strong pressure [from the administration] to manage student behavior" and that attempting to modify such patterns of instruction was, "nothing less than attempts to modify the very culture of the classroom" (p. 307). They determined that their six-month intervention in the form of clinical supervision aimed at getting students to elaborate more on their answers during discussion was "mostly unsuccessful" (p.331). Alvermann and Hayes (1989) attribute this to the fact that teachers did not want to 
discourage students from impulsively "calling out" (as sometimes occurs instead of students raising their hands) during the lesson (p. 332) as well as the teachers' desire to have their students participate in ways that would be acceptable outside of their own classroom, in the dominant or mainstream culture of the school (p. 332).

\section{Characteristics of Authentic Discussion. Beach, Campano,} Edmiston, and Borgmann (2010) also discovered that in order for authentic discussion to occur, teachers must move beyond the need to control the class with quick give and take Q \& A to what is defined as an "inquiry stance" and cultivate students' critical literacy (p. 23). There are four dimensions to the complex definition of critical literacy: "(1) disrupting the common place, (2) interrogating multiple view-points, (3) focusing on sociopolitical issues, and (4) taking action and promoting social justice" (Lewison, Flint, \& Van Sluys, 2002, p. 382). The presence of these four elements is likely to move forward and sustain authentic discussion in the English classroom (Golden \& Christensen, 2008; Christensen, 2009). In order for these four dimensions of critical literacy to exist in the classroom, research indicates that teachers need to structure activities that allow students to develop a sense of agency (Beach et al., 2010). Agency is defined as, "having the potential or capacity to enact change in status-quo practices, beliefs, or self-perceptions" (Beach et al., p. 52).

Another element needed to foster critical literacy is attention to both physical and social spaces: "We recognize how classroom organizational 
structures and social interactions are material and social manifestations of a more equitable distribution of intellectual authority among the classroom community" (Beach et al., p. 18). Attention to the physical space (arrangement of furniture, access to materials, performance areas) and social interactions that value the voices and identity of all participants increase the likelihood of students' inclinations to engage in authentic discussion that shows evidence of critical literacy.

Physical and social space featured prominently in Hadjioannou's (2007) qualitative case study in a classroom where authentic discussion frequently occurred. The purpose was to determine the, "elements that shaped the classroom community" (p.374). The classroom in the study had a comfortable reading niche with comfortable chairs, classroom desks that were frequently rearranged, and many displays of student work. The teacher rarely sat at her desk during class discussion (p.374). Additionally, Hadjioanno (2007) found that the following components aided the teacher in her ability to foster authentic classroom discussion: choice of interesting, well-written literature; a low priority placed on test preparation; direct instruction when needed for lower-level thinking assignments; respect for students' intelligence; a climate of friendlessness and acceptance, clear expectations, emphasis on respecting the rights of others'; explicit rules regarding classroom behavior; a social constructivist approach to teaching and learning; and a sense of cohesiveness in the classroom community (pp. 374-382). 
The Non Neutrality and Multiple Perspectives of Authentic

Discussion. Authentic discussions include open-ended inquiries, a vital component in developing critical literacy. However, discussions with no predetermined outcome may be "uncomfortable" for teachers due to conflicting perspectives, non-neutrality, and the messy nature of conversation (Lewison, Leland, \& Harste, 2000). Authentic discussion is less predictable than question-and-answer and many teachers are not comfortable with less classroom control.

To assist teachers in becoming more comfortable with multiple perspectives, Appleman (2009), a teacher/researcher, identified eleven different theories that can be used to promote critical literacy as a part of classroom discussion (see Table 3). Beach et al. (2010) explain that critical literacy involves the "unpacking of systems of meaning" or making use of different critical theory lenses (p. ix) for the purpose of "disrupting the commonplace, interrogating multiple perspectives, focusing on the sociopolitical, and taking social action" (p. ix). Critical literacy is exhibited when students read and write about literature from different theoretical perspectives. Once students are old enough to psychologically grasp that a teacher's expert opinion or their own personal response is not the only way to view text, they are old enough to examine literary works through multiple perspectives such as gender theory or Marxist/social theory (Appleman, 2009). 
Table 3

Literary Theory Lenses and Their Assumptions

\begin{tabular}{|l|l|}
\hline Theory Name & Assumptions \\
\hline $\begin{array}{l}\text { Psychological } \\
\text { Criticism }\end{array}$ & $\begin{array}{l}\text { An author's creative writing is representative of } \\
\text { repressed fears and dreams. }\end{array}$ \\
\hline $\begin{array}{l}\text { Feminist/Gender } \\
\text { Literary Theory }\end{array}$ & $\begin{array}{l}\text { Men and women read and write differently and we need } \\
\text { to value these differences. }\end{array}$ \\
\hline $\begin{array}{l}\text { Marxist/Social Class } \\
\text { Theory }\end{array}$ & $\begin{array}{l}\text { Those in power and those with money are in a position } \\
\text { to force their values and beliefs on other social groups. }\end{array}$ \\
\hline $\begin{array}{l}\text { Reader Response } \\
\text { Theory }\end{array}$ & Readers make personal meaning from text. \\
\hline $\begin{array}{l}\text { Formalist theory/New } \\
\text { Criticism }\end{array}$ & $\begin{array}{l}\text { Focus is on the form and convention of the work itself } \\
\text { with no other outside considerations. }\end{array}$ \\
\hline Postcolonial Theory & $\begin{array}{l}\text { Colonized people are seen as different from those who } \\
\text { colonized them. }\end{array}$ \\
\hline Archetypal Theory & $\begin{array}{l}\text { There are recurring myths, symbol and character types } \\
\text { in text that we are programmed to recognize. }\end{array}$ \\
\hline Biographical Criticism & $\begin{array}{l}\text { Since authors write about things they know and care } \\
\text { about, their lives are reflected in their text. }\end{array}$ \\
\hline Structuralist Criticism & Examine underlying system or patterns of language. \\
\hline $\begin{array}{l}\text { Deconstructionist } \\
\text { Criticism }\end{array}$ & $\begin{array}{l}\text { Meaning is made by two opposing constructs and one } \\
\text { item is privileged over another. }\end{array}$ \\
\hline
\end{tabular}

Hines and Appleman (2000) conducted research on multiple

perspectives as it is used to interpret literature in the secondary English

classroom. In a qualitative study using three case studies involving ten

secondary and college literature classrooms, Hines and Appleman (2000)

found that contemporary literary theory and authentic discussion have the

potential to enrich instruction. They argued that, "theories of interpretation

offer not only ways of reading texts, but also, either implicitly or explicitly,

ways of seeing and interpreting ourselves and our surroundings beyond the

world of the classroom" (p. 142) and that this skill is part of the complex

definition what it means to be a critically literate student. 
What conditions influence classroom discussion? Nystrand and

Gamoran maintain that, "Significant academic achievement is not possible without sustained, substantive engagement which transcends procedural engagement" (1991, p. 262). The majority of students' involvement in formal schooling is procedural; that is, students go through the motions of school. In contrast, substantive engagement “depends on students' psychological investment in class activities, and fully played out, this investment will lead to mastery" (p. 263). The difficulty lies in measurement of what constitutes "engagement." Nystrand and Gamoran note that a possibility of the measurement of engagement could be questions that students ask (not connected to procedural issues), the presence of sustained attention, or perhaps engagement can't even be measured until after the student has left school and there is a need for application of learned skills (p. 263). With such a dilemma, it is worth investigating the conditions that may promote engagement in classroom discussion.

One way to create the foundation for engagement is to ask authentic, open-ended questions with no pre-specified answers (Nystrand \& Gamoran, 1991, p. 264). This may be difficult for some because it requires the teacher to give up some of the control and allow students to "have input into the business of learning" (p. 266). In their study, Nystrand and Gamaron hypothesized that "student engagement is a cognitive phenomenon having to do with the extent to which students are mentally 
involved with the issues and problems of academic study" (p. 269). They studied 58 eighth-grade English classes in 16 Midwestern schools (p. 270). Each class was visited four times by an evaluator trained to observe instructional discourse. Coded data sources included student tests, questionnaires, teacher questionnaires, and classroom observations. Nystrand and Gamoran also coded for question types, which included procedural questions, rhetorical questions, and authentic questions.

Classroom Outcomes of Authentic Discussion. Nystrand and Gamoran (1991) were looking for evidence of high levels of teacher evaluation of discourse, which involved a teacher validating a student's response, and asking follow-up questions to prompt further exploration. As noted earlier in the problem statement section of this review, little time was spent on substantive engagement within the 58 classrooms studied. The researchers found, however, that "teachers who spend more time in discussion were more likely to assign authentic writing tasks and respond to writing at a high level, more likely to treat readings authentically, and more likely to use uptake and other forms of contiguity in their lessons" (p. 278).

Hadjioannou (2007) points out that although there is much praise for discussion-based approaches within the educational community, there are many variables that may determine whether or not authentic discussion can take place in a classroom. These factors include the physical environment, curriculum concerns, teacher and student beliefs about discussion, relationships among the students in the class, and classroom norms 
regarding participation (p. 371). Hadjioannou's qualitative study utilized recordings from class sessions, interviews, and field notes to examine how identified factors influenced classroom discussion.

If the teacher has not fostered a relationship of trust within the classroom and shown an interest in nurturing the students' ideas, the ability to conduct authentic discussion in the classroom may be limited (Hadjioannou, 2007). In a study conducted in 2003 and published in 2007, Hadjioannou found that common elements that lead to productive class discussion include a teacher who circulates around the room, does not stress test-taking techniques and test preparation, and creates different configurations of furniture conducive to comfort and belonging (2007, pp. 376-377). Additionally, a sense of humor and playfulness (Hadjioannou, 2007) is also a factor in case studies in which conversation played a significant role in the classroom.

Teachers who support the social constructivist framework of learning and allow students to explore their ideas are most likely to place an emphasis on classroom conversation (Hadjioannou, 2007). Those teachers who believe more strongly in direct instruction or skills-based instruction are less likely to develop students' critical literacy through authentic discussion. It is those teachers who establish a humane and liberating classroom that may have success "reshaping imagination...released through many sorts of dialogue" and only then are the "young stirred to reach out on 
their own initiatives. Apathy and indifference are likely to give way as images of what might arise" (Greene, 1995, p.5).

In order for authentic discussion to occur, a learning community of trust and respect must be established and maintained. Beach et al. (2010) noted that those teachers who adopt an "inquiry stance" to learning are more likely to succeed, and points out that "this type of creative and intellectual work cannot be learned prescriptively" (p. 23). In concluding their research, Beach et al. (2010) reiterate the four essential elements needed for establishing critical literacy in the classroom: identity, agency, critical inquiry, and the construction of spaces. Each element is equally important. This mode of literacy learning is grounded not only in constructivist theory and encourages the assessment of students based on their use of literacy tools to cultivate their own identities and beliefs rather than the assessment of isolated language arts skills.

Although she did not conduct official studies, Maxine Greene was well recognized for her influence on discussion techniques and the juxtaposition of art and discussion in the constructivist classroom. Prior to her death in 2014 at age ninety-six, she taught at Teachers College at Columbia University for almost fifty years and was Philosopher in Residence at the Lincoln Center for the Arts. She wrote that teaching with conversation occurs best when teachers are able to encourage students to perceive connections, view alternatives and devise new orders (2001). In her extensive writings that stress an imaginative and aesthetic framework, 
she wrote that teachers should spend more time thinking about the actual spaces that are created for dialogue (2001, p. 124). Greene advocated for expanding the traditional curriculum with new texts that bring a modern audience into the joys of stories and spark conversation. It is up to the teacher to choose the right kinds of materials that will bring readers into new worlds and expose them to new cultures and ideas while stressing that "so much depends on our - the teachers' own recognition that meanings must be achieved by those with a sense of agency; they do not preexist, to be dug up like nuggets of coal" (p.124). So both the quality of the text and its relevance to the audience are related to the dialogue that has the potential to occur as students can construct meanings for themselves.

Maxine Greene also stressed that students must be afforded the opportunity to use text in order to explore their own personal narratives and this too could lead to transforming, authentic dialogue. She wrote that it is an obligation of the aesthetic and constructivist teacher to find ways in which students can find their own voices (2001, p. 120). Possibilities abound for accomplishing this goal. Some teachers suggest the use of either fishbowl or concentric circles to allow students to explore and build on ideas (Kletzien \& Baloche, 1994, p. 542). Fishbowl occurs when an inner circle of students discusses a text while the outer circle observes and takes notes on aspects of the discussion such as how many times a particular student speaks or how many times a particular theme is mentioned. 
In the circle activity, the student comes prepared with index cards (about an event in a text and what this event may reveal about a character) that he has completed for homework and a student from the inner circle discusses his or her card with a partner in the outer circle. The partner is instructed to ask clarifying questions. After this, as Kietzen and Baloche (1994) point out:

...students in the outer circle share their events and interpretations. After both sets of explanations, the students trade cards, and the students in the outer circle rotate clockwise so that each student in the class now faces a new partner. Students must now explain the event and characterization represented by the new card they hold, the card given to them by the previous partner. With little teacher intervention, the students review many of the novel's critical events and share many interpretations of the characters as they continue to move around the circle. (p. 542)

Nystrand and Gamoran stress that authentic discussion depends on how students and teachers interact, "teachers are key to creating classrooms where reciprocity is respected and possible. It is, after all, teachers who must carefully attune their questions and assignments to student interests, expectations, and abilities, which they must take seriously and obviously respect" (1991, p. 284).

Teachers "however, are rarely given any information or practical approaches to teaching students how to discuss or how to evaluate the 
process of discussion so they may build upon and learn from the interaction" (Smith \& Smith, 1994, p. 582). Smith and Smith proposed an activity for a "discussion simulation" in which the teacher assigns students roles that are likely to either support or hinder authentic discussion. An example of a role likely to support discussion is "ask someone to support your point of view—for example, call them by name: Jane, don't you agree?" and an example of a role likely to negatively affect the class discussion is "You're bored! Act it out nonverbally. Look at a book or out the window" (p. 584). These roles are written on a "Role Behavior Card". Those students who are not assigned roles, are assigned the task of observing and recording the roles that positively or adversely affect the discussion (p. 583). Smith and Smith suggest that the "art and science of discussion is teachable" (p. 585). Their additional suggestions are that students must sit facing each other, roles should rotate among students, and judgments should be based on criteria that can be supported and explained (p. 585).

\section{Conceptual Frameworks}

Four underlying assumptions, social constructivism, aesthetic theory, feminist perspective, and social justice theory, support the development of the study as well as the chosen grounded theory methodology.

Social Constructivism. The first, Social Constructivist Theory, provides the theoretical foundation for the study. An individual's cognitive development is the result of social interaction, in which language usually 
lies at the core, between adults and children, and children and their peers (Vygotsky, 1978; Brunner \& Harste, 1987; Halliday, 1993). According to Creswell (2009), "Social constructivists hold assumptions that individuals seek understanding of the world in which they live and work. Individuals develop subjective meanings of their experiences - meanings directed toward certain objects and things" (p.8). Social constructivists view the classroom as a community of learners in which the teacher functions as a facilitator to guide students to make meaning from texts, experiences and interactions.

Aesthetics. A second assumption is that learning is best situated within aesthetics. Maxine Greene was an educational philosopher grounded in aesthetics. She wrote that educators must adopt a pedagogy that advocates for freedom, non-conformity, and creativity. She grounded this ideology in the writings of classic poets and novelists and in the theories of human potential that drove the Enlightenment. She defined "aesthetic education" as follows, an intentional undertaking designed to nurture appreciative, reflective, cultural participatory engagements with the arts by enabling learners to notice what there is to be noticed, and to lend works of art their lives in such a way that they can achieve them as variously meaningful. When this happens, new connections are made in experience: new patterns are formed, new vistas are opened. (Greene, 2001, p. 6) 
Along with appreciating and reflecting on the aesthetic value of literary texts, students are encouraged to read materials written from diverse viewpoints.

Feminist Perspective or Approach. A third framework for examining authentic discussion is the feminist perspective or a feminist approach to research and discussion. The feminist perspective on research, "presumes the importance of gender in human relationships and societal processes and orients the study in that direction" (Patton, 2002, p. 129). Creswell also states that the feminist perspective may include a sense of equality between the researcher and the participants as well as the inclusion of emotion, intuition, and experience along with analytic thought.

Furthermore, the feminist approach stresses reflexivity, centrality of practice to effect change and equality, process as ongoing and seamless as opposed to segmented, and the rethinking of paradigms and the accepted canon (Fox \& Murray, 2000). Reflexivity, "is the recognition by the scholar that he or she is an actor intimately involved in the generation of knowledge, rather than simply a recorder and reporter of what is seen outside oneself' (p. 1161). Centrality of practice concerns both the what and how of teaching. Scholars address the, "need for sensitivity to diverse student experiences and the value in building connections among and empowering students" (MacDermid, Jurich, Myers-Walls, \& Pelo, 1992). Critical literacy naturally occurs as an outcome of using the feminist perspective. Students are empowered by the realization that there is more 
than one expert interpretation of text. In regard to process, "a feminist approach takes as centrally problematic the social process through which the described patterns are generated, sustained over time, and come to reproduce themselves" (Fox \& Murray, 2000, p. 1162). In the case of this study, Initiation/Response/Evaluation is the pattern of instruction that has been sustained over time and may impede a students' knowledge of multiple interpretations of text. Finally, the feminist perspective views knowledge as much for knowledge for its own sake, but also knowledge for social change (Patton, 2002, p. 129) or knowledge that questions the existing canon and dominant view (Fox \& Murray, 2000, p. 1163). This is not necessarily the view of knowledge as conveyed with the use of IRE.

Patton defines the feminist perspective as one that "presumes the importance of gender in human relationships and society processes and orients the study in that direction" (2002, p. 129). In terms of a methodology to approach research and teaching, the feminist perspective, "provides not only conceptual and analytical direction but also methodological orientation in emphasizing participatory, collaborative, change-oriented, and empowering forms of inquiry" (p.130). This collaborative and change-oriented method is connected to constructivist grounded theory that puts preconceived notions to the test. As Patton suggests, authentic discussion breaks with predetermined norms and the culture of accepting a few privileged, educated white men as being the 
ultimate authorities on what constitutes a good work of literature or a way of thinking about how students should be educated (p. 129).

Social Justice Education. The third assumption is that social justice has a place in the language arts classroom; Students read to cultivate an understanding of what it means to be a member of marginalized groups and in so doing, text is placed within social, cultural, and historical contexts. This assumption states that students need to be presented with opportunities, "to understand a wider human experience" and to learn about, "people who disrupt the script society has set for them" (Christensen, 2009, p. $5 \& 6$ ). When students are emotionally moved by the literary content or able to empathize with the protagonists, the teacher increases the possibility of engaging students in authentic discussion (Bracher, 2009; Glascow, 2001).

Researchers have found that institutions perpetuate, rather than mitigate microagressive behavior, "schooling often reproduces patterns of social and economic inequality that have historical roots and that characterize contemporary society" (Adams \& Love, 2009, p. 6). As such, a call to action, a call to implement social justice education exists. English language arts (ELA) teachers are in a unique position to use curriculum to, "decenter the dominant worldview and incorporate multiple perspectives that reflect under-represented peoples' viewpoints" (p.13). ELA teachers and their students encounter and discuss universal themes including what it means to be human in this world. As such, the stories they encounter and 
the character shoes they walk in represent powerful weapons to counteract intolerance.

\section{Summary of the Literature}

The literature has clearly described that students benefit when teachers incorporate authentic discussion into their instruction. However, because its use is not the norm in English language arts classrooms at the high school level (Applebee, Langer, Nystrand, \& Gamoran, 2003, Hadjioannou, 2007, Rex \&Schiller, 2009, little data about its implementation is available. Initiation/Response/Evaluation continues to constitute what is considered discussion for a variety of reasons including its maintenance of classroom control, linear progression of ideas, and reliance on right-or-wrong answers (Nystrand \& Gamoran, 1991; Wells, 1999, 2001; Applebee, Langer, Nystrand \& Gamoran, 2003; Hadjiouannou, 2007; Appleman, 2009). The use of authentic discussion is supported by the constructivist approach to learning. It is a messier, riskier way of promoting talk in the classroom, but it yields opportunities for students to engage in high-order thinking, critical literacy, and Accountable Talk (Cazden, 2001; Billings \& Fitzgerald, 2002; Appleman, 2009; Beach, Campano, Edmiston \& Borgmann, 2010). The use of authentic discussion in the classroom increases students' voice and agency as it provides an opportunity for students to utilize multiple lenses to examine literature and an opportunity to learn how to become citizens in a socially just, diverse world. 


\section{CHAPTER 3 \\ METHODOLOGY}

\section{Introduction}

This study implements qualitative, grounded theory (or constant comparative method) that was developed forty-four years ago by Glaser and Strauss (1967). Grounded Theory is a methodology for developing theory based in data that are systematically gathered and analyzed (Strauss \& Corbin, 1994; Charmaz, 2008). Grounded theory is similar to other qualitative methods in that it uses similar data sources such as interviews, field observations, and documents. However, it differs from other qualitative methods because its emphasis is on theory development that occurs throughout the course of the research project.

\section{Rationale for Research Approach}

I chose grounded theory for this study because it allowed me to constantly review lessons, make changes, compare data, and continually attempt to answer the question "why" while working toward building theory. I viewed the research project like the act of teaching itself: reflection and revision occur on a day-to-day basis, within the act of teaching as well as after teaching. Grounded theory was also selected due to the fact that, "suggested guidelines and procedures [of grounded theory] allow much latitude for ingenuity and are an aid to creativity" (Stauss \& Corbin, 1994, p. 273). This research approach is appealing because rather than a prescriptive formula, it represents an organic process that, "when 
combined with insight and industry, offer a sharp tool for generating, mining, and making sense of data" (Charmaz, 2006, p. 15).

\section{Setting}

East High School is a public high school located in a rural/suburban New England town that has a mostly white, middle to lower-middle class population. Students are placed in one of two tracks at East High: college preparatory or honors. All students are prepared for college. There is no vocational track. Although East High has a school improvement team, parent-involvement in the school is uncommon; on average, only ten percent of the parents of the students in the study attend open houses and conference nights. A common complaint among the students is that there is "nothing to do" in the town. Although, classroom discipline problems are relatively rare among the honors students, apathy and poor attendance are common. The teacher/researcher has noted that despite the fact that participation accounts for ten percent of a student's grade, in previous years a surprising majority of the students have declined to engage in class discussion.

The Town. Woolen mills built during the Industrial Revolution characterize the town in which East High is located. It was founded in 1662 by English setters who worked the farms. Eventually French, French Canadian, and Irish immigrants came to the area and worked in the mills. According to the most recent census, the current demographics are much the same in the town's population of 15,000 . 
Surrounding these mills, are forests and lakes where residents like to camp and boat. The town is a half an hour by car to the state capital's theatres, restaurants, shopping centers, and other cultural activities.

The latest census on the Department of Labor and Training website reveals that $98.6 \%$ of the population is white. The median household income is $\$ 67,408$. Of the population 25 years or older, $80.4 \%$ are high school graduates and $16.2 \%$ have a bachelor's degree or higher. The median value of houses in the town is $\$ 135,100$ (http://www.dlt.ri.gov). Although the town, consisting of many villages, is labeled as "suburban" by the Department of Education, it is unique in that it contains some areas, those where the mills were located, that have become densely populated and other areas, where the farms were, where neighbors are few and far between. One high school serves the students from all the various villages that comprise the town. 


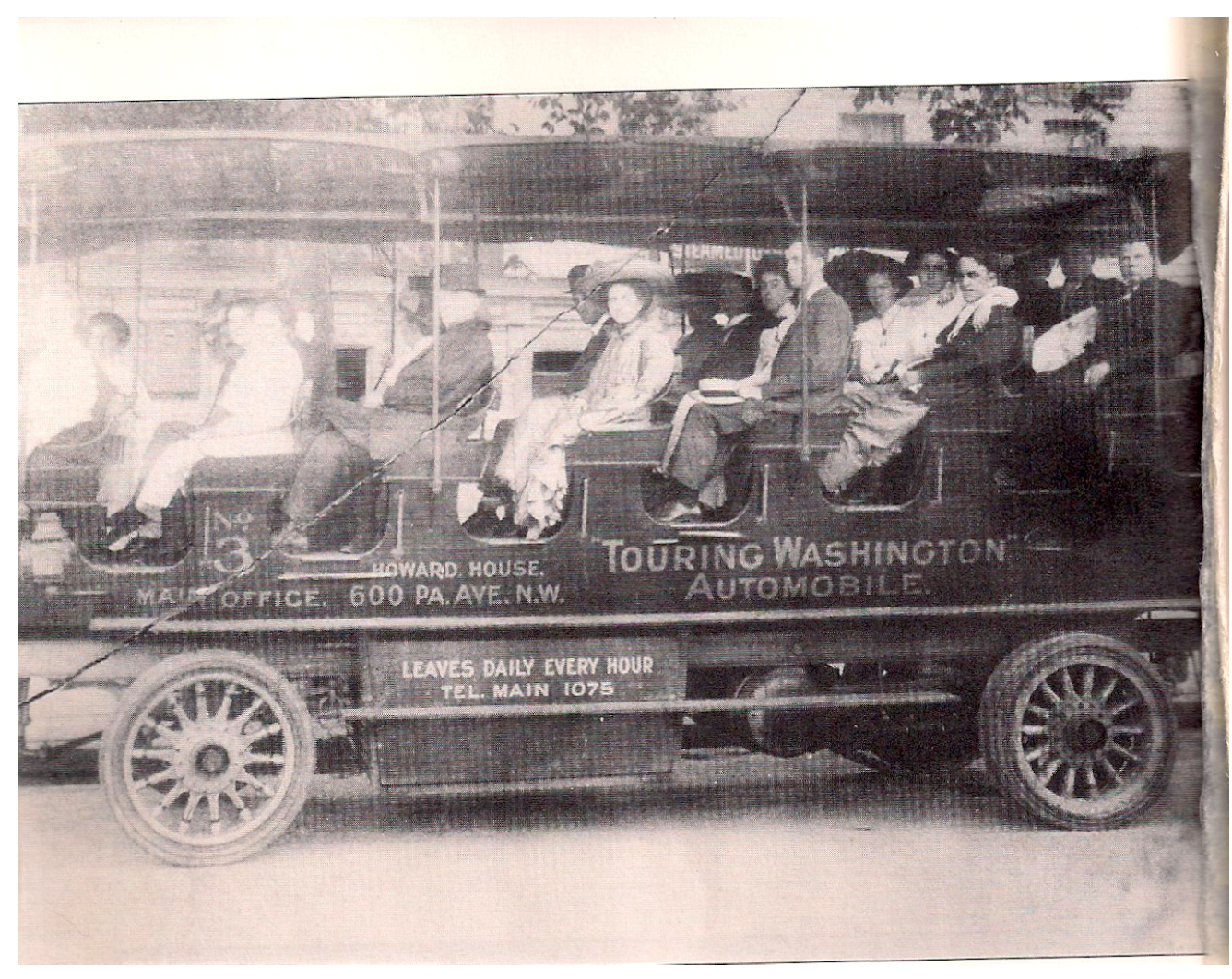

1996)

Figure 2. 1910 Class trip to Washington, D.C. (as cited in Mehrtens,

East High School. The town's high school is located in a picturesque, former mill village that includes the town hall and small businesses. The current building was remodeled in 2000, but the roof is old and when it rains hard, numerous buckets can be seen along the hallways. Teachers are told to cover their computers and personal belongings with plastic bags. The beige paint on the walls is dirty and the termite-infested bookshelves in many of the rooms have never been replaced. The heating system is old and the radiators in many of the classrooms constantly rattle and groan. When the temperature outside exceeds 75 degrees, most classrooms, except for the main office and the media center, become uncomfortably warm due to the brick construction. 


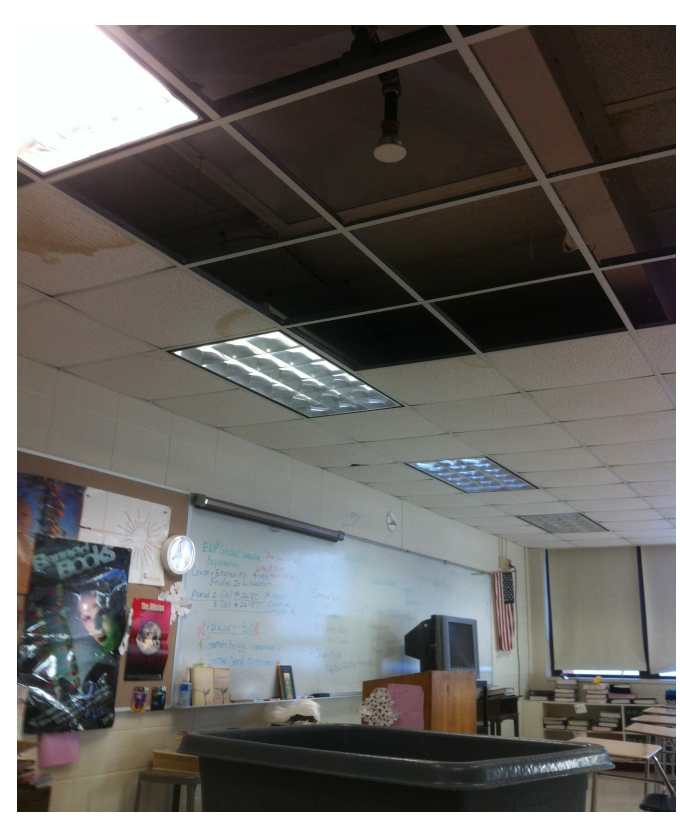

Figure 3. Rain inside the traditional classroom space Spring 2013

New furniture and carpet were installed in the media center in 2000 but already are in disrepair. The lack of a librarian (the position has remained unfilled since the 2012-13 school year) has resulted in torn furniture, stained carpets, broken DVD's and TV's, and stolen books. There have been seven different principals and almost as many vice principals in the last ten years. The last vice principal left after only one year. At first, he said the school resembled a "dollhouse" compared to the multi-level, large urban school he came from. As the year progressed, his perception changed. Before he left, he said he was astounded at the lack of tolerance and respect that the students demonstrated toward members of marginalized groups such as homosexuals and the tiny African American and Japanese populations in the town. He returned his former large, urban district.

Of all the state high schools considered "suburban" by the state's Department of Education, East High School has the highest drop-out rate, 
at $12.2 \%$. The administration hopes that a new state law preventing students from dropping out before their eighteenth birthday, even with a parent signature, may decrease this drop-out rate.

A current survey administered to students across the state by the Rhode Island Department of Education reveals some disturbing statistics (Rhode Island Department of Education, 2013). All of the percentages are above the state average (see Table 4).

Table 4

East High School's Student Behavior Compared to Other Schools in the State (Rhode Island Department of Education, 2013)

\begin{tabular}{|l|c|c|c|}
\hline & $\begin{array}{l}\text { East High } \\
\text { School } \\
\text { Percentages }\end{array}$ & $\begin{array}{l}\text { State Average } \\
\text { Percentages }\end{array}$ & Difference \\
\hline Suspensions (per 100 & 57.5 & 53.1 & 4.4 \\
\hline $\begin{array}{l}\text { Student reports of at least } \\
\text { one type of bullying }\end{array}$ & 59.0 & 49.7 & 9.3 \\
\hline $\begin{array}{l}\text { Student reports of more than } \\
\text { 4 hours a day playing video } \\
\text { games, watching television, } \\
\text { or on the computer (besides } \\
\text { homework) }\end{array}$ & 28.1 & 24.8 & 3.3 \\
\hline $\begin{array}{l}\text { Student reports of using } \\
\text { marijuana in the last 30 days }\end{array}$ & 59.3 & 57.0 & 2.3 \\
\hline $\begin{array}{l}\text { Student report more than 11 } \\
\text { texts a day }\end{array}$ & 55.2 & 41.2 & 14.0 \\
\hline
\end{tabular}

In the $2011 / 2012$ school year, $45.5 \%$ of students reported being bullied, $25.2 \%$ of students reported being robbed at least once at school, $13.8 \%$ of students reported having been under the influence of alcohol one or more times during school, and $18.4 \%$ of students reported having been under the influence of drugs one or more times during school. All of the 
percentages are above the state average and all have been identified as impediments to instruction (Infoworks, 2011/2012).

The structural dimension (Eisner, 1998) of the high school is similar to many of the high schools around the state. There are seven periods in every day that rotate on a six-day cycle. Each class is 48 minutes and occurs every day. There are 4 minutes to pass from class to class between periods. Hallways are crowded, so the student punctuality that is stressed by the administration, is often difficult to achieve. Students have a 12minute "advisory" period after the second period of the day and a 22minute lunch period sometime during the fifth period of the day. All classes take place every day even though they rotate six different ways for the sixday cycle.

The school's various wings are organized by subject area. One wing houses social studies and English. Another wing houses math and science and a third houses industrial technology classes. The special education classrooms are located throughout the building. The school contains grades nine through twelve, with approximately 200 students in each grade. The faculty includes about 70 teachers divided into 8 departments. Teachers meet in grade level meetings two or three times a week in order to ensure conformity in terms of common tasks, such as writing assignments that each grade must complete at the same time. These tasks align with the Common Core State Standards (CCSS) adopted by almost all of the states to ensure uniformity and high standards of instruction. 
English Department. The academic year 2012-2013 was the first year that the Common Core State Standards and its accompanying assessments. That year represented the second-to-last year of The New England Common Assessment Program that was transitioning to the Partnership for Assessment of Readiness for Careers and College (PARCC) as required by the Common Core for the 2014-2015 school year. The CCSS represents the foundation of the English curriculum as mandated by the State Department of Education in order to streamline national curriculum and assessments. Almost no CCSS mandatory professional development had been provided to the English department faculty, with the exception of two members who had minimal training. In the 2012-2013 school year, these two members of the English department were sent to professional development sessions regarding the CCSS; the plan was for the two faculty members to instruct the rest of the faculty, including all other departments, except for math and the arts.

The English department is made up of nine members including a reading specialist. Monthly department meetings are held to discuss issues such as summer reading, common final exams, and testing schedules. All nine English classrooms are located in the same wing. Only one English teacher works on an interdisciplinary team in an Academy program geared for at-risk college preparatory students.

Unlike the other English courses offered, because they are college level courses and the required texts and writing assignments were different, the 
EEP English courses, and a college writing course did not follow the standardized senior English curriculum with its required literature and common assessments. This was an area of concern for the district's assistant superintendent and the high school principal who believed that all grade 12 English classes should be doing exactly the same work and assessments at the same time. The year after I completed my data collection for this study, the principal decided not to offer the EEP courses for the following year in order to streamline the curriculum.

The Classroom and the Salon Setting. The study was conducted in two separate but connected classroom spaces - a traditional classroom and the salon setting — at the end of the rectangular humanities department wing at East High School. A hallway on the left side of the wing could access the traditional classroom and a hallway on the right side of the wing could access the salon classroom. An inside connecting door joined the two classrooms so students did not have to go out in the hall to pass between the two rooms. The traditional classroom resembled almost any other classroom in the building with rows of desks and a teacher desk at the front. The salon was a more informal space with artwork on the walls couches and chairs similar to those found in the media center. Authentic discussions took place in the salon setting. Figure 4 shows one area of the salon with a small table, easel, and three comfortable chairs. 


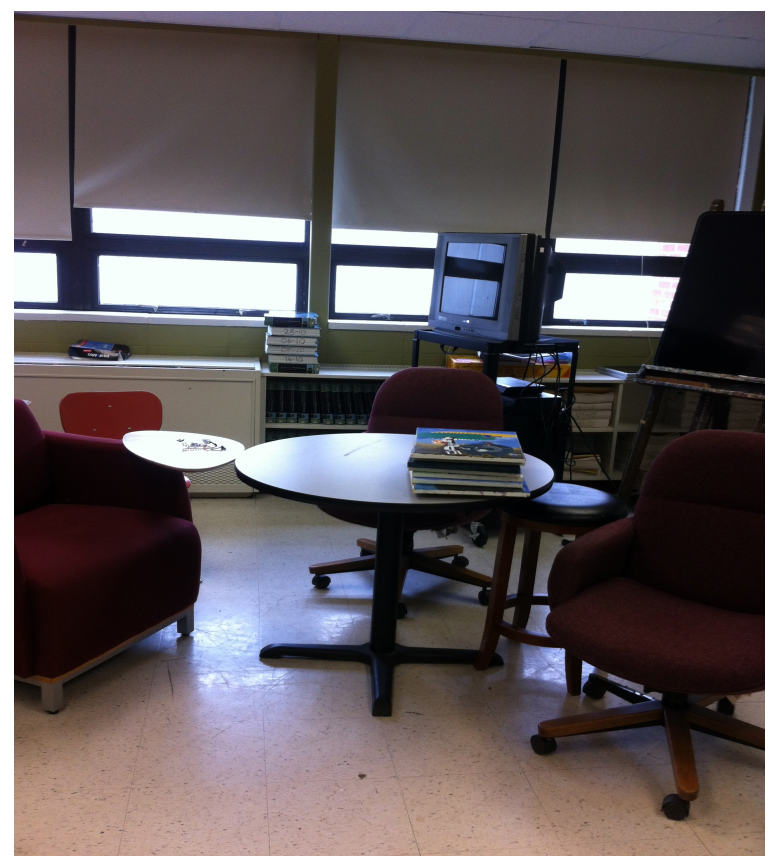

Figure 4. One area in the salon classroom

Research Sample

The study included thirty-nine participants, who were students in two senior honors-level, Early Enrollment Program (EEP) English classes at East High School. EEP is a concurrent enrollment program in which students register for college credits while taking the courses at the high school. The study participants were enrolled in English 100: Studies in Literature, taught in the fall semester, and English 113: Approaches to Drama, taught in the spring semester. Both English 100 and 113 are fourcredit courses. I informed the students of the study and the salon discussions during the first week of each semester. The study took place during the spring semester, when participants were taking English 113: Approaches to Drama. I taught both courses in affiliation with the state 
college. Instructional practices specified in the study are part of the established curriculum for the 2012-2013 academic year.

About Honors Courses at East High School. A student with a parent/guardian signature may elect an honors course whether or not a teacher has recommended it. The guidance department recommends that only students with a "B" average or better elect honors courses. A teacher does not have authority to remove a student from an honors level class. The teacher recommends that students register for the concurrent college credits, but the student is not required to do so. Students may drop an honors course during the first three weeks of the semester. Although students cannot drop the spring course, they may elect not to sign up for the college credits if they do not think they will earn a grade that will transfer to the college they decide to attend.

The average grade earned by the students in the study was a " $\mathrm{B}$ " although there was a great range of skills and abilities among the sample set especially in regard to reading comprehension and writing skills. Twenty percent of the students received free or reduced lunch, two students possessed physical learning disabilities. Teacher modifications for these two students included offering preferential seating, enlarged font texts, and retakes on failed tests, quizzes, and projects. East High School does not have a program for gifted and talented students, as such none of the students in the sample were identified in this category.

\section{Data Sources}


Over the eight weeks of the study, data was collected from several sources to inform the study's primary objective: to discover and identify critical literacy processes and higher level thinking processes students employ as they participate in authentic discussion. Data sources include:

- Pre- and Post-Questionnaires. Questionnaires were used to determine students' attitudes toward discussion and the degree of change that occurred in these attitudes. Pre- and Post-questionnaires were the same and utilized a Likert Scale from 1 (strongly disagree) to 10 (strongly agree) with a space for comments under each item to respond to the statements shown in Table 5.

Table 5

Pre- and Post-Questionnaire

1. I participate often in English language arts class.

2. I have ideas that I would like to share in English class.

3. I have the confidence that I need in order to participate in English class.

4. I believe that my teachers and my peers would like to hear my ideas in English class.

5. I'd like to participate in English class, but I don't know what to say.

6. The other students listen to me when I speak up in English class.

7. The teacher is the one who leads talk about text in English class.

8. I believe it is important for students to be able to make their own judgements about text in English class.

9. I respond to what other students say in English class.

10. I listen to other students when they speak in class. 
- Teacher-researcher reflection/ field journal. I kept a personal

journal in which I recorded my perceptions, beliefs, and analyses of the authentic class discussions.

- Student reflection journals. As part of the curriculum, students regularly write journals to reflect on their class experiences. Their journal entries were part of the data included in the study.

- Student interviews. A paid, trained research assistant conducted two half-hour interviews with each participant. The interview content was based on approximately ten open-response questions, listed in Table 6. The assistant assigned a number to each participant to ensure anonymity. Interviews were recorded and transcribed by the assistant.

Table 6

Open-ended questions for the pre- and post-interviews

Describe some discussions about texts that you have been part of or listened to in your English classes.

How do you feel about participating in English language arts class?

Describe your confidence level in terms of participating in English language arts class.

When your class is discussing a text, what types of things would you add to the discussion?

Describe the skills that a student needs in order to feel comfortable participating in English class or contributing to class discussion about text.

What behaviors do you think a person who is a good listener demonstrates? 
- Writing prompts. These writing assignments assessed how students use class discussion to help them answer questions that require higher-level thinking.

- Authentic Discussions. I took notes during discussions, which took place in the salon to determine how higher-ordering thinking skills, critical literacy, and Accountable Talk were used by the students. Some discussions were recorded to provide more time for reflection.

\section{Data Collection Methods}

At the beginning of the study, all student participants were asked to complete a questionnaire, and each student participant was individually interviewed. Interviews were audio recorded and questionnaires were collected and saved in a secure location. Throughout the study, student reflection journals were collected and reviewed at regular intervals (twice each week), and several times each week, I recorded entries in the teacherresearcher reflection journal. At the end of the study, all student participants were again asked to complete a questionnaire, and each student participant was once again individually interviewed.

\section{Data Analysis Methods}

All data was continuously evaluated as per the constant comparative nature of grounded theory. I engaged in data analysis throughout the study.

There are four steps that guide the researcher conducting grounded theory: coding, memo-writing, the development of tentative categories in 
selective coding, and the use of theoretical sampling (Charmaz, 2008). The raw data that is coded includes statements, actions, events, and documents (Charmaz, 2008). Codes represent a connection between empirical reality and the researcher's view of it (Charmaz, 2008), The researcher interacts with the data and uses action verbs in the form of gerunds to begin the initial or open codes. I recorded these codes in the margins of the students' notebooks. For example, codes regarding a students' journal entry may read "making connections to the literature" or "exploring a new idea". Initial coding explores what the study is about and looks closely at the point of view and perspective of the participants and are sometimes referred to as in vivo codes or codes that look at the participants own words (Strauss \& Corbin, 1998). Table 6 depicts open or initial coding of an except from one of my student's journal entry concerning his opinion of what classroom discussion should look like and sound like.

This method of coding allows the researcher to see the data in a fresh, new manner. Initially every line is coded until coding saturation in the form of repetition is reached. It is considered complete when the researcher believes she has arrived at the codes she wants to explore and new analytical questions to guide the research have emerged, "the combination of asking analytic questions, coding in gerunds to the extent that you can, and comparing data and codes lifts the analytic level of your emerging interpretations of data" (Charmaz, 2006, p. 8). However, 
grounded theory coding is flexible and a researcher reserves the right to return to it again and again.

Table 7

Initial Coding of a Student Journal Entry

\begin{tabular}{|c|c|}
\hline Initial Coding & Student's Journal Entry \\
\hline $\begin{array}{l}\text { Asserting Student } \\
\text { autonomy } \\
\text { Deciding Protocol } \\
\text { Speaking out against } \\
\text { interruptions } \\
\text { Protocol } \\
\text { Explaining the importance } \\
\text { of being present } \\
\text { Describing the content of } \\
\text { discussions } \\
\text { Noting important literary } \\
\text { elements } \\
\text { Defining a good discussion }\end{array}$ & $\begin{array}{l}\text { During discussion I believe it should be student-run. } \\
\text { I feel that hands should not be raised in order to } \\
\text { allow for natural conversation flow. Students should } \\
\text { be allowed to speak their minds without being } \\
\text { interrupted or made fun of. Furthermore, no } \\
\text { bathroom breaks should be allowed because it } \\
\text { interrupts the flow of conversation and then that } \\
\text { person will not be able to participate while he/she is } \\
\text { in the bathroom. During discussions we should talk } \\
\text { about particular quotes in the story, the tone of the } \\
\text { author, character descriptions, and other literary } \\
\text { elements in order to get a good literary analysis } \\
\text { discussion going. }\end{array}$ \\
\hline
\end{tabular}

Memo-writing is the intermediary phase that takes place between initial and selective coding. Memos are extended notes made in the field journal. These help the researcher make sense of emerging data and develop and refine ideas. Grounded theorists write whenever ideas occur in the research process, so sometimes other paper is substituted if the field journal (called the teacher/researcher journal in my study) is unavailable. Memos are ongoing notes that support the researcher and provide a record of thoughts and ideas. Although sometimes difficult, it is important to make memos shortly after experiences occur (Strauss \& Corbin, 1998). Table 8 illustrates a memo I wrote in my field journal early in the study when 
students like Sam whose writing was used in Table 7, were articulating their ideas of how classroom discussion should sound.

Table 8

Field Journal Excerpt

The students articulate more than I expecting regarding how much control they want over the discussion. They have little tolerance for gum chewing and leaving to go to the bathroom and this surprises me. Many have quit a bit to say about eye rolling and "making fun" of others. This, too, is something I would expect to exist at the honors level. They seem intent on conveying that their class is full of future science and math majors and they are not especially interest in the humanities. I wonder if this is supposed to be a warning? I don't remember this much focus on the possibility of being made fun of. It makes me think I need to put extra measures in place to guard against this possibility. But what will they be? This making fun must be so subtle that it is done when the teacher is looking in another direction.

The discoveries made in the intermediary memo-writing phase are used to refine the open or initial coding. Selective or more focused codes are the result. These selective codes help determine the analytical questions that the researcher poses as the study proceeds and the emerging theoretical direction that moves the study forward (Charmaz, 2006, p. 50). Selective or focused coding, "requires decisions about which initial codes make the most analytical sense to categorize your data incisively and completely" (Charmaz, p. 57). In this stage, the researcher can move freely between interviews and notes to check preconceptions and ideas about the emerging data. Charmaz notes that preconceptions can only be challenged when a researcher is immersed in data (p. 68). Focused or selective codes are not done in a line-by-line manner as initial codes. Instead they consider whole sections of data and begin to group or categorize it. The categories concern problems, issues, and concerns of the participants. These categories will be 
studied and pondered as the teacher/research begins to develop an emerging theory (Strauss \& Corbin, 1998). Table 8 illustrates focused coding based on a student journal entry in my study. This student is writing about the Privilege Walk activity that will be described in detail in Chapter 4. This was an activity I put in place after discovering early on in the student that many students were concerned about being mocked or made fun of during class discussion.

Table 9

An Example of Focused Coding

\begin{tabular}{|c|c|}
\hline Focused Coding & Student's Journal Entry \\
\hline $\begin{array}{l}\text { Ability to see other perspectives } \\
\text { Multiple perspectives }\end{array}$ & $\begin{array}{l}\text { I ended up at the front of the line. } \\
\text { Instead of feeling good as I probably } \\
\text { would/should have, I actually felt sad. I } \\
\text { looked back and saw everyone else } \\
\text { behind me and it made me sad to think } \\
\text { that most of my friends/classmates are } \\
\text { not as privileged as I am. I never } \\
\text { actually realized this, but it showed me } \\
\text { all of the privileges that I have that I } \\
\text { took for granted or did not much } \\
\text { attention to in the past. Now that I have } \\
\text { seen this, I am much more thankful for } \\
\text { everything that I have. This walk also } \\
\text { made want to help those who were not } \\
\text { as privileged as I. } \\
\text { I actually enjoyed the walk because it } \\
\text { opened my eyes even further to the } \\
\text { world around me. It also made we want } \\
\text { to help out all my friends and go to } \\
\text { stores or to their car with them to make } \\
\text { them feel more comfortable [in } \\
\text { reference to the possibilities of } \\
\text { discrimination an violence]. I thought } \\
\text { there was a big privilege separation, but } \\
\text { I have realized that gender creates a big } \\
\text { gap as well. }\end{array}$ \\
\hline
\end{tabular}


The categories that reoccur during focused coding are crucial to the developing or emerging theory and will be repeated until theoretic saturation is researched or the point in which no new or relevant data emerges (Strauss \& Corbin, 1998.)

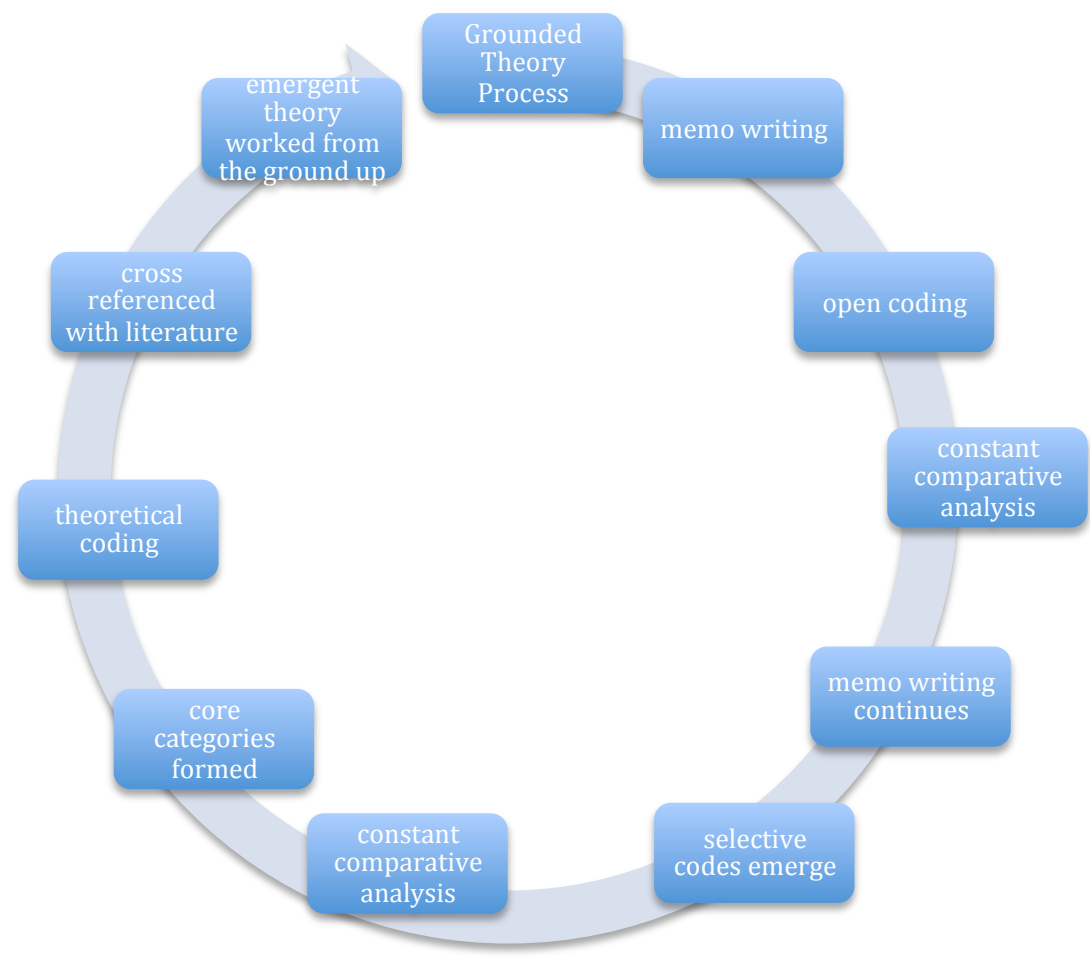

Figure 5. Graphic Representation of Grounded Theory Process (adapted from Jones \& Alony, 2011)

\section{Limitations and Delimitations}

Despite the use of triangulation as indicated in Table 1, action research is not meant to be generalizable to all other classrooms and other teaching scenarios. The nature of this grounded theory qualitative study is to document the effects of various authentic discussion methods on individual students. Patton cautions, "The critical point is that a common 
activity for all students can result in drastically different outcomes for different students" (Patton, 2002, p. 158).

Validity in qualitative research is "relative" as it is dependent on the perspective of the researcher (Maxwell, 1992, p.284). There is a natural bias when the teacher and the researcher participating in the study is the same individual. Therefore, the best way to ensure some level of validity is to thoroughly disclose the experience and pedagogies that inform my perspective. Specific threats to validity that are prevalent in this teacher research include, but are not limited to, "maturation of subjects between measurements, subject selection effects on results" and "interaction of maturation and selection effects on results" (Eisenhart \& Howe, 1992, p. 646).

I monitored internal validity by conducting member checking or "review by inquiry participants". After the study was completed and grades were given for the course, I also checked with some participants to make sure that the way I interpreted the writing in their journals was the way they intended it to be meant. Patton writes, "Researchers and evaluators can learn a great deal about accuracy, completeness, fairness, and perceived validity of their data analysis by having the people described in that analysis react to what is described and concluded" (p. 560). The use of a third party interviewer and the anonymity gained by using numerical subject identities helped to ensure that students did not feel pressured to answer in a certain way due to my dual role as teacher and researcher. 
Additionally, during the first phase of coding, I asked another member of the English department who taught senior English whether or not she agreed with my codes. We discussed how coding was done and whether or not she agreed with my codes in an effort to reduce my bias as the teacher/researcher.

The credibility of qualitative research (Patton, p. 465) lies in the degree to which it contributes to meaningful dialogue in the field and the degree to which it exposes new questions that warrant further investigation. When I interpreted the data for the dissertation, I used the themes and patterns that emerged from the data to answer the research questions stated earlier.

Limitations are elements over which the researcher has no control. Some researchers may view the limitation of this study as its lack of generalizability or usefulness to other populations. However, it is understood that results are generalizable only to educators or stakeholders who are working with similar populations in regard to community demographics and student characteristics. Since the use of grounded theory is rooted in the immediate social context, a limitation is that the theory is pertinent to current social trends as well as current educational ideas. Strauss and Corbin note that the nature of grounded theory, "allows for endless elaboration and partial negation (qualification)" (p. 279). Another may negate what one researcher sees as truth in a given context. Member checking is the tool the researcher selected to counteract this limitation. 
Delimitations are those characteristics selected by the researcher that are used to define the aspects of the study. The convenience sampling is a delimitation used to realistically address the fact that the researcher was a full time teacher at the time of the study and relied on the population available to her. As such, the study is delimited to students who registered for EEP English in the spring of 2013 and agreed (along with their parents) to participate in the study.

\section{Conclusion}

Constructivist grounded theory is an appropriate and useful methodology for examining discussion in a secondary classroom. Like teaching itself, qualitative research, "relies on those who conduct it" (Charmaz, 2006, p. 15). This methodology was crucial to the study because like a master teacher, a grounded theorist does, "not force preconceived ideas and theories directly on the data" (Charmaz, p. 17). Instead, the preconceived ideas or assumptions, as discussed in the Chapter 1, provide a place to start and a lens to examine the data. 


\section{CHAPTER 4}

\section{ANALYSIS OF DATA}

\section{Introduction}

In grounded theory I stopped and wrote in my field journal when new connections were made. These memos served as preliminary notes that recorded new ideas about codes and worked toward the forming of conceptual categories (Charmaz, 2006). Strauss and Corbin (1998) suggested creating visual images of conceptual categories to show the relationships between theses categories. More importantly, I found that talking about the relationships among the categories with colleagues and committee members assisted me as much as the creation of visual images. After the relationships among theoretical codes were established, an emergent theory (Glaser, 1992) was formed that told the story of the student participants' perspectives of the eight-week study.

As noted, it wasn't until I sat and really talked over the coded data with committee members that a theory began to emerge - a theory that really did speak to the relationships among the four categories. The theory that emerged, which will be made explicit in Chapter 5, ran contradictory to what my study originally set out to do prescribe the physical conditions that would lead to more authentic discussions in Early Enrollment senior English class. Truly listening to 
my codes or listening to what the students were trying to teach me involved the need to make myself vulnerable in terms of my so-called expertise as a teacher and recognize the need to truly understand students' fears of participation. In so doing, I needed to ask myself, what could I do to assist them? To my own embarrassment and fear, setting up a circle and calling the special room a "salon" only worked for the students who were already in a participatory mindset. It did nothing for those who had years before adopted a "fixed mindset" (versus a "growth mindset") in which they felt like their comments weren't good enough and viewed any attempt at offering an opinion as risking failure - a risk they simply had convinced themselves not to take (Dweck, 2006)

The common thread of student fear of embarrassment runs throughout my four conceptual categories. Failure to recognize this prior to analytic coding, resulted in my failure to encourage those students, self-labeled as minimal participants, to change their minds (and my mind) about the definition of what it means to participate.

Personal experiences in high school and college led me to believe that to be an active participant in class discussion, one must raise her hand several times during class and make meaningful and intelligent comments to which others would nod their heads in agreement. Any less than that would be considered failure and I myself didn't want to risk failure. I even remember teachers telling my father 
that I was so "smart" they just wished I would participate more. These experiences helped form my assumptions of what participation meant. I did not acknowledge this assumption earlier in Chapter 1 because at the time, I did not recognize it as an assumption. Assumptions are counterproductive in teaching, learning, and researching. Fear of embarrassment due to failure stops the student from trying which is turn stops true learning from taking place. Dweck (2006) considers this need for validation and avoidance of a failure to be a fixed mindset. She notes that students are not in school because they know everything, they are in school to learn and learning means risking failure and taking on challenges (p. 25). How could my students take risks when I was not doing that in my own work? I needed to listen to what the coding was really telling me and ask the difficult questions: What do I need to do as the instructor to make my classroom a nurturing place to take challenges, risk failure? How could I help students adopt a growth mindset instead of one in which they feared embarrassment of having the "wrong" answer and being viewed as a "failure"?

Before deciding on the common thread of fear of embarrassment, I narrowed the coded material into four conceptual categories: the individual, the community, protocol and knowledge as 
illustrated in Figure 6. I stopped initial coding when I reached

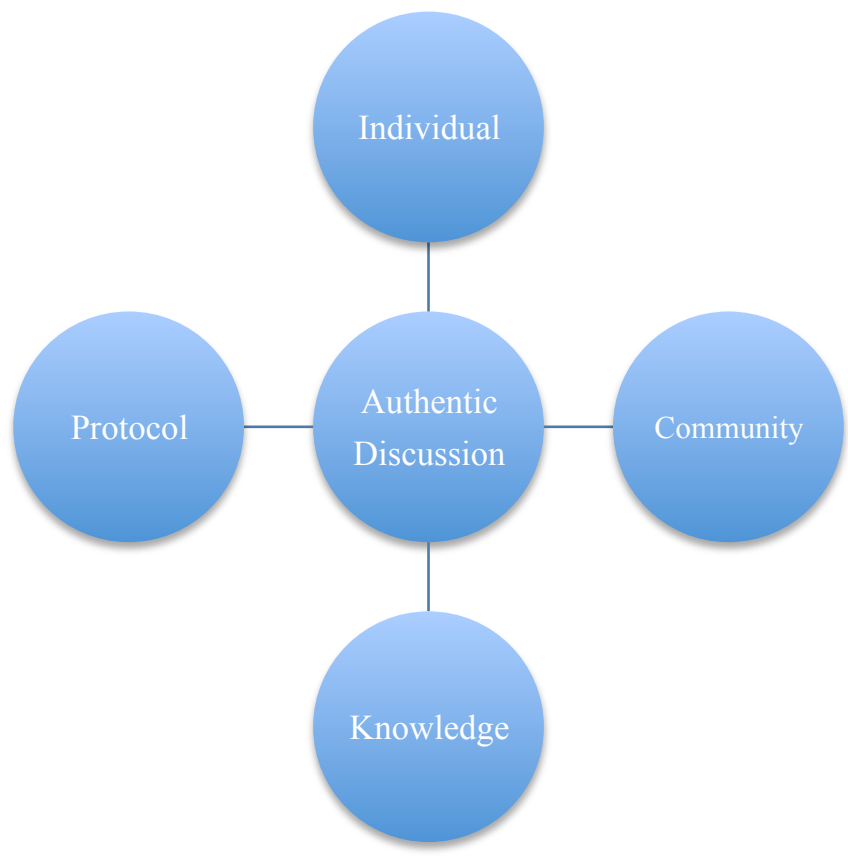

Figure 6. The Relationships between Conceptual Categories

saturation or the point when no fresh data sparked insights or revealed new aspects of my conceptual categories (Charmaz, 2006, p. 116).

Table 10 depicts the initial coded themes of my four conceptual categories. I have highlighted fear of embarrassment, intimidation, tolerance, and personal reaction because they appeared repeatedly as commonalities in both the interviews and journal entries of those of students in at all three levels of participation.

In retrospect, I realized that at the time of the study, I did not attend to what the students were trying to tell me about embarrassment and fear. In the writing of Chapter 4 and 5, I struggled with the themes, talked with committee members, and asked myself 
what exactly this meant for me, the discussion facilitator. This required setting aside more superficial elements such as the set up the room and scripted transitional phases used during discussion, in order to deal with what really mattered.

I came to the conclusion there that was no recipe for discussion success but the time and energy needed to deal with the fear of embarrassment of the individuals sitting in the classroom was at the heart of the matter. As grounded theory dictates, my dissertation was not going to be a blue print for success or recipe book for creating productive discussions, but rather the humble offer of a theoretical perspective grounded in coded data, psychology and self-reflection.

The following are the four core categories or themes that are represented in Figure 6 and in Table 10:

- THE INDIVIDUAL - students' sense of self impacts their involvement in authentic discussion

- PROTOCOL - an established code of conduct is critical to sustained authentic discussion

- THE COMMUNITY - a clearly defined idea of social order and hierarchy impacts how discussion occurs in the classroom

- KNOWLEDGE - an understanding of different literary theories enables students to utilize voice and agency 
Table 10

Core Categories that Interact in Authentic Discussion

\begin{tabular}{|c|c|c|c|}
\hline $\begin{array}{l}\text { The } \\
\text { Individual }\end{array}$ & The Protocol & Community & Knowledge \\
\hline $\begin{array}{l}\text { Fear of } \\
\text { embarrassment }\end{array}$ & Body language & Acceptance & Critical theory \\
\hline concerns & $\begin{array}{l}\text { Facial } \\
\text { expressions }\end{array}$ & Privilege & $\begin{array}{l}\text { Accountable } \\
\text { Talk }\end{array}$ \\
\hline Self-esteem & $\begin{array}{l}\text { Outside } \\
\text { distractions }\end{array}$ & Tolerance & $\begin{array}{l}\text { Critical } \\
\text { Literacy }\end{array}$ \\
\hline confidence & Note taking & Knowledge & Literary text \\
\hline knowledge & interest & $\begin{array}{l}\text { Physical set-up } \\
\text { of furniture }\end{array}$ & $\begin{array}{l}\text { Previous } \\
\text { discussion } \\
\text { experience } \\
\end{array}$ \\
\hline privilege & preparation & & $\begin{array}{l}\text { Personal } \\
\text { response to } \\
\text { text }\end{array}$ \\
\hline maturity & format & & \\
\hline goals & $\begin{array}{l}\text { Homework/ } \\
\text { study guides }\end{array}$ & & \\
\hline $\begin{array}{l}\text { Interest in } \\
\text { subject }\end{array}$ & $\begin{array}{l}\text { Intimidation/ } \\
\text { bullying }\end{array}$ & & \\
\hline
\end{tabular}

The discussion of each category begins with an example of both open coding and selective/ focused coding pertaining to that conceptual category or theme. Tables are included for each core category to illustrate how data was coded and analyzed according to grounded theory.

Conceptual Category 1: The Individual

This section examines the third study question about student perceptions toward authentic discussion. All participants were given a prequestionnaire that contained 10 statements pertaining to the role of the 
individual and his or her perceptions of self during authentic discussion.

Thirty-nine students turned in the pre-questionnaire to the research

assistant. The same questionnaire was distributed as at the end of the eight-

week study and 25 of the 39 students returned it to my office mailbox.

Students answered on a Likert Scale where "1" was "strongly disagree" and

"10" was "strongly agree". Table 11 displays the results of the pre-

questionnaire (a copy of which is located in Appendix G).

Table 11

Pre-Questionnaire Responses

\begin{tabular}{|l|l|l|l|l|l|l|l|l|l|l|}
\cline { 2 - 10 } & \multicolumn{10}{c|}{ STATEMENT \# } \\
\cline { 2 - 10 } N=39 & 1 & 2 & 3 & 4 & 5 & 6 & 7 & 8 & 9 & 10 \\
\hline $\begin{array}{l}\text { 1. I participate } \\
\text { often in English } \\
\text { class. }\end{array}$ & 1 & 0 & 3 & 2 & 6 & 4 & 10 & 6 & 3 & 4 \\
\hline $\begin{array}{l}\text { 2. I have ideas } \\
\text { that I like to } \\
\text { share in English } \\
\text { class. }\end{array}$ & 1 & 1 & 1 & 2 & 5 & 7 & 8 & 7 & 3 & 4 \\
\hline $\begin{array}{l}\text { 3. I have the } \\
\text { confidence that I } \\
\text { need in order to } \\
\text { participate. }\end{array}$ & 0 & 2 & 1 & 5 & 5 & 4 & 6 & 7 & 4 & 5 \\
\hline $\begin{array}{l}\text { 4. I believe that } \\
\text { my teachers and } \\
\text { peers would like } \\
\text { to hear my ideas. }\end{array}$ & 1 & 0 & 2 & 3 & 4 & 7 & 13 & 6 & 2 & 1 \\
\hline $\begin{array}{l}5 . \text { I'd like to } \\
\text { participate, but I } \\
\text { don't know what } \\
\text { to say. }\end{array}$ & 2 & 3 & 7 & 7 & 5 & 4 & 2 & 5 & 3 & 1 \\
\hline $\begin{array}{l}6 . \text { The other } \\
\text { students listen to } \\
\text { me when I speak. }\end{array}$ & 0 & 0 & 0 & 3 & 6 & 6 & 4 & 9 & 5 & 6 \\
\hline
\end{tabular}




\begin{tabular}{|l|l|l|l|l|l|l|l|l|l|l|}
\hline $\begin{array}{l}\text { 7. The teacher is } \\
\text { the one who } \\
\text { leads talk about } \\
\text { text. }\end{array}$ & 0 & 0 & 1 & 3 & 7 & 3 & 8 & 7 & 5 & 5 \\
\hline $\begin{array}{l}8 . \text { I believe it is } \\
\text { important for } \\
\text { students to be } \\
\text { able to make } \\
\text { their own } \\
\text { judgments about } \\
\text { text. }\end{array}$ & 0 & 0 & 0 & 0 & 1 & 1 & 2 & 5 & 14 & 16 \\
\hline $\begin{array}{l}\text { 9. I respond to } \\
\text { what other } \\
\text { students say. }\end{array}$ & 0 & 0 & 3 & 2 & 4 & 3 & 5 & 14 & 6 & 2 \\
\hline $\begin{array}{l}\text { 10. I listen to } \\
\text { other students } \\
\text { when they speak } \\
\text { in class. }\end{array}$ & 0 & 0 & 0 & 0 & 0 & 0 & 0 & 8 & 6 & 25 \\
\hline Mode & 3 & 7 & 8 & 7 & 4 & 8 & 7 & 10 & 8 & 10 \\
\hline
\end{tabular}

The research assistant used participants' answers to these statements as a starting point for the interview questions and asked students she met with to further elaborate on their answers. She taped and transcribed the interviews. Then I coded transcripts of the interviews using open coding. Per grounded theory protocol, I then narrowed the open codes to focus or selective codes and looked for emerging themes. This process was repeated over and over and codes were constantly compared. Analysis of repeated themes in the data collected from my students led to the development of a theory from the ground up.

Table 12 shows a sample of how initial or open codes led to the first core category or theme of the individual.

Table 12

Coding Procedure Leading to First Core Category: The Individual 


\begin{tabular}{|c|c|c|c|}
\hline Initial codes & $\begin{array}{l}\text { Questionnaire answer } \\
\text { to statement } \# 1 \text {--I } \\
\text { participate often in } \\
\text { English class (where } 0 \\
\text { is never and } 10 \text { is very } \\
\text { often) and then } \\
\text { elaboration on the } \\
\text { answer during the } \\
\text { taped interview }\end{array}$ & Memo Writing & $\begin{array}{l}\text { Focused or } \\
\text { Selective } \\
\text { Code }\end{array}$ \\
\hline $\begin{array}{l}\text { Struggling with } \\
\text { confidence } \\
\text { Struggling with } \\
\text { uncertainty } \\
\text { Embarrassing } \\
\text { to say anything } \\
\text { wrong }\end{array}$ & $\begin{array}{l}\text { Megan: 6. "Usually not } \\
\text { comfortable, confident } \\
\text { with my answers, others } \\
\text { are quick to answer } \\
\text { before I can think. As I } \\
\text { mentioned before, I } \\
\text { normally and am unsure } \\
\text { of my responses and do } \\
\text { not want to say } \\
\text { something that is } \\
\text { incorrect. English is one } \\
\text { of my harder subjects." }\end{array}$ & $\begin{array}{l}\text { Seniors, } \\
\text { although they } \\
\text { may project } \\
\text { confidence, are } \\
\text { actually fearful } \\
\text { of being } \\
\text { embarrassed if } \\
\text { they answer } \\
\text { something } \\
\text { "wrong". }\end{array}$ & Confidence \\
\hline $\begin{array}{l}\text { Extending } \\
\text { effort depends } \\
\text { on liking and } \\
\text { understanding } \\
\text { of the material } \\
\text { Viewing } \\
\text { himself as a } \\
\text { science major } \\
\text { - literal thinker } \\
\\
\text { Getting } \\
\text { through is a } \\
\text { labor --not } \\
\text { meant to enjoy }\end{array}$ & $\begin{array}{l}\text { Sean: 7. 'Depends on the } \\
\text { literature. If it's } \\
\text { something I enjoy and } \\
\text { understand I'll } \\
\text { participate more. } \\
\text { Honestly, I'm going to } \\
\text { be an engineering major } \\
\text { and English is my least } \\
\text { favorite subject. I think } \\
\text { too literally to be able to } \\
\text { enjoy literature and I just } \\
\text { have to force myself } \\
\text { through it. I'm with } \\
\text { language and comp } \\
\text { because I can just treat } \\
\text { them like science, but } \\
\text { literature is just not my } \\
\text { thing." }\end{array}$ & $\begin{array}{l}\text { Although EEP } \\
\text { English is } \\
\text { offered as an } \\
\text { elective, many } \\
\text { seniors are } \\
\text { taking it } \\
\text { because it is the } \\
\text { only senior } \\
\text { honors English } \\
\text { class available } \\
\text { aside from } \\
\text { Advanced } \\
\text { Placement } \\
\text { Literature } \\
\text { where a test is } \\
\text { required. This } \\
\text { year's } \\
\text { graduating } \\
\text { class is heavily } \\
\text { into math and } \\
\text { science and not } \\
\text { so much into } \\
\text { the humanities. }\end{array}$ & Interest \\
\hline $\begin{array}{l}\text { Feeling } \\
\text { introverted }\end{array}$ & $\begin{array}{l}\text { Chelsea: 7. "I get } \\
\text { nervous and shy. My }\end{array}$ & $\begin{array}{l}\text { It is less risky } \\
\text { to take a back }\end{array}$ & \\
\hline
\end{tabular}




\begin{tabular}{|c|c|c|c|}
\hline $\begin{array}{l}\text { Fearing a } \\
\text { mistake, } \\
\text { /getting } \\
\text { embarrassed }\end{array}$ & $\begin{array}{l}\text { experience in literature } \\
\text { discussions are that I } \\
\text { normally do not involve } \\
\text { myself and instead I } \\
\text { listen. If I put any input } \\
\text { in I normally have to be } \\
110 \% \text { sure of myself } \\
\text { before I say anything." }\end{array}$ & $\begin{array}{l}\text { seat and learn } \\
\text { by listening. I } \\
\text { can tell by the } \\
\text { look on her } \\
\text { face she has a } \\
\text { lot more to say } \\
\text { than she is } \\
\text { offering. }\end{array}$ & Confidence \\
\hline $\begin{array}{l}\text { Enjoying the } \\
\text { idea of } \\
\text { expressing } \\
\text { thoughts and } \\
\text { opinions }\end{array}$ & $\begin{array}{l}\text { Kara: 10. "Some of the } \\
\text { best moments of learning } \\
\text { are when you're } \\
\text { interacting with other } \\
\text { people, so I kinda } \\
\text { stepped out of my } \\
\text { comfort zone and sort of } \\
\text { built up the confidence } \\
\text { with talking to making } \\
\text { and making my thoughts } \\
\text { known while, like, still } \\
\text { learning from others, } \\
\text { too." }\end{array}$ & $\begin{array}{l}\text { There is an air } \\
\text { of maturity } \\
\text { about Rebecca. } \\
\text { She is } \\
\text { demonstrating } \\
\text { the social } \\
\text { constructivist } \\
\text { approach to } \\
\text { learning. She } \\
\text { talks freely } \\
\text { about her } \\
\text { feelings and } \\
\text { opinions. }\end{array}$ & Conforming \\
\hline
\end{tabular}

I examined the sample of students closely and continuously compared their attitudes and perceptions to the degree to which they participated in class. Thirty-nine students agreed to participate in the study, 21 females and 18 males. All of these students completed a questionnaire and participated in authentic discussions in English class. In my field journal, I documented some of the events that transpired during these discussions. I coded journals that were kept by all of the participants. The research assistant interviewed nine students. This sample size of 9 (23\% of participants) represents a purposive sample (Patton, 1990) that incorporated all three levels of participants (minimal, average, and above average participants). 
The pre- and post-questionnaires assessed students' perceptions of speaking and listening through a Likert Rating wherein 0-3 represents minimal participation, 4-7 represents average participation, and 8-10 represents above average participation. The total number of participants who completed the pre-questionnaire was 39 . Of the $39,10 \%$ described themselves as minimal participants, 22 students or $56 \%$ described themselves as average participants, and 13 students or $33 \%$ described themselves as above average participants. They self-identified their level of participation in question \#1 of the pre-questionnaire which asked "I participate often in English language arts class.” All names of the participants have been changed to pseudonyms in this study. Minimal Participation: Christopher, Jess, Tom, Ed, Average Participation: Austin, Sandy, Abby, Harry, Tony,

Erin, Alan, Darryl, Chelsea, Robin, Liam, Barry, Erik, Jason, Robert, Lynn, Sean, Ann, Megan, Larry, Tina, Shannon

Above Average Participation: Carrie, Andria, Beth, Ethan, Leah, James, Aaron, Sara, Missy, Sam, Susan, Kara,

Danielle

Minimal Participants. Four students, or $10 \%$ of the sample size of 39, self-identified as minimal-level participants. Christopher (rated himself 
a 1), and Ed, Jess and Tom (rated themselves a 3) all characterize themselves as shy and quiet. Jess said she loved English and literature so I was wondering what kept her so quiet. She said that she was more apt to participate in a class, "where [she] feel[s] comfortable and am surrounded by my friends." This course, an advanced level elective, concurrent enrollment course, did not necessarily guarantee that a student would be surrounded by his/ her friends.

Based on Jess's comments and the idea of salon as a social gathering and not a structured classroom, I allowed students select their own seats. She had two students she considered friends in the class and she selected a seat next to Christopher, another minimal participant. In his interview, Christopher said he dreaded discussion to the point where he would write papers prior to class discussions in his junior year English class and then submit the papers to his teacher to earn participation credit, rather than participating during class discussion. This made me question my assumptions of the meaning of participation. I had assumed previously that the number of verbal comments would constitute participation. What if, however, submission of a journal and depth of reflection could constitute participation?

Christopher attributed his lack of participation to his introversion and lack of confidence. He was afraid to participate and during the study, I failed to allay his fears regarding embarrassment and lack of confidence. 
He said that he felt his confidence would improve as his maturity (age) did. I now question his assumption given his fixed mindset and fair of failure.

Similarly, Ed did not like to participate in class. He rated himself a " 3 " on the Likert rating regarding how often he participates in English class. He characterized himself as more of a listener than a talker. He appears to suffer from a lack of confidence as he remarked during his interview, 'I just feel like other people's ideas are better than mine and that when they say their stuff it's more correct than what I thinking and I just feel like my ideas are not as processed as theirs." That comment prompted me to think that, in addition to social comfort, it would be necessary to increase the students' level of confidence in their ideas in order to guarantee participation in authentic discussion. Comments such as these further caused me to question my assumptions again regarding the definition of participation. Could listening constitute participation? If so, could listening be assessed in a non-verbal method at the end of discussion? This would ease Ed's fears but still allow him to demonstrate his "participation". For someone who prided myself on my ability to think "outside of the box," I really hadn't done so until the conclusion of the study.

Ed also said, "In order for them [students] to be really confident to express their opinion they need to think that it's [their opinion] right but some people might feel that theirs is right but not be sure and want to express it just to see what other people say about it." Again, this comment 
speaks to the need to teach students that failure is a form of learning. How was I to help them understand that they needed to view other people's judgmental behavior as a challenge and not a detriment to learning? My initial idea of addressing confidence was to increase their knowledge of literary theory and arm the students with that toolkit of theories that would enable them to have confidence in their opinions and increase their agency and voice. However, this idea of increasing literary theory knowledge and providing a toolkit did nothing to increase Christopher's or Ed's level of verbal participation. Their ratings of themselves as participants did not change after the eight weeks of the study. That indicated that none of my strategies were effective for the minimal participants. Suggestions for further study in Chapter 5 will address this failure in more detail.

Average level participants. Twenty-two students (56\%) rated themselves as average-level participants. Two of the "average-level" participants, Tina and Larry, rated themselves a 5 and a 6 respectively in terms of their level of participation. Both said they liked literature classes. Also, both admitted that a smaller class size and furniture set up in a circular fashion encouraged them to contribute to discussion. Even though Larry stated he liked debates and talking in class, he also cited the presence of certain individuals as a threat to his inclination to participate:

I like to get my ideas heard, but it depends on who's there, like if there's certain people that are absent, I don't mind talking freely because I know I'm not going 
to get the sarcasm and not going to get the looks from them, not going to get any of that so I can actually say my mind and not be judged.

Again, I saw the theme of social acceptance and fear of embarrassment as contributing to the students' inclination to participate.

To mitigate the problem of social acceptance as a deterrent to discussion, I decided to engage the students in a "Privilege Walk" in an attempt to break down socially established lines and discourage the sarcasm and intolerance that must be present, albeit unknown, to me. (The Privilege Walk is described in detail in the "Community" section of this chapter.) Tina's comments about bullying and intimidation also factored into my decision to use the Privilege Walk in the second week of the study. This activity was the one that had the most impact on eliminating students' fear of embarrassment during the entire study. While it didn't change my assumptions of participation, student journal entries showed that it encouraged students to be more tolerant of one another.

Tina was new to the school in her junior year. When asked why she thought some students did not participate in class, she said, "There's always those people that bully other kids for stupid reasons and sometimes that can be the reason why some people don't participate, they're afraid they're going to say the wrong thing and get made fun of for it." She also said that some people don't participate because they don't take the discussion 
seriously. She remarked that students in this school seemed to care more about discussions than did the students in her former, more urban school. She said that her former school was very poor and students from East High should realize how lucky they are to have books and paper. In terms of her own participation, she indicated that she was more likely to participate if she liked the teacher. Dweck (2006) states that blaming the teacher for one's lack of participation is a demonstration of the fixed mindset and symptomatic of a fear of failure.

Tina suggested in her interview that after class, a teacher should talk to students who aren't participating much and ask them if anything could be done to make them more comfortable. During the study, I never did pull students aside and talk with them personally about their feelings of comfort and fear. Had I truly listened to what she was telling me in the spirit of grounded theory, I would have taken the time to have these post-class discussions Tina suggested.

Above Average Participants. Thirteen students (33\%) selfidentified as above-average participants. When asked about her inclination to participate, Kara, a high-level participant, said that she liked to share her thoughts and opinions. However, she did say that some of her best book discussions did not occur in the classroom, but outside of it when she gathered with friends to discuss a book for an assignment because, "It is on our own terms and we don't have to think about it too critically at one time." This comment prompted me to think about what students" "own 
terms" were. Most likely they involved emotional comfort with minimal academic risk and social pressure.

Kara, class valedictorian, had very involved parents in the school community, said she used to be insecure and self conscious in middle school but that she realized she should try talking more, and that getting involved and stepping outside of her comfort zone helped build her confidence. Clearly, she viewed learning as a challenge and had a growth mindset (Dweck, 2012). She describes her first real experience with a literary discussion as having taken place during her sophomore year:

I think my first real exposure to, like, having a group circle was in my sophomore year. We were talking about The Scarlet Letter and I thought that was really great because you could look around the circle and you could, like build off of what other people said.

Danielle, too, liked to share her thoughts and ideas. She rated her level of participation in English class an 8. She said that the best discussions arise when students are given material ahead of time and asked to prepare thoughts on the topics. She said she was comfortable with the people in the class because she had been with the students for a long time. She indicated that her comfort level and ability to participate would be much different in a different environment. When asked why she thought some students did not participate, she said it was probably because they did not understand the book, lacked confidence, or were prone to "zone out." 
She said she thought more people were inclined to participate in the salon room versus the room with the desks in rows, and noted that the teacher as a fellow participant in the circle seemed to make a positive difference in the discussion as well.

Summary of selective/focused coding for Conceptual Category 1: The Individual.

The individual's perceptions of his or her own self-confidence directly impact his or her ability to participate during authentic discussion. The confidence level of individuals reached saturation as a theme during the open coding of student interviews and students' journals.

Other open codes that were merged into the core category of the individual are interest in the subject area and the material being studied, and comfort level with the other members of the class and the teacher. Intimidation and bullying were cited as impediments to discussion more than I expected. The physical set up of the classroom was not mentioned as much as I thought it might. The themes of comfort, confidence, fear of embarrassment and intimidation that emerged during constant comparative analysis of data led to a focus on discussion protocol that might promote the student agency.

\section{Conceptual Category 2: Protocol}

A comparison and analysis of data on students' initial perceptions of their inclination to participate yielded the next step in the grounded theory. This section and the section entitled "Community" address the second study 
question that asks how participation in authentic discussion affects student agency and ownership of the lesson. The activities discussed in these sections (designed by me after initial coding of students' answers on the pre-questionnaire) enable student agency to be examined more than would ordinarily be possible in a situation when the teacher was not also the researcher. There had to be a way to enable all individuals to feel confortable and increase tolerance of all participants, build the confidence of students who were lacking, and find ways to facilitate uptake (or the follow up of ideas and opinions). Table 13 reveals the coding process in terms of what students value in a listener. Their values are a direct link to the issues of tolerance and acceptance that emerged in the focus coding.

Table 13

Coding and Memo Writing: Protocol Concerning Attentive Listening

\begin{tabular}{|c|c|c|c|}
\hline Initial codes & $\begin{array}{l}\text { Interview question: } \\
\text { What behaviors do you } \\
\text { think a person who is a } \\
\text { good listener } \\
\text { demonstrates? }\end{array}$ & $\begin{array}{l}\text { Memo } \\
\text { Writing }\end{array}$ & $\begin{array}{l}\text { Focused or } \\
\text { Selective } \\
\text { Code }\end{array}$ \\
\hline $\begin{array}{l}\text { Judging } \\
\text { whether people } \\
\text { listen by facial } \\
\text { expressions } \\
\text { Feeling bullied } \\
\text { by the way } \\
\text { people react } \\
\text { during } \\
\text { discussion }\end{array}$ & $\begin{array}{l}\text { Larry: "They [other } \\
\text { students] look interested } \\
\text { in what somebody else is } \\
\text { saying. You don't sit } \\
\text { there and make and make } \\
\text { mean faces at them. } \\
\text { That's what I get a lot." }\end{array}$ & $\begin{array}{l}\text { The fact that } \\
\text { this type of } \\
\text { covert bullying } \\
\text { takes place } \\
\text { right in front of } \\
\text { me is startling. } \\
\text { I never } \\
\text { suspected it } \\
\text { and I am } \\
\text { unhappy that } \\
\text { some students } \\
\text { feel as Larry } \\
\text { does. This } \\
\text { means I am not } \\
\text { doing enough } \\
\text { as the }\end{array}$ & $\begin{array}{l}\text { Attentive } \\
\text { listening } \\
\text { Supportive } \\
\text { facial } \\
\text { expressions }\end{array}$ \\
\hline
\end{tabular}




\begin{tabular}{|c|c|c|c|}
\hline & & $\begin{array}{l}\text { instructor to } \\
\text { make them feel } \\
\text { safe and } \\
\text { comfortable in } \\
\text { the learning } \\
\text { environment. }\end{array}$ & \\
\hline $\begin{array}{l}\text { Looking up } \\
\text { Attending to } \\
\text { body language } \\
\text { Making eye } \\
\text { contact } \\
\text { Nodding } \\
\text { Taking notes }\end{array}$ & $\begin{array}{l}\text { Kara: "If you are doing } \\
\text { one of these [she looks } \\
\text { toward her lap] and } \\
\text { looking down, they're } \\
\text { texting, they're not } \\
\text { looking at you. I feel eye } \\
\text { contact to an extent is } \\
\text { important...I feel like } \\
\text { body language of looking } \\
\text { a someone and facing } \\
\text { that direction and maybe } \\
\text { nodding your head or } \\
\text { scribbling down } \\
\text { something you might } \\
\text { have thought of while } \\
\text { they were saying...that } \\
\text { kind of shows I'm } \\
\text { listening to you and I am } \\
\text { thinking about what } \\
\text { you're saying." }\end{array}$ & $\begin{array}{l}\text { The idea of } \\
\text { having to tell } \\
\text { seniors in high } \\
\text { school } \\
\text { repeatedly to } \\
\text { put their } \\
\text { phones away in } \\
\text { a discussion is } \\
\text { daunting and } \\
\text { unexpected. As } \\
\text { is the basic fact } \\
\text { that body } \\
\text { language, } \\
\text { nodding and } \\
\text { taking notes } \\
\text { are perceived } \\
\text { as interested } \\
\text { and important } \\
\text { to the one } \\
\text { doing the } \\
\text { speaking. }\end{array}$ & 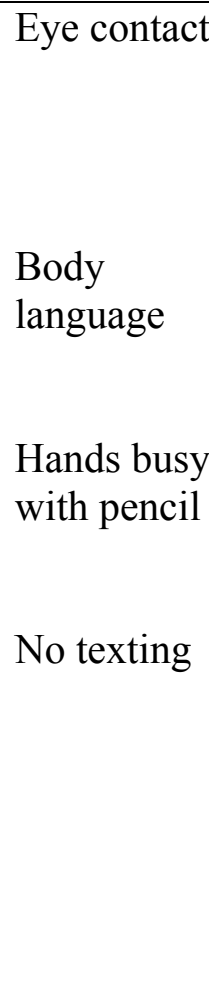 \\
\hline $\begin{array}{l}\text { Understanding } \\
\text { the point of } \\
\text { view of others } \\
\text { Ability to } \\
\text { understand why } \\
\text { others think } \\
\text { and feel and } \\
\text { they do }\end{array}$ & $\begin{array}{l}\text { Ed: "They [the listener] } \\
\text { look at the other side like } \\
\text { the other point of view } \\
\text { and see where they, the } \\
\text { other person, is coming } \\
\text { from and why they would } \\
\text { that and understand that } \\
\text { people have different } \\
\text { opinions about stuff and } \\
\text { can support their } \\
\text { opinions in different } \\
\text { ways." }\end{array}$ & $\begin{array}{l}\text { Instead of } \\
\text { focusing solely } \\
\text { on the physical } \\
\text { appearance of } \\
\text { looking, Mike } \\
\text { thought about } \\
\text { the ability to } \\
\text { entertain } \\
\text { another point } \\
\text { of view and } \\
\text { understand } \\
\text { where it is } \\
\text { coming from. }\end{array}$ & $\begin{array}{l}\text { Open- } \\
\text { mindedness } \\
\text { Tolerance }\end{array}$ \\
\hline
\end{tabular}

From interview question 6, I realized that students were concerned about both the physical and mental aspects of being a listener. They attended more to the facial expressions and body language of others than I 
anticipated. Several students also mentioned their appreciation for teachers in the past that had reinforced the concept that different opinions were not bad opinions and that everyone should exercise his or her voice, what I refer to as student agency in this study.

The students who rarely participated, Christopher, Jess, and Ed, said they wrote more than they would ever share out loud. However, they were concerned with the appearance of respectful learning. After initial coding, I further explored the interview question 6 when I asked students to write in their journal about the ground rules that they would like to see implemented during discussions. Christopher wrote in capital letters, "AVOID INTERRUPTING OTHERS." He also expressed that the opinions of others should be encountered with politeness and respect. It was not surprising that was so concerned. He was a non-conformist in a school that sometimes had little tolerance for non-conformity. He was openly gay and painted his nails black. Jess was the only student in the class with whom I had ever seen him conversing. He was struggling to be accepted. Jess struggled with poverty and some of the difficulties associated with a single-parent upbringing. She described her single mother as being uninvolved in her education.

Given the differing comfort and confidence levels, I asked the students to write about and discuss ground rules that could be established so discussions ran smoothly and everyone could feel as comfortable as possible. Jess wrote about using a class technique called "work shopping" 
in a state university's introduction to essay writing course taught on the high school campus by a high school teacher. She said in that class, "we have discussions where we all talk, no hand raising, and when someone talks we don't talk but wait until the person is done talking" (Michaels, O'Connor, \& Resnik, 2008). She liked this approach and emphasized that there should never be any side conversations or people talking over anyone else. Lastly, of the rare participants, Ed agreed with respecting others' opinions and waiting for participants to finish before disagreeing with them but added the importance of not eating or chewing gum and the importance of staying on topic.

Of the students who called themselves average-level participants, Sandy said that participation should not be mandatory. This view was tricky because, as a teacher/researcher trying to prepare students for college, I knew that participation in literature seminars was a highly valued behavior. At the time, I viewed part of my role as to prepare the seniors for college.

Sandy also stressed the importance of not arguing or interrupting others - an emerging concern and a significant theme that would dictate the nature of my direction and facilitation as the study progressed. I was curious to discover what the frequent participators suggested for participation protocol. Frequent participants echoed the concerns of their peers and emphasized the importance of being respectful and refraining from interrupting speakers. 
Danielle, an above average participant, was concerned that points made be relevant to the topic under consideration. James, another above average participant, noted that books should be at the ready to help make points so it didn't slow down the pace of the discussion and Kara stressed uptake - the building on others' points and the importance of not rambling if one has a point to make. She also wrote that students should, "take notes on what [they were] interested in [and] what [they] wanted to go back to so [they] don't forget." So, those students comfortable with their own voices and agency during class discussion were concerned with critical analysis such as citing text and making use of uptake.

Once we established the ground rules, I put all the students' suggestions on the board. Table 14 represents the list of what the students brainstormed as our ground rules. I would eventually transfer them to chart paper so they could remain visible on the wall next to the white board at all times. When analyzing data and discussing these ground rules with a committee member I realized, in accordance with constructivist tradition, they should have been rephrased by me in the positive to eliminate the "no's" and define what attentive listening and participation is versus what it is not. For instance "don't dominate the time" could have been "be aware of how much time you are speaking”.

Table 14

Student Generated Protocol List for Discussion

No interrupting 


\begin{tabular}{|l|}
\hline No gum chewing \\
No eating \\
No texting \\
No asking to go to the bathroom (in \\
emergency get up and go quietly) \\
Take notes \\
Have book ready to look up passages \\
No rambling_-stay on topic \\
Make eye contact with speaker \\
Be prepared-do your \\
homework/reading \\
Respect others ideas \\
When possible, comment on others \\
ideas \\
Don't dominate the time \\
No side conversations \\
\end{tabular}

After establishing ground rules, we embarked on our first wholeclass discussion that would utilize the ideas we set forth as a group. The topic was Oedipus Rex by Sophocles. Students reflected both in discussion and in their journals about the success of our protocol during the discussion. Although, it was generally agreed that we, as a group, followed the protocol, we had some difficulty. Kara said that we lacked a flow between points and I agreed with her. Implementing a guide or an agenda ahead of time would help to structure the discussion. Austin pointed out that even though we had topics for discussion on the board (put there immediately prior to discussion), we weren't very organized and suggested ranking those topics in order of importance to supply organization or direction to the conversation. Not enough people participated in my opinion and James echoed this by writing, "I felt like I was only hearing the opinions of a few people." 
I realized after this initial salon discussion that my role as facilitator would require more effort to structure and focus the discussion. In my field journal, I wrote about the difficulty of doing this on the spot the day a reading or assignment was due. I noted that we would either have to use the question/study guides I handed out for homework to frame the discussions or provide the students with a list of topics to be considered and written about prior to the discussion. If students did a cursory job of either the reading or the homework (which Kara pointed out in her interview is often the case), they would be less able to participate in discussion. This was a frequent complaint of fellow department members. The only sure way to guarantee that all did the reading was to do it together, and in a collegelevel course, I did not have the time to read entire works out loud in class nor should that be an expectation in a college-level course.

In addition to the need for tighter structure, student journal entries reflecting on the Oedipus Rex discussion revealed other insights into how it went and how it could be improved. James felt that we didn't violate our protocol but that each person should have a question ready before each salon discussion. Kara suggested that the class break into small groups to get ideas flowing prior to large group discussion. Erik, who did not participate that day, echoed these ideas, "I think to make things easier perhaps having a first round where everyone gets one thing to say would definitely help with the problem of getting everyone involved." Through their comments, James, Kara, and Erik were teaching me how to make class 
more comfortable for them. Teachers learn from their students. I did listen to what they were saying and twice during the eight weeks had students prepare questions to ask prior to salon and break up into small groups for sharing before large group discussion. This had a positive impact on the frequency of student participation. When I implemented these strategies, I tallied at least 10 different speakers that represented an increase over the average of 7 different speakers in previous discussions. I must be prepared to listen to and learn from the student voices in order to improve their comfort levels and reduce their fears.

Summary of selective/focused coding in Conceptual Category 2: Protocol Students' ideas of protocol focused on the physical and mental acts of engaged listening. They overwhelmingly agreed that body language and facial expressions should convey active and concerned listening. Many mentioned that eye rolling and dirty looks were outward expressions of disapproval and discouraged participation in authentic discussion. Texting and gum chewing and leaving to go to the bathroom also conveyed disinterest in the students' opinions. They stressed the preparation of doing homework and coming to class prepared for discussion. In general, they worried more about what their peers thought of their contributions than I thought they would. This fear permeated their feelings about their own individual participation as it also permeated their desire to ensure that respectful protocol was followed. The students' concerns made me realize just how self-conscious they were at seventeen and eighteen and how 
weighty the work of diminishing their fears was going to be. I will address this "work" more in Chapter 5 when I address areas for further study.

Conceputal Category 3: Community

\section{Establishing Social Norms and Breaking Down Barriers of}

Intolerance. As discussed in the previous section entitled "Protocol", the first step in my promotion of authentic discussion was to establish ground rules, and then to attempt to eliminate the sarcasm that Larry spoke of and increase tolerance and appreciation for one another. Table 15 depicts the coding process that led to the activities that were designed to help build community and to enhance the effectiveness of authentic discussion. To help accomplish this community/tolerance goal, I decided to take the students on a Privilege Walk. I was introduced to this activity in a doctoral course, Teaching Social Justice (EDP 665), and after having participated in a Privilege Walk, I viewed it as a memorable activity that would represent a crucial step toward building students' abilities and desires to learn from one another, listen to one another, and feel confident enough to express their opinions in front of a diverse social group. As noted previously, it was the most effective activity in the study in terms of increasing comfort and eliminating fear.

Although East High was mostly white, students came from a variety of social and economic demographic groups and this had a tendency to create divides between classes. 
Table 15

Coded Student Responses: Community

\begin{tabular}{|c|c|c|c|}
\hline Initial codes & $\begin{array}{l}\text { Journal: What grade } \\
\text { would you give yourself } \\
\text { for the discussion? }\end{array}$ & $\begin{array}{l}\text { Memo } \\
\text { Writing }\end{array}$ & $\begin{array}{l}\text { Focused or } \\
\text { Selective } \\
\text { Code }\end{array}$ \\
\hline $\begin{array}{l}\text { Hesitating to } \\
\text { address bigotry } \\
\text { in a } \\
\text { community } \\
\text { that might still } \\
\text { exhibit some } \\
\text { of it } \\
\text { Realizing a } \\
\text { history of } \\
\text { bigotry in his } \\
\text { own town }\end{array}$ & $\begin{array}{l}\text { Jason: I wouldn't give me } \\
\text { a very good grade. I } \\
\text { listened but I didn't } \\
\text { contribute. I had stuff I } \\
\text { wanted to say like our } \\
\text { stereotyping of African } \\
\text { Americans up here, } \\
\text { because when we went } \\
\text { over the KKK in history } \\
\text { with Mr. S one of the } \\
\text { biggest meetings was } \\
\text { actually here. So this } \\
\text { perception has been going } \\
\text { on far longer than we } \\
\text { have been around. }\end{array}$ & $\begin{array}{l}\text { In my time at } \\
\text { East High I } \\
\text { have heard } \\
\text { many racial } \\
\text { and anti- } \\
\text { Semitic } \\
\text { remarks. I felt } \\
\text { it was a } \\
\text { constant } \\
\text { struggle to } \\
\text { address the } \\
\text { way students } \\
\text { might have } \\
\text { been brought } \\
\text { up in a non- } \\
\text { diverse } \\
\text { community }\end{array}$ & $\begin{array}{l}\text { Tolerance } \\
\text { Acceptance } \\
\text { Open- } \\
\text { mindedness }\end{array}$ \\
\hline $\begin{array}{l}\text { Hesitating to } \\
\text { bring up a } \\
\text { personal } \\
\text { connection to } \\
\text { the literature } \\
\text { Writing what } \\
\text { he was unable } \\
\text { to say during } \\
\text { the discussion }\end{array}$ & $\begin{array}{l}\text { Austin: I would give } \\
\text { myself a } 90 \text { [grade for } \\
\text { Laramie Project } \\
\text { discussion] because I } \\
\text { prepared and participated } \\
\text { adequately, however I } \\
\text { didn't make a point that I } \\
\text { probably should have. My } \\
\text { brother is a bisexual and } \\
\text { has recently come out } \\
\text { within the last year }\end{array}$ & $\begin{array}{l}\text { Bisexuality in } \\
\text { his family is an } \\
\text { issue Austin } \\
\text { won't reveal in } \\
\text { a group. I have } \\
\text { noticed that the } \\
\text { class } \\
\text { sometimes } \\
\text { picks on him } \\
\text { for other } \\
\text { things. This is } \\
\text { something to } \\
\text { consider } \\
\text { throughout the } \\
\text { study. }\end{array}$ & $\begin{array}{l}\text { Tolerance } \\
\text { Acceptance }\end{array}$ \\
\hline $\begin{array}{l}\text { Participating } \\
\text { actively leads } \\
\text { to confidence. } \\
\text { Perceiving } \\
\text { sensitive } \\
\text { material as }\end{array}$ & $\begin{array}{l}\text { Ann: I would have given } \\
\text { myself a high grade } \\
\text { because I was prepared } \\
\text { and actively participating. } \\
\text { I think the topic in } \\
\text { general opens up a lot of } \\
\text { room for discussion }\end{array}$ & $\begin{array}{l}\text { Although I } \\
\text { view Ann as a } \\
\text { quiet girl she } \\
\text { perks up when } \\
\text { a controversial } \\
\text { topic is } \\
\text { introduced and }\end{array}$ & $\begin{array}{l}\text { Interest } \\
\text { level in } \\
\text { subject } \\
\text { matter. } \\
\text { Student } \\
\text { choice is }\end{array}$ \\
\hline
\end{tabular}




\begin{tabular}{|l|l|l|l|}
\hline $\begin{array}{l}\text { thought- } \\
\text { provoking } \\
\text { fodder for } \\
\text { discussion. }\end{array}$ & $\begin{array}{l}\text { because it is a sensitive } \\
\text { matter and everyone has } \\
\text { their own opinions. }\end{array}$ & $\begin{array}{l}\text { she lets her } \\
\text { views be } \\
\text { known in a } \\
\text { courteous and } \\
\text { respectful } \\
\text { manner. }\end{array}$ & $\begin{array}{l}\text { discussion } \\
\text { topics. }\end{array}$ \\
\hline
\end{tabular}

The objective of this deeply contemplative activity, the Privilege Walk, was to allow students a chance to think about the degree of privilege they held in their life or more specifically, to understand privileges society grants or withholds to individuals based on their gender, color of their skin, sexual preference, and monetary status. As with many activities that fall within the category of social justice, the goal is to foster compassion and understanding for those that have not have it as easy as we have because of the circumstances into which they were born (Christensen, 2009).

On the day of the activity it was cold outside so I took students to a fairly large entranceway foyer between the gym and the auditorium. I lined students up in the foyer facing me and then proceeded to make statements that required them to take one step forward or not move at all based on their answers. All the statements revolved around various areas of privilege that they experienced in their lives. Table 16 represents a sample of Privilege Walk statements and their target areas of privilege.

\section{Table 16}

Sample Privilege Walk Questions (adapted from 1994, National Curriculum \& Training Institute, Inc.)

\begin{tabular}{|l|l|}
\hline Instruction (read out loud to & $\begin{array}{l}\text { Target Area(s) of Privilege (not } \\
\text { read to students) }\end{array}$ \\
\hline
\end{tabular}




\begin{tabular}{|l|l|}
\hline students) & \\
\hline $\begin{array}{l}\text { Take one step forward if you have } \\
\text { never felt afraid to walk to your car } \\
\text { alone in the dark. }\end{array}$ & Gender \\
\hline $\begin{array}{l}\text { If you study the culture of your } \\
\text { ancestors in elementary school, take } \\
\text { one step forward. }\end{array}$ & Race, culture \\
\hline $\begin{array}{l}\text { If your family ever had to move } \\
\text { because they could not afford the } \\
\text { rent, take one step back. }\end{array}$ & Money \\
\hline $\begin{array}{l}\text { If you were told that you were } \\
\text { beautiful, smart, and capable by } \\
\text { your parents, take one step forward. }\end{array}$ & Upbringing \\
\hline $\begin{array}{l}\text { If you ever tried to change your } \\
\text { appearance, mannerisms, or } \\
\text { behavior to avoid being judged or } \\
\text { ridiculed, take one step back. }\end{array}$ & Personality, sexuality, individuality \\
\hline
\end{tabular}

Those students who ended up in the front at the conclusion of the exercise were the white, middle or upper-middle, heterosexual males. As when I did the exercise in the Social Justice course, females, especially females of color who had financial struggles, were left toward the back of the line. From my position at the foyer door, I appreciated how honest the students were being and at how realization was slowly emerging. At the completion of the exercise, I asked students to look at their own physical position in the room in comparison to the position of others. Then I asked them to go to a different location where they felt comfortable and sit down with their journals and write about the activity. I asked them to write about their feelings in terms of statements that made them uncomfortable or feel devalued. I also asked them to consider how the activity made them view themselves and their classmates differently than they had previously- 
assuming a shift in point of view had actually taken place. Lastly, I asked them how the activity might influence how they interact with their classmates in the future. I was hoping to see some growth of tolerance that would carry over into salon discussions. The results were eye opening and encouraging.

Beth, a popular, athletic, white girl, born to professional parents, wrote in her journal:

The privilege walk was a little uncomfortable for me, not because of where I stood, but the standings of some of my classmates around me who are less fortunate than I am. I felt selfish, for all the times I have taken advantage of the privileges I am given and take for granted. I felt lazy in the fact that I am offered so much more and as result I have to do so much less than others, to get where I am and want to be. Such a simple activity made me realize just how lucky I am.

Christopher's response in his journal was painful to read:

I felt horrible during the walk. It reminded me that I have little to no privileges based on my sexual orientation. I wasn't surprised since growing up I've always had second best privileges and society has always reminded me of this. It's no surprise that everyone else went further 
than me since I know them and I know how privileged they are as a group.

Erik, a white male, wrote, "The truth is life is really harder than what it seems it may be" while discussing his family's (he lived with his grandparents) finances. Jess's entry reflected some of the anger and resentment that she displayed throughout the study. She wrote:

Personally, this walk for me wasn't surprising because I know where I stand. I know that I have to work 3 jobs to afford the things I want and I also know that I have to leave my mother behind and go to England so I don't have to spend the next 30 years paying off student loans. This was an eye opening activity for some but for me my eyes were already opened.

In my memo-writing regarding Jess's entry, I noted that I would have to make a special effort to connect with her before or after class in order to give her a chance to say more about England and her other thoughts. Unfortunately, as may be the case with teaching over one hundred students a day, I never made the time to try to connect with Jess on a deeper level. Examining data brought this failure to light and I take responsibility for this failure to listen and respond to a student's voice. In reflecting, I realize that grounded theory has the potential to reveal both successes and mistakes, and present the researcher with the opportunity to learn from them. 
I thought that teaching plays such as "The Laramie Project" and "Fences" would continue the lessons learned during the Privilege Walk. I wanted to encourage students to see their place in the line but also consider the places of the others and think about, as a peer group, how could they support and encourage one another. This is a life skill that has the potential to remain with students long after high school and into college and the world of work (Sizer, 2002). It's one objective to begin to open the eyes of the students to the idea of privilege, but it is a long-term extension of the idea to get them to be able to apply it to characters in fiction or non-fiction (Appleman, 2009). I stressed this concept as the study proceeded by using the characters of Matthew Shepard in The Laramie Project by Moises Kaufman and the character of Cory (Troy's son) in the play Fences by August Wilson. Both of these young men were denied privileges because of either his sexuality or race. In my memo writing, I noted that it could be an effective application of critical literacy if the students could see a character's conflicts through the lens of social privilege.

Personal and Invisible Fences. Inspired by "Fences", I asked each member of the class to draw a graphic organizer in their notebook by drawing a box and putting themselves inside it. Also inside the box, I wanted them to include words for things that were part of what they preferred to be surrounded by_-people and things important in their lives. Outside the box, they were instructed to write words that represented their fears and troubles - things they were literally trying to keep at bay. About 
ten minutes was used to write and think about this privately, and another ten minutes dedicated to voluntary sharing.

Inside Danielle's (an active participator's) box she wrote, “Sleep, music, family, \$, shopping, dance, books, food, kindness, dogs, relaxation, TV, friends." Outside her box she wrote, "Procrastination, college apps, cruelty, heartache, spookies, school work, digital portfolio." Austin also included digital portfolio outside his walls, along with, "snakes, winter, fake, and overreactions." Inside his box he had the following: "Friends \& family, dessert, secrets, perseverance, football, Alan [his friend], real, basketball, working \$, and college.” Digital portfolio is one of East High's proficiency-based graduation requirements in which each senior was required to collect their best work in regard to various learning standards and present it to a committee.

Many students expressed fear at the possible inability to complete college applications while at the same time, meeting the high school's newly implemented graduation requirements. I thought that we could use this idea to spring board into a discussion that incorporated the themes of "fences" in August Wilson's play by the same name. It left me wondering if I could capitalize on the fears and the comforts of these senior students as I continued to make my way through the plays on the syllabus and at the same time, increase the comfort level of each student during discussion.

"Laramie Project" Authentic Discussion. After reading the play, the students participated in an authentic discussion about the "The Laramie 
Project" a docudrama by Moises Kaufman about the real life hate crime that occurred in 1998 in Laramie, Wyoming when two men beat, tortured and murdered Matthew Shepard, a gay college student. The students wrote about their perceptions of our discussion about the play. Austin who describes himself as a "half-Jewish, half-Irish", hockey player wrote an entry that surprised me. Over the course of the study, I noticed that other students got angry with him when made unsolicited comments in class, some of which were considered temperamental and immature. Reading his entry allowed to me to know him much better. I realized that teachers can never truly know why someone chooses to remain quiet during a discussion about human behavior unless they have an inside view into that person's feelings or speak with them directly - a view that reading Austin's entry gave me:

I would give myself a 90 [grade for Laramie discussion] because I prepared and participated adequately, however I didn't make a point that I probably should have. My brother is a bisexual and has recently come out within the last year. I don't really know how to react to this but I feel bad for my brother because he lost a lot of friends when he came out. I tell myself that it doesn't change my brother as a person and I still love him. I've just always thought about other people being gay, not my brother. I have dealt with it maturely and so have my parents. It has 
made me a more open minded person and appreciate the feelings of others more.

Austin's journal entry illustrated a time that a particular literary element hit so close to home that the student was embarrassed to make public, personal connections. In my memo writing regarding his entry I noted that I if I were to count journal reflections as participation and truly learn from them, I would need to make the time and effort to read through each students' personal reflections and respond to them before the next one was assigned. Austin's willingness to respond in writing but not in conversation reveals how much the fear of embarrassment can stop a student from participating.

As in the case with Jess, I should have taken Austin aside after class and praised his effort and his candor in his journal. Desk formation was not going to address this issue. In reflection, I noted that tolerance exercises like the Privilege Walk and one-on-one nurturing of students' confidence seemed like the answer. I also needed to address the students' teasing of Austin and remind them of what it meant to be tolerant and respectful and of the ground rules that they had set up themselves before our initial discussion.

Summary of selective/focused coding in Conceptual Category 3:

\section{Community}

The ways in which the students in the room interact with one another and within the classroom community directly impact the quality of 
authentic discussion. Lack of tolerance and acceptance can shut down a discussion or a student as it did in the previous example of Austin. Students need to feel comfortable and secure with their peers and with their teacher. Comfort will increase their sense of agency. They will participate more and have a greater sense of ownership over the lesson when they care about the content of the discussion and/or help determine its course. I needed devise more ways to do this and the study made me see that I did not have all the answers.

Additional concerns such as college applications and senior graduation requirements may contribute to the stress and workload during the senior year. This could impact their ability to complete all their reading, and that will directly affect their ability to participate in authentic discussion. Reflecting on this made me realize that perhaps the pace needed to slow down and the personalization needed to increase. It was more important to make the students comfortable than it was to cover more plays. The study made me acknowledge that although I genuinely cared for each one of my students as individuals, I needed to slow down and take the time to show it.

\section{Conceptual Category 4: Knowledge}

The conceptual category of Knowledge directly addresses the study's first question concerning the language processes students demonstrate as they participate in authentic discussion, including the 
language processes involved with critical literacy, higher order thinking skills, and Accountable Talk.

The idea of teaching literary theories was born from the need to increase student agency. Literary theories include gender theory, Marxist theory, and psychological theory. If students had multiple lenses with which to view a piece of literature, then they would not be solely relying on Reader Response theory, an approach to literature used in elementary school that requires them to respond to a work of literature with only a personal reaction. I know from reading their journals that most students won't risk the embarrassment of revealing personal information especially in a group where they are not comfortable.

Students were given the handout included in Appendix A that summarizes eleven different literary theories. They cut out cards that summarized each theory (Appleman, 2009). The cards were printed on cardstock and held together with a ring. They were instructed to keep them in a pocket of their school bag for ready access during authentic discussion. To enhance understanding, I modeled the application of theory, and taught lessons with Power Point slides and activities that helped the students learn to apply the theories to works of literature. Table 17 illustrates coding as students wrote about different theories in their journals. We applied the theories to previously studied works in English 100: Studies in Literature such as Jane Eyre by Charlotte Bronte and The Stranger by Albert Camus. 
Table 17

Coded excepts of Students Reflecting on Literary Theories/Literary Criticism Theory Practice Assignments

\begin{tabular}{|c|c|c|c|}
\hline Initial codes & $\begin{array}{l}\text { Journal question: What } \\
\text { literary theory makes } \\
\text { the most sense to you } \\
\text { or what literary theory } \\
\text { confuses you? }\end{array}$ & $\begin{array}{l}\text { Memo } \\
\text { Writing }\end{array}$ & $\begin{array}{l}\text { Focused or } \\
\text { Selective } \\
\text { Code }\end{array}$ \\
\hline $\begin{array}{l}\text { Putting events } \\
\text { in context } \\
\text { Understanding } \\
\text { that what an } \\
\text { author lives } \\
\text { through is } \\
\text { reflected in } \\
\text { his/her writing }\end{array}$ & $\begin{array}{l}\text { Ethan: "...historical } \\
\text { criticism. I can see how } \\
\text { historical events and the } \\
\text { time period that the } \\
\text { author lived in can relate } \\
\text { to the particular events } \\
\text { that occur in the novel." }\end{array}$ & $\begin{array}{l}\text { Seniors have } \\
\text { had world } \\
\text { history and } \\
\text { two years of } \\
\text { American } \\
\text { history. } \\
\text { Hopefully this } \\
\text { is enough to } \\
\text { understand the } \\
\text { major } \\
\text { historical } \\
\text { events that } \\
\text { shaped the } \\
\text { lives of writers } \\
\text { that that they } \\
\text { will study. }\end{array}$ & $\begin{array}{l}\text { Knowledge } \\
\text { leads to } \\
\text { agency and } \\
\text { voice }\end{array}$ \\
\hline $\begin{array}{l}\text { Transferring } \\
\text { what he learned } \\
\text { in other classes } \\
\text { to literature } \\
\text { Applying } \\
\text { socio-economic } \\
\text { principles to } \\
\text { characters' } \\
\text { situations } \\
\text { Integrating } \\
\text { Marxism and } \\
\text { gender theory }\end{array}$ & $\begin{array}{l}\text { Erik: "I would say the } \\
\text { theory I understand the } \\
\text { most would be the theory } \\
\text { of Marxism. After taking } \\
\text { many history classes in } \\
\text { school and sociology this } \\
\text { year, I understand the } \\
\text { point of socio-economics } \\
\text { and standards set } \\
\text { throughout the world. } \\
\text { They heavily change } \\
\text { depending on where you } \\
\text { are, but in one instance, } \\
\text { for example talking } \\
\text { about Jane Eyre, this } \\
\text { takes place in Victorian } \\
\text { England so being } \\
\text { married often would put } \\
\text { you almost under a legal } \\
\text { bond that you would be } \\
\text { almost subservient to the }\end{array}$ & $\begin{array}{l}\text { I have to do } \\
\text { more work for } \\
\text { students like } \\
\text { Eric to } \\
\text { separate } \\
\text { gender theory } \\
\text { and Marxism. I } \\
\text { am pleased } \\
\text { that he was } \\
\text { thinking about } \\
\text { a former work } \\
\text { studied and } \\
\text { thinking about } \\
\text { Jane's } \\
\text { struggles with } \\
\text { both money } \\
\text { and the idea of } \\
\text { marriage. He is } \\
\text { using historical } \\
\text { criticism as } \\
\text { well. }\end{array}$ & $\begin{array}{l}\text { Literature in } \\
\text { cultural, } \\
\text { historical } \\
\text { context } \\
\text { Agency }\end{array}$ \\
\hline
\end{tabular}




\begin{tabular}{|c|c|c|c|}
\hline & man in the marriage." & & \\
\hline $\begin{array}{l}\text { Thinking about } \\
\text { the details of a } \\
\text { theory } \\
\text { Wondering } \\
\text { why there } \\
\text { aren't more } \\
\text { specialized } \\
\text { theories }\end{array}$ & $\begin{array}{l}\text { Sean: "On a specific } \\
\text { note, I find postcolonial } \\
\text { criticism hard to interpret } \\
\text { because it almost seems } \\
\text { too specific. It is a blend } \\
\text { of historical and social } \\
\text { criticism but is specific } \\
\text { to a part of history. If } \\
\text { post colonial is a type of } \\
\text { criticism, why aren't } \\
\text { there more like it?" }\end{array}$ & $\begin{array}{l}\text { Sean is one of } \\
\text { the students } \\
\text { who considers } \\
\text { himself } \\
\text { heavily } \\
\text { grounded in } \\
\text { the sciences. } \\
\text { He thinks } \\
\text { analytically. I } \\
\text { have to do } \\
\text { more research } \\
\text { into this theory } \\
\text { and perhaps } \\
\text { make them see } \\
\text { that sometimes } \\
\text { the lines } \\
\text { between the } \\
\text { theories are } \\
\text { blurred. }\end{array}$ & Connections \\
\hline $\begin{array}{l}\text { Thinking about } \\
\text { how authors } \\
\text { operate } \\
\text { Connecting } \\
\text { author's life } \\
\text { experience to } \\
\text { plot events in } \\
\text { text }\end{array}$ & $\begin{array}{l}\text { Hailey: "I really believe } \\
\text { that the biographical } \\
\text { theory makes a lot of } \\
\text { sense. I've heard many } \\
\text { times that authors will } \\
\text { 'write about what they } \\
\text { know' and in Jane Eyre } \\
\text { it's very obvious that } \\
\text { Charlotte Bronte wrote } \\
\text { from experience." }\end{array}$ & $\begin{array}{l}\text { Students may } \\
\text { not have know } \\
\text { this unless we } \\
\text { spent time on } \\
\text { Bronte's life- } \\
\text { importance of } \\
\text { teaching } \\
\text { background } \\
\text { and putting } \\
\text { works in } \\
\text { context. }\end{array}$ & $\begin{array}{l}\text { Analysis } \\
\text { Connections } \\
\text { Synthesis }\end{array}$ \\
\hline
\end{tabular}

Since we had previously studied Jane Eyre, I asked the students to work in groups with their literary theory cards to decide the theory that was best demonstrated by each statement. This self-designed activity can be found in Appendix E. Table 18 depicts two of the passages and the corresponding literary theory. 
Table 18

Sample questions from Literary Criticism Group Worksheet

Typical of Gothic literature, the novel contains the stereotypical character of the "evil stepmother" and her two self-centered, pushy daughters. Mrs. Reed fits the enduring stereotype by never giving Jane a chance to be truly part of her family and disliking her for her looks and personality. Even as older women, the two stepsisters want to use Jane to help them fulfill their needs. Answer: archetype criticism

Jane dreams of a child (just as she did before the message came from Mrs. Reed) and of Thornfield Hall in ruin. Jane says she believes in, "presentiments...sympathies...signs"; In other words, dreams are messages to be heeded and interpreted. Some consider dreams to be repressed, unconscious desires. Answer: psychological criticism.

During the activity, students noticed that sometimes more than one theory could apply to a passage. After that activity, I asked them to pick out examples of how literary criticism could be used to interpret another work from the previous semester, The Stranger by Albert Camus. They continued to do this is their small groups, then we joined together for an authentic discussion of their answers, and lastly, they wrote about the discussion in their journals. Their journal discussions reveal a variety of a synthesis of ideas, critical thinking about the text and application of literary theory. I asked students to write about the topic that provoked the most discussion in either their small group or the whole group. James said his group talked about psychological criticism and they were wondering what had happened in Meursault's (the protagonist's) past that influenced his actions. I was especially pleased that they speculated on his missing father and possible trauma associated with that. Danielle thought the idea of historical criticism and Existentialism generated the most conversation in her small group. 
They discussed the Post World War II loss of faith in God experienced by many individuals and speculated on why Meursault's lack of faith led to his crime of murder. Groups put the events of the novel in both historical and psychological context. My memo writing on this class speculated that the journal writing was definitely enhanced by the fact that the students had participated in small group conversation prior to whole class discussion. Kara's group applied psychological criticism to the novel's cover art. This small group discussion never came up in the larger discussion and centered on the protagonist's emptiness. She wrote:

The topic we discussed the most was how the cover of the novel parallels many of the main themes of the book. For example, the narrator seems to see the world in black and white, which are the only two colors on the book. Also, there is a black and white circle which could possibly show Meursault's emptiness, which cannot be penetrated by the world around him (sharp black lines). This cover can also represent contrast regarding religion and light.

Although I had never considered the cover art as material for the literary criticism, I was pleased with the group's efforts. They knew that psychological criticism relates the work to psychologically significant events in the character or author's life and finds patterns in symbols and images. It was an impressive point. 
Also impressive was 's group's discussion of gender criticism. They discussed how Meursault treated Marie, and whether or not Meursault actually loved her. Chris said this interesting topic dominated their discussion. The students were able to apply their knowledge of gender theory to the discussion. They were able to look at the effects of power arising from gender and at sexual stereotypes that were reinforced by the plot elements of the novel (Appleman, 2009). Knowledge of the theories had enabled student voice and confidence. Although I had taught them about the history of French Algiers, none of the groups decided to focus on post colonialism. They were more interested in character motivations and relationships.

Accountable Talk. Since knowledge of literary theory increased student agency and voice, I wanted to investigate the effects of Accountable Talk on student agency and voice. Prior to a discussion about Everyman, a medieval morality play, I taught the students phrases they could use to link to a previous participant's comments. Everyman concerns an average man's call by Death to his reckoning before God. He must account for his both his sins and his Good Deeds in order to receive his Judgment. He is afraid to journey to Death alone so he desperately seeks friends and family to come with him but finds that only Good Deeds is willing to do so. However, because of his lack of effort in life, Good Deeds is too weak to handle the journey. (Words in capital letters indicate actual characters in the play.) 
Prior to the discussion, students were to select one prompt and write a welldeveloped paragraph response in their journals. The prompts were:

A. Think about one of the most influential lessons you have learned in your life. What did you learn and what is it that makes this lesson so important to you? Did you learn this lesson right away or did it take a long time for the lesson to be fully appreciated? How has this lesson changed who you are as a person right now and who you aspire to become?

B. In every person's life, there are certain things that are valued higher than others. Think about what you value most and why it is important to you. This can be a person, object, place, feeling, or memory. What do your values say about your priorities?

C. Imagine you are "Everyman" in a play about your life and are about to embark on your journey to Judgment. Who or what would you want to bring with you? What would you do or say to convince your companions to make the perilous journey? Do you think you would be successful?

The students and I brainstormed possible Accountable Talk phrases such as those located in Chapter 2, Table 2, Accountable Talk Stems. The next day as a way to follow up on the homework assignment, we attempted to have a whole class discussion. I reminded students to follow the protocol and ways of Accountable Talk that we had established in the beginning. Even though I allotted time to write and reflect first, the discussion did not 
go smoothly. It was choppy. Ideas were thrown out and there was very little if any follow up on them by respondents. We were not well enough prepared as a group and I suspected not enough trust and comfort had been established in our classroom community. As a result, I felt the overwhelming need to jump into the discussion to follow up myself or validate the input of students who offered a suggestion. I reflected also on my inability to let go of the control over where the discussion was headed; I wanted it to sound more cohesive than it did.

The discussion focus on Accountable Talk seemed too contrived. One possibility was that the prompts were too personal and students were unwilling to share in a whole class setting. Small groups may have been preferable. Several student journal entries indicated that this would have been a much better personal narrative essay assignment. It was too complicated and too emotional for a one-paragraph response or a whole class discussion and that is why the discussion failed. Jess's response could have comprised a part of a longer personal narrative, as it seemed to elicit emotions she was unwilling to share in class discussion:

What I value most in life is my ability to stand out from others. I never conformed to the façade that girls try to fit into today. I stick to myself and am proud that I'm smart and want more out of life than parties in the woods and clubs on Friday nights. The other thing that I value highly is the fact that I'm very independent. I act on my own and 
am not afraid to rely on other people. For example when I graduate high school I'm moving to England to further my education I won't stay in this crap hole of a town because I value being independent. I value life and I can get out of it.

In retrospect, Accountable Talk by itself is not a viable focus during an authentic class discussion. It detracts from content and puts the focus on phrases and technique and contributes to the self-consciousness of some participants. I lost an important opportunity to by trying to force a discussion out of such personal topics, and not having the students develop their ideas more in a full-length essay. I should have asked Jess to explore the ideas such as: What makes you believe England will be a good place to further your education? How would you define independence? How do girls differ from boys when it comes to acting independently? What makes you consider your town a "crap hole"? Jess, as a shy person and a rare participant, would not have answered these questions in a whole classroom setting.

Jess stated in her journal that although no protocol had been violated, she noted, "a lot of room for improvement." She didn’t say anything because she was not comfortable. She said, "I think the people talking wouldn't take any notice even if I did speak up." This is a tough situation for a teacher. Artistic, introverted, and intelligent, how would I get her to open up in class? She wrote, "I definitely believe that you should not 
force the quiet people to talk. That would make people even more uncomfortable writing on the black board worked really well also."

Andria, an average-level participant who often looked as if she had something to say but didn't articulate her thoughts, confirmed my suspicions that the Everyman prompt should not have been forced into a whole group discussion. She too, would have been able to explore multiple ideas and have been led to write a personal narrative after a writing conference with me. The second half of her paragraph, which does not attempt to connect to the play at all, reads:

I know where I want to go to college, what I want to do and how I'm gonna get there. I plan to take CDL [commercial driver's license] classes this winter and get my license so wherever I choose to go and also be in the field of what I want to go to school for. Although I am only a senior in high school and this may sound silly, I don't care, I have an exact mental list of the things that I want in life and how I'm gonna get them.

I question whether Andria read the text in addition to the personal nature of the prompts.

Fishbowl. In order to focus on Accountable Talk, particularly uptake, in a less contrived situation, I tried an adapted for of the Fishbowl activity (Kletzien \& Baloche, 1994, p. 542). I set two of the salon chairs in the front of the room and asked for two volunteers to sit there and begin to 
discuss whatever they wanted about the text and try to integrate the literary theories and critical thinking we had been discussing in class. When the conversation appeared to have run its course, another student from the audience was to go up and tap one of the participants on the shoulder and take his or her place at the center of the classroom. The conversation turned lively and animated. The students who disagreed with one another did so politely, following our protocol. I could see that some students were so eager to join the center conversation that they were literally jumping out of their chairs. However, as the coding of the journals, indicated, opinions about the activity and its success were greatly mixed. The students who participated often in whole class discussion did not like the method. Some of the average level participants liked it a great deal, however, it did not change the perceptions of students who were less likely to participate in any forum. I did notice, however, that it greatly enhanced the students' use of Accountable Talk stems. In my field journal, I recorded almost twenty uses of stems such as "I liked when you said....", or "I disagree with your point about....". Table 19 depicts several student responses to the Fishbowl method of discussion.

Table 19

Student Journal Entries Reacting to the Fish Bowl Lesson

\begin{tabular}{|l|l|l|l|}
\hline Initial codes & $\begin{array}{l}\text { Journal question: What } \\
\text { did you think of the Fish } \\
\text { Bowl discussion? }\end{array}$ & Memo & $\begin{array}{l}\text { Focused } \\
\text { or } \\
\text { Selective } \\
\text { Code }\end{array}$ \\
\hline $\begin{array}{l}\text { Granting } \\
\text { everyone a } \\
\text { possible }\end{array}$ & $\begin{array}{l}\text { Jess: "I thought the } \\
\text { discussion was very } \\
\text { interesting. I liked it }\end{array}$ & $\begin{array}{l}\text { Jess contradicts } \\
\text { herself because } \\
\text { previously she }\end{array}$ & \\
\hline
\end{tabular}




\begin{tabular}{|c|c|c|c|}
\hline $\begin{array}{l}\text { Forcing } \\
\text { attention on the } \\
\text { two people at } \\
\text { front } \\
\text { Restricting shy } \\
\text { people from } \\
\text { coming up }\end{array}$ & $\begin{array}{l}\text { because it gave everyone } \\
\text { who wanted a chance to } \\
\text { speak and it worked better } \\
\text { than a group discussion } \\
\text { because in that everyone } \\
\text { talks over everyone. } \\
\text { However I didn't } \\
\text { participate because it } \\
\text { seemed like people were } \\
\text { attacking each other and I } \\
\text { didn't like being on } \\
\text { display like that." }\end{array}$ & $\begin{array}{l}\text { had written } \\
\text { that the class } \\
\text { was good at } \\
\text { following } \\
\text { protocol of not } \\
\text { interrupting. } \\
\text { Fishbowl } \\
\text { seems to have } \\
\text { sparked her } \\
\text { interest. }\end{array}$ & $\begin{array}{l}\text { Protocol } \\
\text { Confidence }\end{array}$ \\
\hline $\begin{array}{l}\text { Limiting to } \\
\text { more } \\
\text { significant } \\
\text { responses } \\
\text { Limiting } \\
\text { participation to } \\
\text { only two at a } \\
\text { time }\end{array}$ & $\begin{array}{l}\text { Kara: "I personally prefer } \\
\text { full class discussions. } \\
\text { Though it was easier to } \\
\text { stay organized and start } \\
\text { conversations when there } \\
\text { were only two people, I } \\
\text { feel less people } \\
\text { participated because they } \\
\text { didn't want to be the } \\
\text { center of attention. I also } \\
\text { disliked this discussion } \\
\text { method because the } \\
\text { audience could not } \\
\text { interject without changing } \\
\text { spots with the two people. } \\
\text { This prevented some } \\
\text { people from joining } \\
\text { because they might have } \\
\text { only had one comment } \\
\text { they wanted to make." }\end{array}$ & $\begin{array}{l}\text { Having been } \\
\text { comfortable } \\
\text { with authentic } \\
\text { group } \\
\text { discussion } \\
\text { from the start, } \\
\text { Kara was not } \\
\text { thrilled with } \\
\text { this method. } \\
\text { She has no } \\
\text { problem } \\
\text { speaking up in } \\
\text { a large group } \\
\text { and no } \\
\text { problem with } \\
\text { confidence no } \\
\text { matter what the } \\
\text { group size. }\end{array}$ & Confidence \\
\hline $\begin{array}{l}\text { Disagreeing } \\
\text { with one easier } \\
\text { than many } \\
\text { Relieving the } \\
\text { person who } \\
\text { runs out of } \\
\text { things to say }\end{array}$ & $\begin{array}{l}\text { Beth: "I participated in the } \\
\text { fish bowl activity and I } \\
\text { enjoyed it. I found it } \\
\text { much easier to disagree } \\
\text { against one person instead } \\
\text { of the entire class. It put } \\
\text { way less pressure on the } \\
\text { two persons speaking and } \\
\text { the private conversation } \\
\text { encouraged the other } \\
\text { classmates to get } \\
\text { involved. When someone } \\
\text { ran out of things to say, } \\
\text { they were substituted by }\end{array}$ & $\begin{array}{l}\text { Beth likes to be } \\
\text { the center of } \\
\text { attention so it } \\
\text { didn't bother } \\
\text { her to sit in the } \\
\text { front of the } \\
\text { room. I could } \\
\text { tell she was } \\
\text { excited } \\
\text { because she } \\
\text { never } \\
\text { participated as } \\
\text { much as she } \\
\text { did this day. }\end{array}$ & Confidence \\
\hline
\end{tabular}




\begin{tabular}{|l|l|l|l|}
\hline & $\begin{array}{l}\text { another. I thought this } \\
\text { actually was very } \\
\text { productive and would like } \\
\text { to do it again." }\end{array}$ & $\begin{array}{l}\text { She made } \\
\text { good, } \\
\text { organized } \\
\text { points when } \\
\text { put on the spot. }\end{array}$ & \\
\hline
\end{tabular}

\section{Summary of selective/focused coding in Conceptual Category 4:} Knowledge

To some degree, knowledge of literary theories supplied students with a toolkit that allowed them to discuss literature by stating more than just a personal reaction. The knowledge of the theories allowed them to analyze, synthesize, and apply knowledge (Bloom, 1956) to literature. Students gravitated toward different theories and were able to articulate confusion over some areas and notice that the lines between theories are often not distinct. This knowledge, however, did not ease any fear of embarrassment or lack of comfort issues that pervaded the eight-week study.

Accountable Talk is a learned behavior that cannot be forced. It is best achieved through modeling and repeated exposure. A well-displayed list of Accountable Talk Stems in the classroom reminds students of phrases they can use for uptake during class discussion. No form of discussion techniques will suit all personalities. Seniors retain much of the self-conscious behavior that they demonstrated as freshmen, sophomores, and juniors, and need to feel very secure in their knowledge before taking academic and personal risks in the classroom. The fear of embarrassment prevents self-described minimal participants from taking such risks even 
when armed with the knowledge of literary theories and Accountable Talk Stems.

\section{Conclusion}

Grounded Theory coding in this study led to the development of four core categories: the Individual, Protocol, Community, and Knowledge. Coding reached saturation when no new coding revealed further selective categories or when selective or focused categories began to repeat themselves. After saturation of codes, some answers to the study's three guiding questions emerged.

What language processes do students demonstrate as they participate in authentic discussion, including the language processes involved with critical literacy, higher order thinking skills, and Accountable Talk?

When provided with appropriate scaffolding as they were in this study, students productively use the language of the literary theories and Accountable Talk they have been taught. It takes time and patience on behalf of the teacher because it is most likely unchartered territory. Necessary scaffolding includes making reference cards, teacher modeling of the application of theory, and practice in applying theory in both prewriting and discussing. Use of literary theory enables students to engage in the higher order thinking skills (Bloom, 1956) and the critical literacy involved in unpacking the systems of meaning (Beach et. al., 2009) and examining multiple perspectives (Appleman, 2009). Students actively make connections, synthesize information, and analyze plot elements by situating 
them in historical, political, and religious contexts. They use language specific to critical inquiry and begin to move away from the reader response theory that has been utilized in English language arts classes since kindergarten.

How does authentic discussion affect student agency or student responsibility and ownership of the lesson? What do students take away as learners from the experience of participating in authentic discussion?

When students move away from reader response, they gain the confidence and agency needed to participate more and take ownership of class discussions. However, although most students claim to take away information and learn from discussions, it was not possible in this study, to ensure the participation of the most introverted, shy learners who lacked confidence. Despite attempts to build confidence by increasing their toolbox of approaches, some students like Jess and Christopher never became active participants in class discussion. These two students seemed almost resentful of my repeated attempts to involve them in class. Activities like the Privilege Walk or even the fact that participation were listed on the syllabus as ten percent of their final grade was ineffective in accomplishing this goal. However, minimal participants did exercise their voice in other forums such as in their journals or in their writing assignments. Journals and writing assignments are not public, unlike a discussion, though these activities do provide a viable means of expression. Students, who regularly 
exercised their voices, began the senior year as confident, expressive, extraverted individuals and remained so throughout the study.

How do students perceive authentic discussion? Why are some students more inclined than others to participate in authentic discussion in an informal classroom environment?

Some students feel that discussion is dominated by the more aggressive students and are afraid to have their voices heard. They fear dirty looks, sarcastic comments, and disinterested body language. Other students view participation as a way to exercise their voice and are not afraid of what others think. They are generally those students who, through various forms of privilege, feel empowered and confident. It takes a great deal of teaching tolerance and understanding to bring grade twelve students to a point at which all feel comfortable, especially in such as small community like the one in which East High is located. Most students have been in the same classes together since kindergarten; it's highly unlikely to change their view of the lines that divide various cliques and social classes. This suggests that a focus on tolerance and understanding should begin much earlier in students' educations. If this were the case, students may still be quiet during discussion, but their journal writing may reveal a greater sense of understanding and acceptance. I will further address the need for early tolerance education in Chapter 5.

Most importantly, it is possible to make small strides within an eight-week study to show improvement in growth of participation within 
the average-level participants. The post-questionnaire includes the same statements as the pre-questionnaire and was distributed at the end of the study. Since it was distributed shortly before graduation and I asked that the students return it to my mailbox in the front office, I received only 25 questionnaires back instead of the 39. Statement \#1, "I participate often in English class" did not show changes in the above average or the minimal participants. However, several of the average level participants showed growth in how they perceived their own participation and the degree to which they felt others listened to them. Their comments also revealed that some of the strategies attempted in the study positively affected their participation as shown in Table 20. These results further demonstrate that the study increased the confidence level of the average-participants and provided them with a toolkit to turn to when they wanted to participate without relying on Reader Response Theory.

Table 20

Demonstration of Growth in Average Participants

\begin{tabular}{|l|l|l|}
\hline $\begin{array}{l}\text { Average } \\
\text { Participant }\end{array}$ & $\begin{array}{l}\text { I participate often } \\
\text { in English class. } \\
\text { Pre/Post Likert } \\
\text { Rating }\end{array}$ & $\begin{array}{l}\text { Comment included in Post- } \\
\text { Questionnaire }\end{array}$ \\
\hline Abby & $7 / 8$ & $\begin{array}{l}\text { "Characters like Meursault are great } \\
\text { for psychological theory. I like } \\
\text { talking about a protagonist in terms of } \\
\text { their issues and how they respond to } \\
\text { what life throws at them." }\end{array}$ \\
\hline Sandy & $6 / 7$ & $\begin{array}{l}\text { "I liked fishbowl a lot. It was fun } \\
\text { joining a conversation already in } \\
\text { progress. Students seemed to know } \\
\text { when to tap you on the back-when } \\
\text { you didn't have any more to say." }\end{array}$ \\
\hline Larry & $5 / 7$ & $\begin{array}{l}\text { "The Privilege Walk" made several } \\
\text { kids in class stop and think about how }\end{array}$ \\
\hline
\end{tabular}




\begin{tabular}{|c|c|c|}
\hline & & $\begin{array}{l}\text { life has been good to them or maybe } \\
\text { not so good to them. We should do } \\
\text { more stuff like that. Then maybe } \\
\text { other kids would be more tolerant and } \\
\text { listen to how other people see things } \\
\text { during discussion." }\end{array}$ \\
\hline Erik & $6 / 7$ & $\begin{array}{l}\text { "I still like writing my ideas down } \\
\text { more than I like talking about them. I } \\
\text { liked the small group discussion when } \\
\text { we got to pick the members of the } \\
\text { group. We had a great conversation } \\
\text { about the courtroom scene in The } \\
\text { Stranger. Since I like history a lot, I } \\
\text { like studying the historical } \\
\text { background of books like The } \\
\text { Stranger." }\end{array}$ \\
\hline Alan & $5 / 7$ & $\begin{array}{l}\text { "I like the theories that put structure } \\
\text { and discipline on a discussion. Maybe } \\
\text { that is why I am going into the } \\
\text { Army!" }\end{array}$ \\
\hline
\end{tabular}

Emergent Grounded Theory as a Result of Constant Comparative Analysis

Teaching tolerance and the critical literary theories, which both involve the ability to look at the world through different lenses and see its characters and events in new and enlightened ways, are effective ways to sustain authentic discussion in the secondary English classroom. In addition, adherence to student generated protocol that emphasizes respect and accountability of both the individual and the classroom community are essential components of authentic discussion. The teacher must adopt a role of facilitator who closely and carefully monitors the expectations and concerns of all participants.

The last chapter of the study, Chapter 5, will discuss the emerged grounded theory itself and the implications of the data analyzed in this chapter as well as offer suggestions for future study. 


\section{CHAPTER 5}

\section{THE THEORY, ITS IMPLICATIONS, AND SUGGESTIONS FOR FURTHER STUDY}

\section{The Wider Purpose of Grounded Theory}

Although the study began with the initial purpose of improving the teaching of discussion on grade twelve Early Enrollment Program, discoveries began to cut across disciplines and raise larger questions regarding social processes. Findings led me to the field of neuroscience, psychology and genetics because they all play a large role in how an individual reacts in a social situation (Reznick, Kagan, Snidman, Gersten, Baak, \& Rosenberg, 1986; Kagan, 1994; Cain, 2012). In an attempt to articulate the relationships between the four conceptual categories introduced in Chapter 4, I had to investigate these new areas to develop a constructivist theory. It was the movement back and forth between the categories and the insight gained that allowed me to articulate such a theory.

Definition of Theory in Grounded Theory

Strauss and Corbin (1998), define theory as a, "set of welldeveloped concepts related through statements of relationship which together constitute an integrated framework that can be used to explain or predict phenomena" (p. 15). Charmaz points out that constructivists see, "both data and analysis as created from shared 
experiences and relationships with participants and other sources of data" (2012, p. 130). She further points out that constructivists want to understand how and why participants act they way they do in specific situations (p. 130). According to my research questions, I wanted to know how students could be encouraged to participate in discussion and why they participated in the manner that they did. I took a reflexive stance as constructivists do, which meant that I strove to understand how my own experience impacted my interpretation of data. As such, my grounded theory states: Participation in class discussion matters. Suppression of voice, "limits one's ability to achieve one's potential, to make meaningful contributions to society and to be productive in one's chosen area of endeavor" (Harter, 1996, p. 38). In order to understand why an individual participates they way he or she does in class discussion, a facilitator should examine the relationships among individuals, established protocol, how the community functions as a whole and how knowledge is presented and interpreted. Each situation is an examination of complex variables. Genetic predispositions, socioeconomic statuses, and early childhood nurturing are important variables to consider. The facilitator can benefit by private conversations which each student and by exploring alternatives to verbal participation. 
The following discussion utilizes the four conceptual or

thematic categories introduced in Chapter 4. These areas require

further study on the part of the researcher and are shown on Table 21.

Table 21

Implications and Suggestions for Further Study as listed within Core Category Results

\begin{tabular}{|c|c|c|}
\hline $\begin{array}{l}\text { Conceptual } \\
\text { Category/Result }\end{array}$ & $\begin{array}{l}\text { Research findings/ } \\
\text { Teacher efforts in the } \\
\text { Classroom }\end{array}$ & $\begin{array}{l}\text { Results of efforts } \\
\text { and/or implications for } \\
\text { Further Study }\end{array}$ \\
\hline Individual & 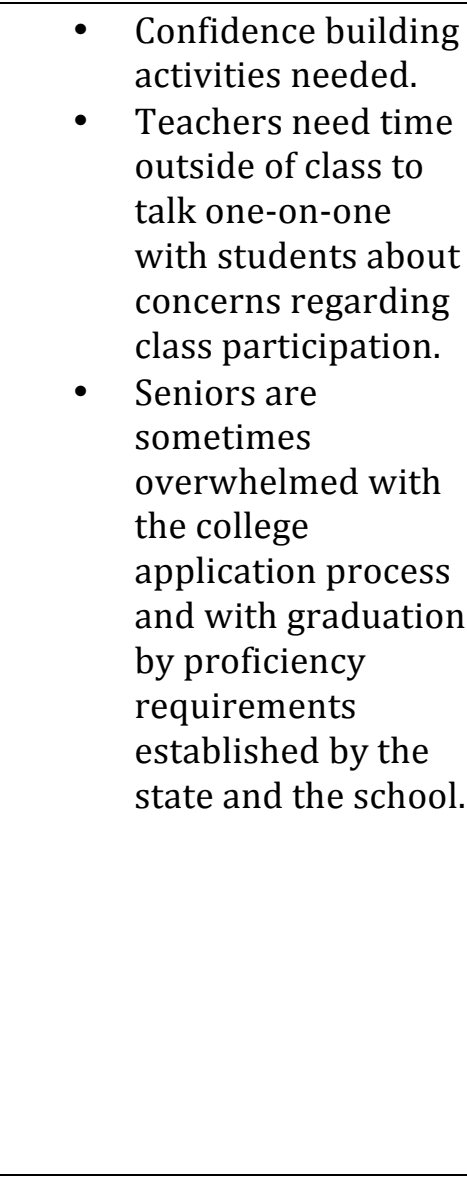 & $\begin{array}{l}\text { - Further study, } \\
\text { similar to (Sizer, } \\
\text { 2004) of } \\
\text { stressors and } \\
\text { concerns to high } \\
\text { school seniors } \\
\text { and how to assist } \\
\text { them in time } \\
\text { management is } \\
\text { needed } \\
\text { Study into how } \\
\text { genetic makeup } \\
\text { controls } 40-50 \% \\
\text { of our } \\
\text { predispositions in } \\
\text { strange social } \\
\text { situations (Cain, } \\
\text { 2012) } \\
\text { Study regarding } \\
\text { alternatives to } \\
\text { verbal } \\
\text { participation such } \\
\text { as counting the } \\
\text { journal as } \\
\text { participation } \\
\text { credit }\end{array}$ \\
\hline Protocol & $\begin{array}{l}\text { Students gain } \\
\text { ownership and } \\
\text { agency when they } \\
\text { establish the } \\
\text { protocol } \\
\text { - Students hold } \\
\text { themselves } \\
\text { accountable for } \\
\text { following protocol }\end{array}$ & $\begin{array}{l}\text { - Social loafing- } \\
\text { allowing others to } \\
\text { do the work } \\
\text { - Production } \\
\text { Blocking-one } \\
\text { person comes of } \\
\text { with idea and } \\
\text { others sit around } \\
\text { passively }\end{array}$ \\
\hline
\end{tabular}




\begin{tabular}{|c|c|c|}
\hline & $\begin{array}{l}\text { and are able to } \\
\text { evaluate their own } \\
\text { performance }\end{array}$ & \\
\hline Community & $\begin{array}{l}\text { Ice-breaker } \\
\text { activities are } \\
\text { needed in the } \\
\text { classroom as the } \\
\text { chemistry of each } \\
\text { class is different. } \\
\text { Efforts need to be } \\
\text { made to eliminate } \\
\text { bullying and } \\
\text { intimidation even in } \\
\text { the advanced, high } \\
\text { school, senior, } \\
\text { English classroom. }\end{array}$ & $\begin{array}{l}\text { Evaluation } \\
\text { Apprehension or } \\
\text { the fear of } \\
\text { looking stupid in } \\
\text { front of peers } \\
\text { - } \\
\text { Power of } \\
\text { conformity can } \\
\text { alter an } \\
\text { individual's } \\
\text { perceptions }\end{array}$ \\
\hline Knowledge & $\begin{array}{l}\text { Knowledge of } \\
\text { critical literacy and } \\
\text { critical theory } \\
\text { needs to be } \\
\text { carefully scaffolded } \\
\text { by the teacher. } \\
\text { - Students' agency } \\
\text { and voice increase } \\
\text { when they have } \\
\text { been presented } \\
\text { with theories, other } \\
\text { than reader } \\
\text { response, to } \\
\text { interpret literature. }\end{array}$ & $\begin{array}{ll}- & \text { Ownership and } \\
\text { choice of material } \\
\text { - } & \text { Return to } \\
\text { differentiated } \\
\text { instruction } \\
\text { versus scripted }\end{array}$ \\
\hline
\end{tabular}

Implications of Findings: The Individual

Students who initially identified themselves as minimal participants did not self-report any growth in their inclination or ability to participate as a result of the study. The thematic codes utilized for these students revealed a lack of self-esteem and inability to conform as the chief reasons for the lack of participation. Due to this fact, the implication is that teachers, in the higher grade levels, should consider alternative modes of participation. For instance, writing in a 
reader response journal submitted at the end of class, may be used to help satisfy the participation requirement of the course. An assessment given at the end of the discussion could also assess the student's listening that is another valid form of participation.

This idea is supported by literature. Neuroscientific research has shown that introverts can stretch their personalities only so far but up to $50 \%$ of what makes introverts in controlled by genes (Reznick et al., 2006; Kagan, 1994; Cain, 2012). Given this fact, a teaching repertoire of strategies constructed to increase verbal participation may never work.

Jerome Kagan and his fellow researchers conducted longitudinal studies that followed infants through adolescence. These researchers tested the hypothesis that inhibited children have a lower threshold for the generation of specific states of physiological arousal to unfamiliar, unexpected, or challenging events (Reznick et al., 1986, p. 661). Their studies did indeed prove that hypothesis and claimed that genetic make up defines up to half of an individual's introverted or extraverted tendencies. "High reactive" babies (or those who cried and pumped their arms in legs in reaction to an external stimulus) grew up to become quiet, thoughtful adults (Reznick et al., 1986). The highly reactive baby was determined by physiological symptoms controlled by the amygdalae in the brain such as increased heart rate, blood pressure, and finger temperature. Throughout life, highly reactive 
babies continued to react to strange social situations with elevated nervous system symptoms. As such, situations in school that created social stress would likely make them more alert and focused but not increase the desire to verbally participate (as shown by the deep level of reflection in Christopher and Jess's journals.)

Considering these findings, it makes sense for a teacher to consider an alternative medium of participation such as the journal or end of discussion assessment for those more introverted students. We can't punish a student for the way his or her genetic makeup controls his/ her ability to participate in strange social situation.

To advance Kagan's studies even further, his protégé and colleague, Dr. Carl Schwartz, continued his longitudinal study from adolescence to adulthood and found that the correlation between external stimuli and behavior remained the same for highly reactive individuals into adulthood. As summarized by Cain, the amygdalae of those children [highly reactive], now grown up, had turned out to be more sensitive to the pictures of unfamiliar faces that did the amygdalae of those who'd been bold toddlers. Both groups reacted to the pictures but the formerly shy kids reacted more. In other words, the footprint of a highor low-reactive temperament never disappeared into adulthood (p.7). 
Just because introverted students don't participate in class, we can't assume that they aren't constantly observing and learning through observation. David Dobbs, originator of "the orchid hypothesis" offers teachers an answer to the dilemma that is summarized by Cain (2012, p. 112), The orchid hypothesis states the high-reactive types, "wilt easily, but under the right conditions can grow strong and magnificent." The right conditions in the classroom involve providing a stable and nurturing environment that promotes curiosity, academic achievement, and self-control. Teachers should take the time to speak privately to these highreactive students in order to personally nurture their interests and address their concerns. I believe Jess and Christopher would have responded positively to this type of nurturing.

Cain noted that in Dobbs' study, he found rhesus monkeys process the serotonin-transporter gene less efficient than low reactive monkeys (p. 112). Processing this gene less efficiently makes an individual more susceptible to depression and anxiety. However, the highly reactive monkeys who were raised by nurturing mothers, did just as well in "key social tasks, like finding playmates, building alliances, and handling conflicts" (p. 112). The teacher, especially a teacher of young childen, can help supply the nurturing the high-reactive individuals need in order to succeed socially in society. 
If the orchid hypothesis were to be applied to the self described mid-level participants who entered class with more bold personalities and less reactive responses to strange social situations, it follows that the teacher's efforts at providing a stable and comfortable environment would have more effect on their desire to participate. Without the genetic inclination not to participate and with teacher efforts and encouragement, average participants reported growth in participation throughout the eight-week study.

Implications of Findings: Protocol and Community

The approval of classmates has a significant correlation to the self-esteem of students within the school context. In fact, the approval of others is the best predictor of self-esteem, even more so than the approval of the teacher (Reznick et al., 1986, p. 678; Harter, 1996, p. 26). Harter conducted an extensive study that examined self-esteem at many developmental levels: middle-late childhood, adolescence, college years, and early to middle age adulthood. In her study, the highest correlational coefficient was classmates (range $.50-.60$ ). This positive agreement was higher than parents $(.49-.56)$, teachers $(.40$ $.45)$, and close friends (.35 - .40). The implications of this finding, as supported by interviews in the study, suggest that the teacher should make efforts to affect this aspect of student self-worth. Student journals and my field journal demonstrate that the Privilege Walk described in the previous chapter was instrumental in encouraging 
students in grade twelve to look at the world through the eyes of their classmates. The implications of this are that further research into tolerance activities has the potential to increase students' approval or acceptance of one another that studies reveal has a direct impact on student voice in the classroom.

The lived experience in this study as Harter (1996) discovered reveals four reasons for lack of participation. These reasons are as follows: "lack of validation of self" or belief that students won't take one another seriously, "threats to the relationship" or fear that opinions may result in tension or conflict, "affective reasons" or concern over embarrassment or bullying, and "lack of opinion." The implication is that students need to be taught to adopt a growth mindset. A growth mindset (Dweck, 2006) teaches that fear of failure or looking stupid can be seen as a challenge to learning and growth (as Kara knew) rather than failure and embarrassment. In order to help develop the growth mindset, further directions for research include the increased use of cooperative learning and an investigation of how student-to-student talk may be useful for reducing the fear of failure in the classroom. My focus on whole class discussion revealed the need to make use of other types of talk as a necessary component of constructivist learning. Implications of Findings: Knowledge 
Study Participants: One Year Later in College. While I was

working on this dissertation, I wrote to many of the study's

participants via e-mail and asked them how they liked college and

asked if they had had an opportunity to use literary theory. Table 22

depicts their responses. Not one student has had a chance to use

literary theory. Several did not have to take introductory literature

courses due to the EEP and AP courses that they took in high school.

The student participants, spread throughout the country, reported

doing well in college. Alan (average level participant) went into the Air

Force, Sam (above average participant) was at an Ivy League University

that did not have any general education requirements, and Kara (above

average participant) and Leah (above average participant) were

enjoying private colleges in different parts of the country. Sean

(average participant) reported responding well to the challenging

work. A couple of the entries indicate that although students did not

directly use the theories, they drew on some of the knowledge they

learned in the EEP course.

Table 22

Students Use of Literary Theory the Year After High School Graduation

Sean (average participant): Everything is going pretty well. I think the best word to describe this semester would be "underwater", but I'm keeping up and really loving Boston and BU. There is a definite big fish in a small pond effect going into a large school like this coming from a small town, but after a semester I feel mostly caught up to the people around me.

As far as literary theory is concerned I honestly have not used it very much, or at least not in the literal sense. Since I'm an engineering major the only English 
courses I need to take are two topic based writing courses with one being more focused on research. The first writing course I took was a course based on American environmental history, more specifically defining the relationship between man and nature. Though the specific eleven literary criticisms were not mentioned, I'm sure that I used a few of them at one point or another during in class discussions on a few novels we read. The essays were more based on making arguments as opposed to analyzing the literature however, so the books were used more as evidence to prove other points instead of being analyzed themselves. The course I'm in now is a research based writing class based on the portrayal of the Vietnam War in American culture. Again I am most likely using the literary criticisms in one form or another on a subconscious level in analyzing and discussing sources, but they have not been mentioned explicitly.

Leah (above average participant): I am doing well! I have loved all my classes so far and made the Dean's List last semester! I have joined a sorority and I am having great time on campus. I am also enjoying the nice Virginia weather :) As for the literary theory, I have not had to use these in my courses yet. The only English classes I have taken are English 110C and English 211C, which are both Writing Composition courses. The reason for not using the theories might be that I am not taking literature courses. The two courses that I have taken are more focused on writing different styles of papers.

Kara (above average participant): Because of my dual enrollment and AP credits I actually do not have to take any additional literary courses, which means I have not heard mention of literary theory since arriving here. However, I am currently taking a class as part of my honors curriculum in which we talk about humanity and morals in the last century. As a part of this class we have read multiple accounts of historical events and then examined the psychology behind them. While we may not make reference to literary theory specifically during class, it does play a key role in the analysis of the literature we read by helping us look at different perspectives. So, while I may not have heard anything about literary theory, I have definitely applied it when analyzing material for this course. Sam (above average participant): I actually (as of yet) have not taken a literary class in college (my school not have any General Education Requirements). As for college life, it is great. I love my school's atmosphere and people, and the professors are generally nice. Classes have been going fine grade-wise, but studying is a lot more challenging than in high school because each class is only a semester, so there is often a great deal of material on a single exam. I am honestly very happy where I am.

Jess (minimal participant): I am in fact studying at college in England. However because I am strictly on art courses I have not used the literary theory that we discussed in English.

Alan (average participant): I have put off college for now to join the Air Force. I am currently in Texas for training. I still plan on attending college as soon as possible. I hope all is well with you and again it was great to hear from you.

Tom (minimal participant): I'm attending Nichols College for business and they actually counted my EEP credits as art credits so I don't have to take any type of drama or literature class, so the answer would be no [to using literary theory]. 


\section{Using a Wider Lens: Policy Makers and Educational Researchers}

A component of the doctoral program required me to examine my study's findings in light of educational policy. I reflected on my data in terms of the NECAP (New England Common Assessment Program) exam on which students in this study needed to show proficiency in order to graduate. The adoption of national standardized tests as one measure of proficiency based graduation, represents a long-term accountability policy on the part of the government. This policy meets with resistance in the field because the costs in the short term are high (pedagogical disagreement, loss of instructional time, stress on students). Policy implementers are not prepared to deal with the pedagogical beliefs and preexisting practices of teachers in conflict with the policy (Honing, 2006; Coburn \& Stein, 2006). Qualitative studies such as this one, "have become important sources of knowledge for implementation" of accountability policies (Honig, 1996, p. 22).

Teacher researchers need to cooperate with the policy makers, for the teachers are the ones to best say what how the assessment results can be used and to interpret the resulting data in terms of growth, change, and reform. Teachers know that standardization is not the same as having standards to which I am not opposed. Tom Newkirk (2009), my graduate advisor states,

There needs to be a careful balance between agreed-upon standards and teacher initiative...Standards are useful when 
they do not proliferate, when they can be used to focus instruction and not disperse it. They are useful when they are general enough to allow for extensive teacher decision making. (p. 6)

The relationship between policy makers and implementers is a complex one. Current research is exploring ways in which the two parties can better work together for policy creation and implementation. One researcher found that, "policy implementation is a messy process marked by combinations of contests, contingencies, and disruptions that cannot be fully anticipated let alone readily controlled" (Malen, 2006, p. 101).

Figure 1, in Chapter 1, based on the findings of Wells (1999), illustrated the disputed territory of teacher practice that lies between the national outcomes and assessments created by policy makers and the idea of inquiry-based, constructed knowledge advocated by the academic researchers. The missing component in this figure is the students, an aspect I did not see at first, but became clear as a result of the study. My study's findings are clear that participation (verbal or otherwise) in "the peer environment within the school context looms large as the critical determinant of one's self-worth as a person" (Harter, 1996, p. 26). In the schools, our goals as teachers include those of arming students with the necessary skills and knowledge to increase their sense of self worth and their ability to be productive citizens. National assessments do not measure 
a students' ability or inclination to participate in the classroom context.

Newkirk (2009), states,

Standardized tests are ill-suited to evaluate expressive abilities, speaking and writing (and creativity in general.)

Though there are standards for speaking in the CCSS, they are unlikely to be tested in any serious or complex way. Yet speaking and strong interpersonal skills are especially necessary in the expanding health care field and on most other growth fields in our postindustrial economy. (p. 5)

Teacher researchers, however, as my Chapter 2, Literature Review, indicates are interested in finding out how and why students participate in class and how to access this participation in an authentic way. The information that has emerged from this study reveals a need for a dialogue between the two concerned parties, policy makers, and educators, concerning the ways in which educators scaffold and assess students' listening and speaking skills. The past decades have witnessed a growth in the focus on both large and small group discussion within the classroom (as exemplified in the NBPTS, National Board for Professional Teaching Standards), yet the written assessments of students' proficiency such as the NECAP exam do not assess these skills.

\section{Conclusion}

Conducting this study, reflecting on the data, and writing the dissertation, caused me to seriously consider how current federal, state, and 
school mandates had changed the face of my profession and more importantly, instruction in East High School. More and more days were spent teaching to a test or testing rather than nurturing the skills that I believed, supported by literature, students needed for college and for life. I wanted to effect policy change - one reason for entering the doctoral program rather than live with a feeling of powerlessness. My efforts within East High were ineffective. I was the minority "holding on to good ideas in a time of bad ones" (the title of Newkirk's latest book, 2009). I became frustrated with the way the high school East High School interpreted the CCSS (using them to disperse instruction rather than focus it), so when the opportunity arose, I applied for a second grade position and was granted a transfer. Before receiving my bachelor's degree at Rhode Island College, I student taught at both grades two and seven, originally receiving a certificate for general elementary (grades one through six) with a middle school endorsement in the teaching of English. My secondary certificate was earned after.

Some may see this transfer as an escape and I suppose in some way it was. I found refuge in a classroom of twenty-three second graders who had a deep, unrestrained joy of the language arts. They loved to listen to stories and discuss them. They were not stressed out due to testing and my teaching was creative, personalized and focused on the human element. In discussion, students reflected openly on the content of the stories without the fear of embarrassment. I was able to encourage even the most high- 
reactive students to offer opinions based on textural details. Growth mindsets were more prevalent than fixed ones that research has shown seriously begin in junior high school (Dweck, 2006). This second grade transfer reinforced that nurturing and teaching of tolerance has to begin in the early grades and be consistently delivered throughout a child's school career. 


\section{APPENDICES}

Appendix A: Student Chart of Literary Critical Theories

\begin{tabular}{|c|c|c|c|c|}
\hline $\begin{array}{l}\text { Literary } \\
\text { Criticism }\end{array}$ & Symbol & $\begin{array}{l}\text { Color } \\
\text { Code }\end{array}$ & Key Words & $\begin{array}{c}\text { Literary } \\
\text { Work for } \\
\text { Example } \\
\end{array}$ \\
\hline Gender & $\begin{array}{l}\text { Mars/ } \\
\text { Venus }\end{array}$ & purple & $\begin{array}{c}\text { Men/women } \\
\text { write differently }\end{array}$ & \\
\hline $\begin{array}{c}\text { Social } \\
\text { Power/Marxist }\end{array}$ & Dollar sign & $\begin{array}{l}\text { Dark } \\
\text { green }\end{array}$ & $\begin{array}{c}\begin{array}{c}\text { Different social } \\
\text { class/economic } \\
\text { status }\end{array} \\
\end{array}$ & \\
\hline Structuralist & House & brown & $\begin{array}{l}\text { Taking apart } \\
\text { sections to } \\
\text { examine the } \\
\text { whole } \\
\end{array}$ & \\
\hline Deconstructionist & $\begin{array}{c}\text { Question } \\
\text { mark }\end{array}$ & red & $\begin{array}{l}\text { Contradictions, } \\
\text { gaps, misreading }\end{array}$ & \\
\hline Psychological & $\begin{array}{c}\text { Greek letter } \\
\text { psi }\end{array}$ & orange & $\begin{array}{c}\text { Repressions, } \\
\text { hopes, fears of } \\
\text { author/characters }\end{array}$ & \\
\hline Biographical & Tree of Life & $\begin{array}{l}\text { Light } \\
\text { green }\end{array}$ & $\begin{array}{c}\text { Author's life } \\
\text { story }\end{array}$ & \\
\hline Archetypal & Black hat & black & $\begin{array}{l}\text { Reoccurring } \\
\text { themes and } \\
\text { characters }\end{array}$ & \\
\hline Reader Response & $\begin{array}{c}\text { Stick figure } \\
\text { person }\end{array}$ & $\begin{array}{c}\text { Light } \\
\text { blue }\end{array}$ & $\begin{array}{l}\text { What the reader } \\
\text { brings to the } \\
\text { table }\end{array}$ & \\
\hline Formalist & book & gray & $\begin{array}{l}\text { Close reading- } \\
\text { interaction of } \\
\text { words and all } \\
\text { literary elements }\end{array}$ & \\
\hline Historical & clock & pink & $\begin{array}{l}\text { What was going } \\
\text { on in historical } \\
\text { time period }\end{array}$ & \\
\hline Postcolonial & $\begin{array}{l}\text { Computer } \\
\text { power sign }\end{array}$ & yellow & $\begin{array}{l}\text { What was going } \\
\text { on in political } \\
\text { time period/who } \\
\text { were the ones in } \\
\text { power }\end{array}$ & \\
\hline
\end{tabular}


Appendix B: Using Critical Theory in "Oedipus Rex"

Approaches to Drama 113 EEP English

Name Using Critical Theory with Oedipus Rex by Sophocles

\begin{tabular}{|l|l|l|l|}
\hline & Reader Response & Psychological & Gender \\
\hline $\begin{array}{l}\text { What aspects of } \\
\text { the play lend } \\
\text { themselves to } \\
\text { this particular } \\
\text { lens? }\end{array}$ & & & \\
\hline $\begin{array}{l}\text { Cite specific } \\
\text { textual passages } \\
\text { that support this } \\
\text { kind of reading. }\end{array}$ & & & \\
\hline $\begin{array}{l}\text { If you look } \\
\text { through this lens, } \\
\text { what themes or } \\
\text { pattern in the } \\
\text { text are revealed? }\end{array}$ & & & \\
\hline $\begin{array}{l}\text { If you look } \\
\text { through this lens, } \\
\text { what questions } \\
\text { emerge? }\end{array}$ & & & \\
\hline & & & \\
\hline & & & \\
\hline & & & \\
\hline
\end{tabular}


Do you believe in this reading?

Why or why not? 
Appendix C: English 100 Syllabus/Studies in Literature

The Early Enrollment Program

Syllabus: English 100 Studies In Literature/ Journeys and Transformations Instructor: Lisa Carpenter carpenter@bsd-ri.net

Course Description: This four-credit course utilizes critical theory to closely examine literature of various genres from around the world, new and old, that explore the themes of physical and emotional journeys and transformations of characters. How and why do characters undergo change? How do they confront conflict? What is to be gained from the experiences? We will explore what literature is and how critical theory offers us different lenses through which to make meaning from text. Additionally, we will utilize the space created in a second classroom, a literary salon connected to the traditional classroom, to experiment with authentic discussion protocols regarding text.

Required Text: The Bedford Anthology of World Literature: The Twentieth Century, 1900-The Present (2003) and other selected books and handouts to be provided as needed by the instructor

Course Requirements: A high level of class participation and engagement is required. Students will write 3 critical papers $(3$ to 5 pages each) that analyze literature and utilize schools of literary criticism. Quizzes and journal entries will be used to check for completion of reading assignments. For each day a paper is late, it will receive a deduction of 10 points.

Grading Policy: Your semester grade will be computed utilizing the approximate English department formula: 50\%tests, projects, essays, 25\% quizzes, reading checks and response journals, 10\% participation, 15\% homework.

Writing and Burrillville High School Required Common Tasks: Both teacher and peer editors will provided for major writing assignments. The instructor is available for after-school assistance two to three nights a week. School rubrics will be used to score all essays and projects on a 4-point scale.

Week 1: Interpreter of Maladies -selected short stories by Jhumpa Lahiri 
Week 2: Lahiri continued

Week 3: Magical realism and selected short stories by Gabriel Garcia

Marquez

Week 4: Marquez continued, Critical Paper due

Week 5: Jane Eyre by Charlotte Bronte

Week 6: Jane Eyre continued

Week 7: Jane Eyre continued, Literature Test and Critical Paper due

Week 9: British poetry including Sir Gawain and the Green Knight, The Lady of Shalott and The Rime of the Ancient Mariner

Week 10: British poetry continued

Week11: poetry continued, Recitation project

Week 12: Existentialism and Camus' The Stranger

Week 14: The Stranger continued

Week 15: Kafka's Metamorphosis, Literature Test and Project due

Week 16: gothic American Short Stories including "The Tell Heart" by Rose, "A Rose For Emily" by

Week 17: selected American Short Stories

Week 18: American Short Stories continued, Final Exam with Critical Paper due 


\section{Rhode Island College and}

Burrillville High School

The Early Enrollment Program

Syllabus: English 113 Approaches to Drama

Instructor: Lisa Carpenter

Course Description: This course will develop students' knowledge of dramatic literature, past and present, through close analysis of historical and cultural settings. We will study theatrical literature as it evolved through time and explore the universal themes therein. We will also utilize schools of literary criticism as we explore these famous works. This course is worth FOUR general education credits at RIC. It is recommended that students register and pay for college credits if they elect this honors-level course.

Required Texts: (located in the Bedford Anthology of Drama)

The Laramie Project

Oedipus Rex by Sophocles

Othello by William Shakespeare

Buried Child by Sam Shepherd

Fences by August Wilson

The Fate of A Cockroach by al Hakim

Everyman by Anonymous

Course Requirements: Students will write critical papers (3 to 5 pages each), either as part of a test or separately. The course will conclude with an essay exam. No one is exempt as this is a college course. Due dates are very important. For each day a paper is late, it will receive a deduction of 10 points. Hand-written papers are preferable to computer excuses. King Lear field trip to Trinity on October 4, 2012. Communicate with the instructor when you have to be absent at lcarpenter@bsd-ri.net.

\section{Grading Policy:}

Week 1: Summer Reading (all three assignments worth 2 test grades)

Week 2: Oedipus Rex

Week 3: Oedipus Rex, test

Week 4: More Lear, theatre review after Trinity 
Week 5: Laramie Project

Week 6: Laramie Project, test

Week 7: Everyman,

Week 8: Everyman, literature test, essay

Week 9: Othello,

Week 10: Othello,

Week11: Othello, test

Week 12: Buried Child

Week 13: Buried Child, project.

Week 14: Fences

Week 15: Fences. literature quiz

Week 16: The Fate of A Cockroach

Week 17: The Fate of A Cockroach, puppet show/test

Week 18: Final Exam

${ }^{*}$ Quizzes and Reading checks may occur at any time

Grading:

$50 \%$ tests, projects, essays

$25 \%$ quizzes, reading checks

$15 \%$ homework, journal entries

$10 \%$ participation 
Appendix E: Literary Criticism In-Class Activity

Using your literary criticism cards, decide which criticism each item best describes.

1. Charlotte's sisters, Maria and Elizabeth, bot died of Tuberculosis at the Clergy Daughters' School at Cowan Bridge. Conditions at that school closely mirror those at Lowood and Helen Burns could represent Charlotte's sister Maria. Charlotte Bronte became a teacher at the Roe Head School and later tried the position as governess. Jane, after several years at Lowood, leaves for a governess position. Biographical Criticism

2. Jane dreams of a child (just as se did before the message came from Mrs. Reed) and of Thornfield Hall in ruin. Jane says she believes in "presentiments...sympathies...signs"; in other words, dreams are messages to be heeded and interpreted. Some consider dreams to be repressed unconscious desires. Psychological Criticism

3. In an effort to assert her independence, Jane insists on retaining her salary and work schedule even after her marriage. She declares that she will earn her keep even within marriage, thus refusing to become one of Rochester's mistresses. She was trying to do what was legally impossible for Victorian woman - maintain a separation between the financial and emotional dimensions of marriage in order to avoid a dependent position. Gender Criticism

4. Mrs. Fairfax has great difficulty accepting Jane as a conjugal partner for Rochester. She would consider this a violation of the Victorian tradition - that members of the upper class marry within their class and the same with the lower class. Mrs. Fairfax may have even suspected Jane of trying to marry Rochester for his money-in a sense, she may see Jane as a Victorian "gold digger". Marxist Criticism

5. Typical of Gothic literature, the novel contains the stereotypical character of the "evil stepmother" and her two self-centered, pushy daughters. Mrs. Reed fits the enduring stereotype by never giving Jane a chance to be a part of her family and disliking her for her looks and personality. Even as older women, the two stepsisters want to use Jane to help them fulfill their needs. Archetypal Criticism

6. The Victorian Era was a time of social evolution as well as technological and economic advance. A distinct, unique middle class was formed alongside the traditional working class and wealthy aristocracy. However, there were certain individuals that fell outside this model of Victorian society. The "abandoned child" was society's scapegoat — a person without a past, without 
connections, without status. They could appear in any class and at any time. The upper and middle classes often had a somewhat romantic perception of them due to their prevalence in Victorian literature. Novels like Jane Eyre made heroines/heroes out of orphans, portraying them as respectable yet troubled. Historical Criticism 
Appendix F: Everyman Take-Home Writing Prompts

Everyman Writing Prompts-Pick one to be completed as homework prior to class discussion

1. Think about one of the most influential lessons that you have learned in your life up until today. What did you learn and what is it that makes this important to you? Did you learn this lesson right away or did it take a long time for the lesson to be fully appreciated? How has this lesson changed who you are as a person right now and who you aspire to become in the future?

2. In every person's life, there are certain things that are valued higher than others. Think about what it is you value most in your own life (it can be more than one thing) and why it is so important to you. This can be a person, an object, a place, a feeling, a memory, etc. What does your highest values say about your priorities in life and who you are as an individual?

3. Imagine you are your very own "Everyman" hero in a play of your life and are about to embark on a passage to judgment. Who or what from your life would you try to bring along with you? What would you say to convince your companions to make the perilous journey? Do you think your efforts to convince them would succeed? Why or why not? 


\section{REFERENCES}

Adams, M \& Love, B.J. (2009). A social justice education: Faculty Development framework for a post-Grutter era. In K. Skubikowski, C. Wright, \& R. Graf (Eds.), Social justice education: Inviting faculty to transform their institituions (pp. 3-25). Sterling, VA: Stylus Publishing, LLC.

Almasi, J. (1996). A New View of Discussion. In J. Almasi, \& L. Gambrell (Eds.), Lively Discussions: Fostering engaged reading (pp. 2-22). Newark, NJ: International Reading Association.

Alvermann, D. E., \& Hayes, D. (1989). Classroom discussion of content area reading assignments: An intervention study. Reading Research Quarterly, 24 (3), pp. 305-335.

Ansbach, J. (2012). Long term effects of bullying: promoting epathy with nonfiction. English Journal , 101 (6), pp. 87-92.

Applebee, A. N. (1996). Curriculum as conversation: Transforming traditions of teaching and learning. Chicago: The University of Chicago Press.

Applebee, A. N., J. A. Langer, M. Nystrand, \& A. Gamoran. (2003). Discussion approaches to developing understanding: Classroom instruction and performance in middle and high school English. American Educational Research Journal, 40 (3), 685-730.

Appleman, D. (2009). Critical encounters in high school English: Teaching literary theory to adolescents, second edition. New York, NY: Teachers College Press.

Appleman, D., \& Graves, M. (2011). Reading better, reading smarter. Portsmouth, NH: Heinemann.

Ayers, R., \& Ayers, W. (2011). Teaching the taboo: Courage and Imagination in the classroom. New York, NY: Teachers College Press.

Ayers, W. (1993). To teach: the journey of a teacher. New York, NY: Teachers College Press.

Ayers, W. (2004). Teaching toward freedom: Moral committment and ethical action. Boston, MA: Beacon Press. 
Beach, R., Campano, G., Edmiston, B., \& Borgmann, M. (2010). Literacy tools in the classroom: Teaching through critical inquiry grades 5 - 12. New York, NY: Teachers College Press.

Billings, L., \& Fitzgerald, J. (2002). Dialogic discussion and the Paideia Seminar. American Educational Research Journal , 4 (39), $907-$ 941.

Bisin, A., \& Verdier, T. (2005). New Palgrave dictionary of economics, second edition. Retrieved March 17, 2012, from Cultural Transmission: http://www.econ.nyu.edu/user/bisina/Cultural\%20Transmissi on\%20Final.pdf

Bissell, A. N., \& Lemons, P. (2006). A new method for assessing critical thinking in the classroom. BioScience, 56 (1), 66-72.

Bloom, B. S. (Ed.). (1956). Taxony of educational objectives handbook 1: The cognitive domain. New York, NY: Longman.

Bloomberg, L. D., \& Vope, M. (Eds.). (2012). Completing your qualitative dissertation: A road map from beginning to end. Thousand Oaks, CA: Sage.

Bracher, M. (2009). How to teach for social justice: Lessons from Uncle Tom's Cabin and cognitive science. College English , 71 (4), 363387.

Bramson, K. (2011, March 2). Seeking the best and the brightest. Providence Journal , A8.

Bronte, C. (2008). Jane Eyre. Radford, VA: Wilder Publications.

Brookfield, S. D., \& Preskill, S. (2005). Discussion as a way of teaching. San Francisco, CA: Jossey-Bass.

Bruner, J. S., \& Haste, H. E. (1987). Making sense: The child's construction of the world. London: Methuen.

Cain, S. (2012). Quiet: The power of introverts in a world that can't stop talking. New York, NY: Crown Publishers.

Camus, A. (1988). The stranger. New York, NY: Cambridge University Press. 
Carbonaro, W. J., \& Gamoran, A. (2002). The production of achievement inequality in high school English. American Educational Research Journal , 39 (4), 801-827.

Cazden, C. (2001). Classroom discourse: The language of teaching and learning. Portsmouth, NH: Heinemann.

Cazden, C. (1995). New ideas for research on classroom discourse. TESOL Quarterly , 29 (2), 384-387.

Charmaz, K. (2000). Grounded theory: Objectivist and constructivist methods. In Norman K. Denzin \& Yvonna S. Lincoln (Eds.), Handbook of qualitative research second edition, (pp. 509-535). Thousand Oaks, CA: Sage.

Charmaz, K. (2006). Constructing grounded theory: A practical guide through qualitative anyalysis. Thousand Oaks, CA: Sage Publications, Inc.

Charmaz, K. (2008). Constructionism and the grounded theory method. In J. Holstein, \& J. Gubrium (Eds.), Handbook of constructionist research (pp. 397-412). New York, NY: Guilford Publications Inc.

Christiansen, L. (2009). Teaching for joy and justice: re-imagining the language arts classroom. Milwaukee, WI: Rethinking Schools, Ltd.

Clergue, H. (1907). The salon: A study of French society and personalities in the eighteenth century. New York, NY: G. P. Putnam's Sons, the Knickerbocker Press.

Coburn, C. E., \& Stein, M. (2006). Communities of practice theory and the role of the teacher professional community in policy implementation. In M. I. Honig (Ed.), New directions in policy implementation: Confronting complexity (pp. 25-46). Albany, NY: State University of New York Press.

Common Core State Standards Initiative (n. d.). (n.d.). Retrieved February 1, 2014, from http://www.corestandards.org/thestandards

Costigan, A., \& Dickson, R. (2011). Emerging practice for new teachers: Creating possibilities for "aesthetic" readings. English Education, 43 (2), 145-170. 
Creswell, J. W. (2009). Qualitative, quantitative, and mixed method approaches (3rd ed.). Thousand Oaks, CA: Sage Publications.

Duffy, T. M., Lowyck, J., Jonasson, D. H., \& Welsh, T. M. (Eds.) (2012). Designing environments for constructive learning. New York: NY: Springer.

Dweck, C. S. (2006). Mindset: the new psychology of success: how we can Learn to fulfill our potential. New York, NY: Ballantine Books.

Eisenhart, M.A. \& Howe, K. R. (1992). Validity in educational research. LeComte, M., Millory, W. \& Preissle, J. (Eds.) The Handbook of Qualitative Research In Education. San Diego, CA: Harcourt, Brace \& Company.

Eisner, E. (1998). Qualitative inquiry and the enhancement of educational practice. Upper Saddle River, NJ: Prentice-Hall, Inc.

Elbaz-Luwisch, F. (2005). Teachers voices: storytelling \& possibility. Greenwich, CT: Information Age Publishing.

Fox, G. L. \& Murray, V. M. (2000). Gender and families: Feminist perspectives and family research. Journal of Marriage and the Family, 62, 1160-1172.

Fulwiler, B. R. (2007). Writing in science: How to scaffold instruction to support learning. Portsmouth, NH: Heinemann.

Geersten, H.R. (2003). Rethinking thinking about higher-level thinking. Teaching Sociology, 31(1), 1-9.

Geertz, C. (1973). The interpretation of cultures: Selecting essays. New York, NY: Basic Books.

Glascow, J. N. (2001, July). Teaching social justice through young literature. English Journal , 54-61.

Glaser, B. (1992). Basics of grounded theory analysis. Mill Valley, CA: Sociology Press.

Glaser, B. G., \& Strauss, A. (1967). The discovery of grounded theory. Chicago, IL: Aldine. 
Golden, J., \& Christensen, L. (2008). A conversation with Linda Christensen on social justice education. English Journal, 97 (6), 59-64.

Greene, M. (1995). Releasing the imagination: essays on education, the arts, and social change. San Francisco, CA: Jossey-Bass.

Greene, M. (1973). Teacher as stranger. Belmont, CA: Wadsworth.

Greene, M. (2001). Variations on the blue guitar: The Lincoln Center Lectures on aesthetic education. New York, NY: Teachers College Press.

Hadjioannou, X. Bringing the background to the foreground: What do classroom environments that support authentic discussions look like? American Educational Research Journal , 44 (2), 370399.

Halliday, M. A. (1993). Toward a language-based theory of learning. Linguistics in Education, 5, 93-116.

Harrison, C. (2005). Banishing the quiet classroom. Education Review, $19(2), 67-77$.

Harter, S. (1996). Teacher and classmates influences on scholastic motivation, self-esteem, and levels of voice in adolescents. In J. Juvonen, \& K. Wentzel (Eds.), Social motivation: Understanding children's school adjustment (pp. 11-42). New York, NY:

Cambridge University Press.

Hines, M. B., \& Appleman, D. (2000). Multiple ways of knowing in literature classrooms. English Education , 32 (2), 141-168.

Honing, M. I. (1996). Complexity and policy implementation: Challenges and opportunities for the field. In M. I. Honing (Ed.), New directions in policy implementation: Confronting complexity (pp. 1-23). Albany, NY: State University of New York Press.

Infoworks! Rhode Island Education Data Reporting (2012). Retreived October 13, 2012 from http://Infoworks.ride.ri.gov

Jacobs, L. A. (2008). Bedford anthology of drama (6th ed.). New York, NY: Bedford St. Martins. 
Jones, M., \& Alony, I. (2011). Guiding the use of grounded theory in doctoral studies: An example from the Australian film industry. International Journal of Doctoral Studies , 6, 96-113.

Kagan, J. (1994). Galen's prophecy: Temperaments in Human Nature. Basic Books: New York, NY.

Kletzien, S. B., \& Baloche, L. (1994). The shifting muffled sound of the pick: Facilitating student-to-student discussion. Journal of Reading , 37 (3), 540-545.

Knuth, R. A., \& Cunningham, D. J. (1993). Tools for constructivism. In Designing environments for consturctive learning (pp. 163-188). Springer Berlin Heidelberg.

Lebow, D. (1993). Constructivist values for systems design: Five principles toward a new mindset. Education Technology, Research, and Development, 41, 4-16.

Lewison, M., Flint, A., \& Van Sluys, K. (2002). Taking on critical literacy: The jounrey of newcomers and novices. Lanugage Arts , 79 (5), 382-392.

Lewison, M., Leland, C., \& Harste, J. (2000). “Not in my classroom!”: The case for using multi-view social issue books with children. The Australian Journal of Language and Literacy, 23(1), 8.

Macdermid, S., Jurich, J., Pelo, A., \& Myer-Walls, J. (1992). Feminist teaching: Effective education. Family Relations , 41, 31-38.

Malden Public Schools. (2013). Accountable Talk. Retrieved September 19, 2013, fromhttp://www.google.com/search?client=safari\&rls=en\&q= malden+public+schools+accountable+talk+power+point\&ie=UT F-8\&oe $=$ UTF- 8 .

Malen, B. (2006). Revisiting policy implementation as a political phenomenon: The case of reconstitution policies. In Honing, M.I., (Ed.), New Directions in policy implementation: Confronting complexity (pp. 83-104). Albany, NY: State University Press.

Maxwell, J. A. (1992). Understanding and validity in qualitative research. Educational Review , 62 (3), 279-300. 
Mehan, H. (1979). Learning lessons: Social organization in the classroom. Cambridge, MA: Harvard University Press.

Mehrtens, P. Z. (1996). Images of America Burrillville. Dover, NH: Acadia.

Michaels, S., O'Connor, C., \& Resnik, L. (2008). Deliberative discourse idealized and realized: Accountable talk in the classroom and in civic life. Studies in Philosophy and Education , 27 (4), 283-297.

National Curriculum \& Training Institute. (1994). Privilege exercise. Retrieved February 13, 2014, from http:// www.ncti.org/contactcommerce/images/resources/Privege_Ex ercise

Newkirk, T. (2009). Holding onto good ideas in a time of bad ones: Six literacy principles worth fighting for. Portsmouth, $\mathrm{NH}$ : Heinemann.

Newkirk, T. (2009). Speaking back to the common core. Retrieved July 14, 2014, from Heinemann: http://www.heinemann.com/products/E02123.aspx

Nystrand, M. (1997). Opening dialogue. New York, NY: Teachers College Press.

Nystrand, M. (2006). Research on the role of classroom discourse as it affects reading comprehension. Research in the Training of English , 40 (4), 392-412.

Nystrand, M., \& Gamoran, A. (1991). Instructional discourse, student engagement, and literature achievement. Research in the Teaching of English , 25 (3), 261-290.

Patton, M. Q. (2002). Qualitative research \& evaluation methods (3rd ed.). London, England: Sage Publications.

Raudenbush, S. W. (2008). Advancing educational policy by advancing research in instruction. American Educational Research Journal, 45 (1), 206-230.

Rex, L. A., \& Schiller, L. (2009). Advancing educational policy by advancing research in instruction. New York, NY: Routledge.

Reznick, J. S., Kagan, J., Snidman, N., Gersten, M., Baak, K., \& Rosenberg, 
A. (1986). Inhibited and uninihibited children: A follow-up study. Child Development, 57 (3), 660-680.

Rhode Island Department of Education. (2013). Rhode Island education survey report. Retrieved November 10, 2013, from http://infoworks.ride.ri.gov/files/surveyworks/2012-2013

Rorty, R. (1991). Cognition, construction of knowledge, and teaching. Synthese, 80, 121-140.

Sappington, J., Kinsey, K., \& Munsayac, K. (2002). Two studies of reading compliance among college students. Teaching of Psychology , 29 (4), 272-274.

Sizer, N. (2002). Crossing the stage: Redesigning the senior year. Portsmouth, NH: Heinemann.

Smith, L. J., \& Smith, D. (1994). Classroom talk about text. Journal of Reading , 37 (7), 582-585.

Sperling, M., Appleman, D., Gilyard, K., \& Freedman, S. (2011). Voice in the context of literacy studies. Reading Research Quarterly , 46 (1), 70-84.

Strauss, A. C., \& Corbin, J. (1998). Basics of qualitative research (2nd ed.): Techniques and procedures for developing grounded theory. Thousand Oaks, CA: Sage Publications.

Strauss, A. C., \& Corbin, J. (1994). Grounded theory methodology. In Handbook of Qualitative research (pp. 273-285).

von Glaserfeld, E. (1989). Objectivity, relativism, and truth. Cambridge, MA: University Press.

Vygotsky, L. S. (1978). Mind in society: The development of higher psychological processes. Cambridge, MA: Harvard University Press.

Wallis, C. (2006, March). The Multitasking generation. Retrieved September 8, 2011, from Time: http://www.time.com/printout/0.8816.1174696.00html

Wells, G. (2001). Action, talk, and text: Learning and teaching through inquiry. New York, NY: Teachers College Press. 
Wells, G. (1999). Dialogic inquiry: Towards a sociocultural practice and theory of education. New York, NY: Cambridge University Press.

Wolf, M. K., Crosson, A., \& Resnik, L. (2006). Accountable Talk in reading comprehension instruction. CSE Technical Report. The Regents of the University of California 